Aus der Klinik für Allgemein-,Viszeral- und Kinderchirurgie

(Prof. Dr. med. B.M. Ghadimi)

im Zentrum Chirurgie

der Medizinischen Fakultät der Universität Göttingen

\title{
Die Expression von SRC vor und nach neoadjuvanter Radiochemotherapie im lokal fortgeschrittenen Rektumkarzinom cUICC II/III.
}

\begin{abstract}
Eine immunhistochemische Analyse prätherapeutischer Biopsien und korrespondierenden residuellen Tumorgewebes
\end{abstract}

\author{
INAUGURAL - DISSERTATION \\ zur Erlangung des Doktorgrades \\ der Medizinischen Fakultät der \\ Georg-August-Universität zu Göttingen
}

vorgelegt von

Felix Rühlmann

aus

München

Göttingen 2015 
Dekan:

Prof. Dr. rer. nat. H. K. Kroemer

I. Berichterstatter:

II. Berichterstatter/in:

III. Berichterstatter/in:

Tag der mündlichen Prüfung:

Prof. Dr. med T. Liersch 
Einleitung und Fragestellung $\ldots \ldots \ldots \ldots \ldots \ldots \ldots \ldots \ldots \ldots \ldots \ldots \ldots \ldots \ldots \ldots \ldots \ldots$

1.3 Epidemiologie des kolorektalen Karzinoms..

Stadienabhängige Therapie des Rektumkarzinoms.................................... 6

1.5.1 Lokal begrenztes Rektumkarzinom (UICC-I-Stadium)................................. 7

1.5.2 Lokal fortgeschrittenes Rektumkarzinom (UICC-II/III-Stadium)...................... 7

1.5.3 Metastasiertes Rektumkarzinom............................................................ 8

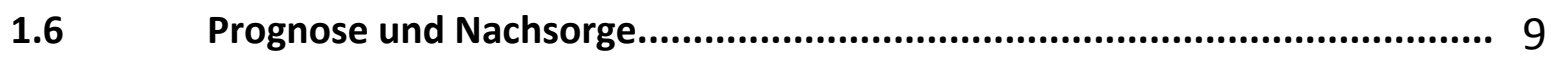

1.7 Biomarker in der Therapie für das Rektumkarzinom.................................. 10

1.8 Die Tyrosinkinase SRC- Entdeckung und Bedeutung................................. 11

Strukturelle Eigenschaften von SRC ................................................... 12

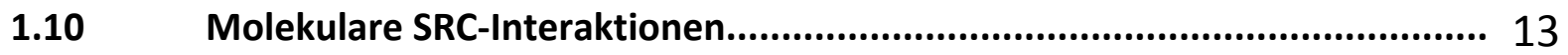

SRC-Inhibitoren als zukünftige Therapieoption..................................... 16

Zielsetzung und Fragestellung................................................................. 17

2.2 Perioperative Qualitätsüberprüfung des Tumorresektats........................... 22

2.3 Postoperative histopathologische Beurteilung des Resektats...................... 23

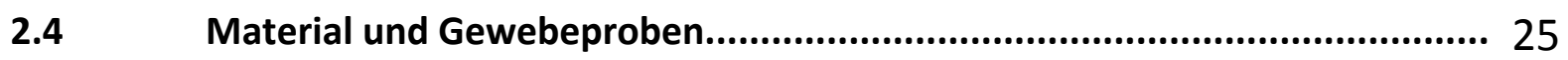


2.5 Immunhistochemie und Herstellung von Gewebeschnitten....................... 25

2.5.1 Immunhistochemische Anfärbung von Geweben...................................... 25

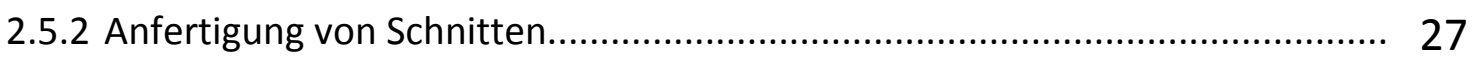

2.5.3 Automatisierte Färbung..................................................................... 27

2.5.4 Auswertung der immunhistochemischen Färbungen................................. 28

2.5.5 Probleme und Nachteile der quantitativen Immunhistochemie.................... 29

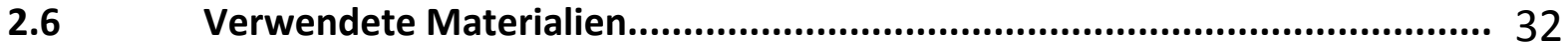

$2.7 \quad$ Funktion des Zielantigens................................................................ 33

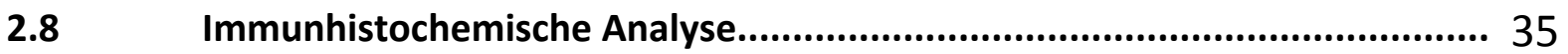

2.8.1 Analyse der immunhistochemischen Färbung............................................. 35

2.8.2 Konventionelle Auswertung der immunhistochemischen Färbung.................. 36

2.8.3 Statistische Analyse ..................................................................................... 36

3.1 Durchgeführte Resektionsverfahren im Patientenkollektiv......................... 38

3.2 Histopathologisch determinierte Tumorstadien..................................... 39

3.3 Rezidive, Auftreten von Fernmetastasen und tumorbedingte Todesfälle...... 42

3.4 Expressionsstärke von SRC aus prätherapeutischer Biopsie und residuellem Tumorresektat......................................................................................... 44

3.5 Korrelation der prätherapeutischen SRC-Expressionsstärke mit dem Tumorregressionsgrad......................................................................... 48

3.6 Korrelation der SRC-Expressionsstärke mit dem Nodalstatus und dem Auftreten von Fernmetastasen................................................................. 49

3.7 Korrelation der SRC-Expression mit dem krankheitsfreien Überleben und dem karzinomspezifischen Überleben................................................. 55

4.1 Potenzial von SRC als Biomarker beim lokal fortgeschrittenen Rektumkarzinom.

4.2 Rolle von SRC bei anderen Tumorentitäten und mögliche experimentelle und klinische Ansätze beim Rektumkarzinom.

4.3 Weitere Biomarker beim kolorektalen Karzinom in der Übersicht 65

4.4 Einsatz von SRC-Inhibitoren im klinischen Alltag 68 
4.5 Das prädiktive und prognostische Potenzial von SRC im lokal fortgeschrittenen Rektumkarzinom.

4.5.1 Prädiktion des Therapieansprechens anhand des (y)pTNM-Status und des TRG.

4.5.2 Das prognostische Potenzial von SRC gemessen an den Follow-up-Daten....... 76

4.6 Bedeutung und Relevanz für den klinischen Alltag................................... 81

Zusammenfassung

Anhang. 85 


\section{Abkürzungsverzeichnis}

Al

AK

APC-Gen

APE

ATP

AUC

bax

$\mathrm{BMI}$

CAS

CEA

Chk

$\mathrm{cm}$

COX-2

CRM

Csk

CSS

CT

CTx

$D A B$

DFG

DFS

DNA

ECOG

EGFR

FAK

FAP

FDG-PET

FLOX-Regime

FOBT

FOLFOX

5-FU

GRCSG

Gy apoptotischer Index

Antikörper

Tumorsuppressorgen

abdominoperineale Rektumexstirpation

Adenosintriphosphat

Area Under Curve

Apoptoseprotein

Body-Mass-Index

CRK-Associated Substrate

carcinoembryonales Antigen

Csk-homologe-Kinase

Zentimeter

Cyclooxygenase-2

circumferentieller Resektionsrand

c-SRC-Kinase

Carcinom-Specific Survival; Karzinom-spezifisches Überleben

Computertomographie

Chemotherapie

Diaminobenzidin

Deutsche Forschungsgemeinschaft

Disease Free Survival; krankheitsfreies Überleben

Desoxyribonukleinsäure

Eastern Cooperative Oncology Group

Epidermal Growth Factor Receptor

Focal Adhesion Kinase

familiäre adenomatöse Polyposis

Fluordesoxyglukose-Positronenemissionstomographie

Chemotherapieregime bestehend aus 5-FU, Oxaliplatin und Folinsäure

fäkaler Okkultbluttest

Chemotherapieschema bestehend aus 5-Fluorouracil, Oxaliplatin und Folinsäure

5-Fluorouracil

German Rectal Cancer Study Group

Gray 


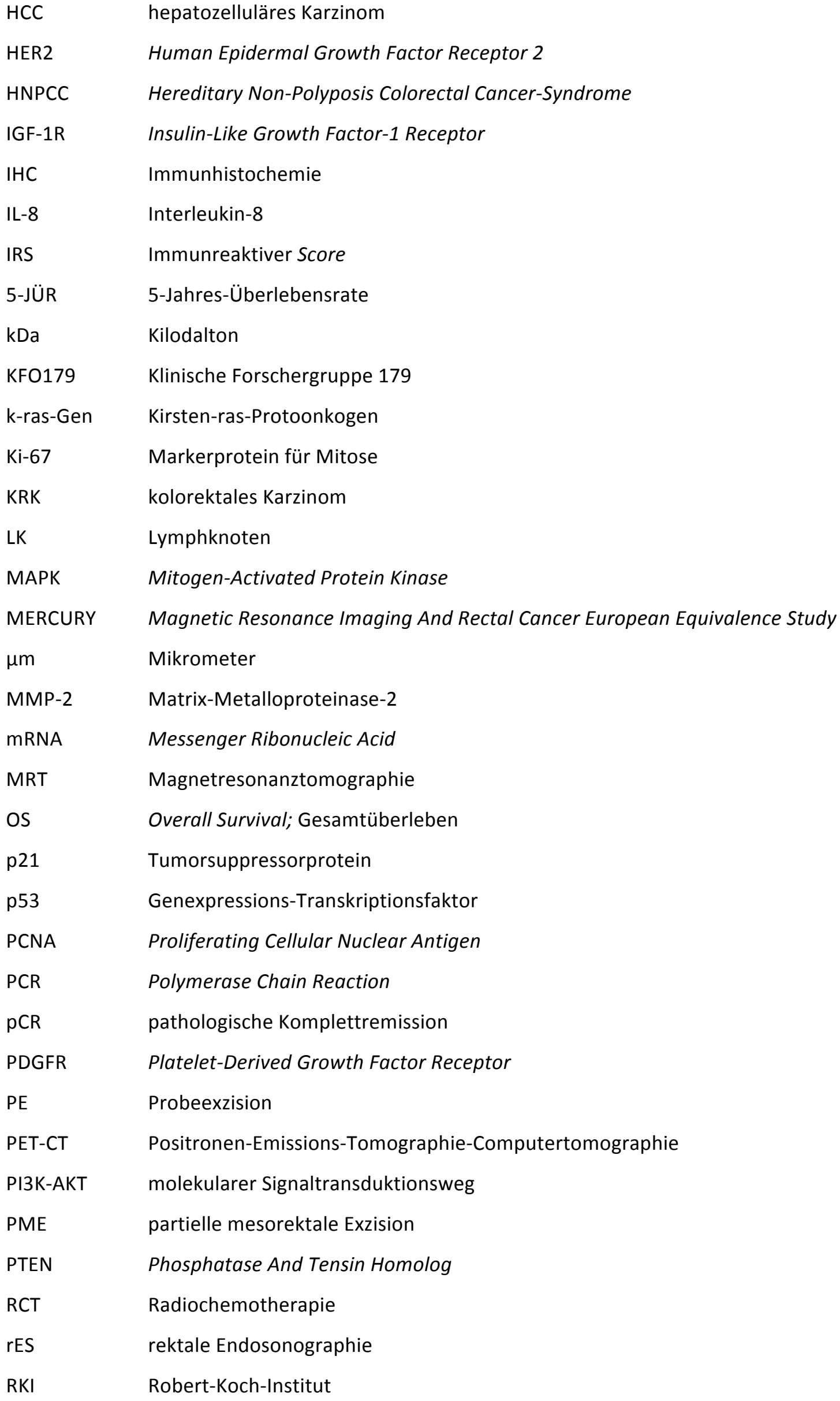




$\begin{array}{ll}\text { ROC-Kurve } & \text { Receiver Operating Characteristic-Kurve } \\ \text { RT } & \text { Radiotherapie } \\ \text { RTK } & \text { Rezeptor-Tyrosinkinasen } \\ \text { RT-PCR } & \text { Reverse Transcriptase-Polymerase Chain Reaction } \\ \text { SFK } & \text { SRC-Tyrosinkinasen-Familie } \\ \text { sh-PTEN } & \text { PTEN-Knockdown durch sh-RNA } \\ \text { Sh-RNA } & \text { Small Hairpin Ribonuclein Acid } \\ \text { SSCP } & \text { Single-Strand Conformation Polymorphism } \\ \text { STAT5B } & \text { Transkriptionsfaktor } \\ \text { TARR } & \text { tiefe anteriore Rektumresektion } \\ \text { TEM } & \text { transanale endoskopische Mikrochirurgie } \\ \text { TKI } & \text { Tyrosinkinaseninhibitor } \\ \text { TME } & \text { totale mesorektale Exzision } \\ \text { TNM } & \text { Klassifikation maligner Tumore } \\ \text { TRG } & \text { Tumorregressionsgrad } \\ \text { TS } & \text { Thymidylatsynthase } \\ \text { TYMS } & \text { Thymidylatsynthase } \\ \text { TUNEL } & \text { Methode zum Nachweis von Apoptosen } \\ \text { UICC } & \text { Union Internationale Contre Le Cancer } \\ \text { UMG } & \text { Universitätsmedizin Göttingen } \\ \text { VEGFR } & \text { Vascular Endothelial Growth Factor Receptor } \\ \text { WHO } & \text { World Health Organization } \\ \text { z.B. } & \text { zum Beispiel } \\ & \end{array}$




\section{Abbildungsverzeichnis}

Abbildung 1: $\quad$ Einteilung des Rektums in oberes, mittleres und unteres Rektumdrittel...... 3

Abbildung 2: $\quad$ Übersicht über Struktur und Aktivierung von SRC.................................. 13

Abbildung 3: $\quad$ Übersicht über molekulare SRC-Interaktionspartner.................................. 15

Abbildung 4: $\quad$ Studiendesign und Ablauf der Therapie.................................................. 20

Abbildung 5: $\quad$ Schema der Immunhistochemie.............................................................. 26

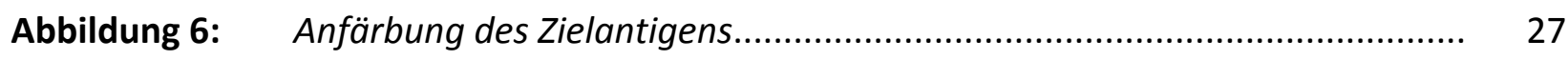

Abbildung 7: $\quad$ Digitale Immunhistochemieaufnahmen in der Zytosolfärbung................... 30

Abbildung 8: $\quad$ Digitale Immunhistochemieaufnahmen in der Membranfärbung............... 31

Abbildung 9: $\quad$ Molekulare Interaktionen von SRC........................................................ 34

Abbildung 10: $\quad$ Übersicht über weitere Interaktionspartner.......................................... 35

Abbildung 11: $\quad$ Übersicht über die SRC-Expression in Biopsie und Resektat in zytosolischer 45 Färbung

Abbildung 12: $\quad$ Übersicht über die SRC-Expression in Biopsie und residuellem Tumor in der 46 Membranfärbung.

Abbildung 13: Wasserfalldiagramm der Expressionsänderung bei korrespondierenden Präparaten in der zytosolischen Färbung

Abbildung 14: Wasserfalldiagramm der Expressionsänderung bei korrespondierenden Präparaten in der Membranfärbung.

Abbildung 15: Korrelation zwischen der prätherapeutischen SRC-Expression mit dem TRG in der Zytosolfärbung

Abbildung 16: Korrelation zwischen der prätherapeutischen SRC-Expression mit dem TRG in der Membranfärbung

Abbildung 17: Korrelation der Expression mit dem Nodalstatus in der Zytosolfärbung der Biopsie.

Abbildung 18: Korrelation der Expression mit dem Nodalstatus in der Membranfärbung 50 der Biopsie. 
Abbildung 19: Korrelation der Expression mit dem Nodalstatus in der Membranfärbung der Biopsie unter neoadjuvanter Therapie.

Abbildung 20: $\quad$ Korrelation der Expression mit dem Nodalstatus in der Membranfärbung der Biopsie unter Einbezug aller drei Behandlungsgruppen

Abbildung 21: Korrelation der Expression mit dem Nodalstatus in der Membranfärbung der Resektate unter neoadjuvanter Vorbehandlung....

Abbildung 22: Korrelation der Expression mit dem Nodalstatus in der Membranfärbung der Resektate unter Einbezug aller drei Behandlungsgruppen

Abbildung 23: Korrelation der SRC-Expression mit dem Auftreten von Fernmetastasen in der Zytosolfärbung von Resektaten.

Abbildung 24: Korrelation der SRC-Expression mit dem Auftreten von Fernmetastasen in der Membranfärbung der Biopsie bei Patienten im pUICC-III-Stadium

Abbildung 25: Korrelation der SRC-Expression mit dem Auftreten von Lokalrezidiven in der Membranfärbung der Biopsie.

Abbildung 26: Korrelation der SRC-Expression mit dem CSS in der Membranfärbung der Biopsie.

Abbildung 27: Korrelation der SRC-Expression mit dem CSS in der Membranfärbung des Tumorresektats mit 5-FU-Oxaliplatin in der Vorbehandlung.

Abbildung 28: Korrelation der SRC-Expression mit dem DFS in der Membranfärbung der Biopsie bei positivem LK-Befall.

Abbildung 29: Korrelation der SRC-Expression mit dem DFS in der Membranfärbung der Biopsie bei Patienten mit positivem LK-Befall

Abbildung 30: Korrelation der prätherapeutischen SRC-Expression mit dem Nodalstatus 60 unter intensivierter neoadjuvanter RCT (FOLFOX $+R T$ ) 


\section{Tabellenverzeichnis}

Tabelle 1: $\quad$ Übersicht über die klinischen Daten des Patientenkollektivs..................... 21

Tabelle 2: $\quad \quad$ Klassifikation des Tumorregressionsgrades (TRG) nach neoadjuvanter $\quad 24$ Radio-/Chemotherapie

Tabelle 3: $\quad$ Einteilung der Zytosolanfärbung in vier unterschiedliche 29 Färbeintensitäten

Tabelle 4: $\quad$ Einteilung der Membrananfärbung in vier unterschiedliche Intensitäten... 29

Tabelle 5: $\quad$ Auflistung der verwendeten Materialien und Substanzen mit Angabe des 32 Herstellers

Tabelle 6: $\quad$ Übersicht über die durchgeführten Operationsverfahren und die Verteilung der Tumorlokalisation auf die dreiRektumdrittel.

Tabelle 7: $\quad$ Übersicht über die klinikopathologischen Parameter der Patienten nach den entsprechenden unterschiedlichen Vorbehandlungsschemata.

Tabelle 8: $\quad$ Übersicht über das Auftreten von Lokalrezidiven, der Detektion von Fernmetastasen und tumorbedingten Todesfällen im Follow-up-Zeitraum

Tabelle 9: $\quad$ Übersicht über die aktuelle Studienlage hinsichtlich eines prädiktiven Potenzials von verschiedenen Biomarkern im lokal fortgeschrittenen Rektumkarzinom

Tabelle 10: $\quad$ Übersicht über die aktuelle Studienlage hinsichtlich eines prognostischen 78 Potenzials von SRC in den verschiedenen Tumorentitäten 


\section{1) Einleitung und Fragestellung}

Das kolorektale Karzinom (KRK) ist in der westlichen Welt eine der häufigsten Malignomerkrankungen. Es stellt dabei sowohl bei Frauen als auch bei Männern die zweithäufigste Krebserkrankung dar (RKI/GEKID 2012). Im Jahre 2008 erkrankten in Deutschland etwa 35.350 Männer und ungefähr 30.040 Frauen am KRK, im Jahre 2012 ca. 38.300 Männer und 31.100 Frauen (RKI/GEKID 2012). In den USA traten im Jahre 2009 insgesamt 106.100 neue KRK-Fälle auf, wovon in 40.870 Fällen das Rektum befallen war (Jemal et al. 2009). In Deutschland sind 50-60 \% der KRK im Rektum lokalisiert (Becker et al. 2006). Die Wahrscheinlichkeit an einem KRK zu erkranken nimmt ab dem 50. Lebensjahr deutlich zu (Schmiegel et al. 2010).

Die hohe Inzidenz des KRK stellt daher sowohl medizinisch als auch sozioökonomisch aufgrund des demographischen Wandels eine besondere Herausforderung dar, basierend auf der Annahme, dass die Inzidenz womöglich weiter ansteigen wird. Um dieser Entwicklung entgegenzuwirken, bedarf es einer medizinischen Versorgung, die in noch stärkerem Maße Früherkennungsprogramme einfordert, sich stets an klinischer und molekularer Grundlagenforschung orientiert und dem Patienten individuell eine bestmögliche und stadiengerechte Therapie anbietet. In den letzten 30 Jahren stieg zwar die 5-Jahres-Überlebensrate (5-JÜR) aufgrund verbesserter therapeutischer Ansätze in Deutschland von $45 \%$ auf $60 \%$ (RKI und GEKID 2010); allerdings liegen nach wie vor bei einem Drittel der Patienten bereits bei Diagnosestellung Fernmetastasen vor.

Aus klinischer Sicht ist die Weiterentwicklung einer individualisierten, Tumorrezidivrisiko- und Tumorstadien-adaptierten Therapie von größter Bedeutung, zumal bisher keine verlässlichen prätherapeutischen Aussagen über ein mögliches Ansprechen der Malignomerkrankung auf eine adäquate Behandlung getroffen werden können.

\section{1 Ätiopathogenese des kolorektalen Karzinoms}

Ätiologisch werden exogene und endogene Faktoren unterschieden, die die KRK-Entstehung begünstigen. Zu den exogenen Faktoren zählen insbesondere Ernährungs- und Lebensgewohnheiten wie mangelnde körperliche Aktivität, Adipositas (BMI > $\left.25 \mathrm{~kg} / \mathrm{m}^{2}\right)$, Rauchen, ballaststoffarme Ernährung, Verzehr von rotem Fleisch in großen Mengen und häufiger Alkoholkonsum (Schmiegel et al. 2010). Als endogene Risikofaktoren gelten adenomatöse Polypen im Gastrointestinaltrakt, genetische Erkrankungen wie die familiäre adenomatöse Polyposis (FAP) oder das auch als LynchSyndrom bekannte Hereditary Non-Polyposis Colorectal Cancer-Syndrome (HNPCC) sowie chronischentzündliche Darmerkrankungen wie Colitis ulcerosa und Morbus Crohn. Genetisch bedingte KRK 
treten ungefähr in 40 \% der Fälle auf, sporadische Karzinome machen etwa 60 \% aus (Fuchs et al. 2014). Auch die erworbenen kolorektalen Adenokarzinome basieren auf der Annahme von genetischen Mutationen, die in der "Adenom-Karzinom-Sequenz" nach Vogelstein beschrieben werden (Fearon und Vogelstein 1990). Nach dieser Hypothese entsteht das Karzinom aus sich vorher ausbildenden benignen Adenomen, es kommt dabei unter anderem zum Verlust von Tumorsuppressorgenen wie p53 und Mutationen des K-ras-Gens, zur Inaktivierung des APC-Gens und zur Aktivierung von Onkogenen (Fearon und Vogelstein 1990). Die Entwicklung vom Adenom in ein Karzinom kann von 10 bis 20 Jahre dauern, wobei flache, breitbasig aufsitzende Adenome aufgrund der kürzeren Strecke schneller die Submukosa erreichen als gestielte Adenome (Fuchs et al. 2014). Auf dieser Hypothese basiert in Deutschland die Empfehlung zur Durchführung einer Koloskopie ab dem 55. Lebensjahr als Darmkrebsvorsorge, um die Früherkennung eines Karzinoms zu ermöglichen. Dabei werden bei einem auffälligen Befund vorhandene Polypen im Rahmen einer Polypektomie abgetragen (RKI/GEKID 2012). Somit kann einer späteren Karzinomentstehung effektiv vorgebeugt werden (Schmiegel et al. 2010).

\subsection{Klassifikation des kolorektalen Karzinoms}

In der vorliegenden Arbeit erfolgt die Klassifizierung von Rektumkarzinomen (nach histopathologischer Karzinomsicherung) anhand der zum Behandlungszeitraum der untersuchten Patienten geltenden TNM-Klassifikation. Die 6. und 7. Auflage der TNM-Klassifikation in Zusammenarbeit mit der UICC (Union Internationale Contre le Cancer) sind im Anhang aufgeführt (siehe Seite 85 bis 87; Wittekind und Sobin 2002, Wittekind und Meyer 2010).

Dabei entscheidet einzig die Höhenlokalisation des Tumors, ob es sich hierbei um ein Kolon- oder ein Rektumkarzinom handelt. Mithilfe eines starren Rektoskops wird der Abstand des Tumorunterrandes ab Anokutanlinie bestimmt. Beträgt dieser mehr als 16 Zentimeter $(\mathrm{cm})$, handelt es sich per definitionem um ein Kolonkarzinom. Rektumkarzinome werden darüber hinaus noch den drei Rektumdritteln zugeordnet (Soreide et al. 1997). Ein Tumor im oberen Rektumdrittel liegt $12-16 \mathrm{~cm}$ ab Anokutanlinie entfernt, im mittleren Rektumdrittel hingegen bei $6-<12 \mathrm{~cm}$. Im unteren Rektumdrittel beträgt der Abstand $0-<6 \mathrm{~cm}$. Diese erneute Unterteilung ist in Deutschland und Europa richtungsweisend für das weitere therapeutische Vorgehen. In den USA hingegen sind Kolonkarzinome durch einen Abstand von mehr als $12 \mathrm{~cm}$ ab Anokutanlinie, Rektumkarzinome entsprechend durch einen Abstand von weniger als $12 \mathrm{~cm}$ ab Linea anocutanea definiert. Begründet wird dies mit der Tatsache, dass die Lokalrezidivrate von Tumoren mit einem Abstand von weniger als $12 \mathrm{~cm}$ bedingt durch die extraperitoneale Lage und die lymphogene Metastasierung über das 
Mesorektum deutlich höher ist. Somit werden im angloamerikanischen Sprachraum Karzinome des oberen Rektumdrittels $(12-16 \mathrm{~cm})$ als Kolonkarzinome angesehen und entsprechend behandelt.

Prinzipiell ist es wichtig, zwischen Kolon- und Rektumkarzinomen zu unterscheiden, da häufig lediglich der Begriff KRK verwendet wird. Das Rektum stellt eine besondere Organentität aufgrund von Kontinenzfunktion, seiner extraperitonealen Lage und Einbettung des mesorektalen Lymphstroms und Fettkörpers in embryonal angelegte Fasziensysteme sowie einer eigenen arteriellen und venösen Gefäßversorgung dar. Durch diese Differenzierung kam es in den vergangenen Jahren erst zu neuen Therapieoptionen beim Rektumkarzinom (Becker et al. 2006, Li und Lai 2009, Li et al. 2012).

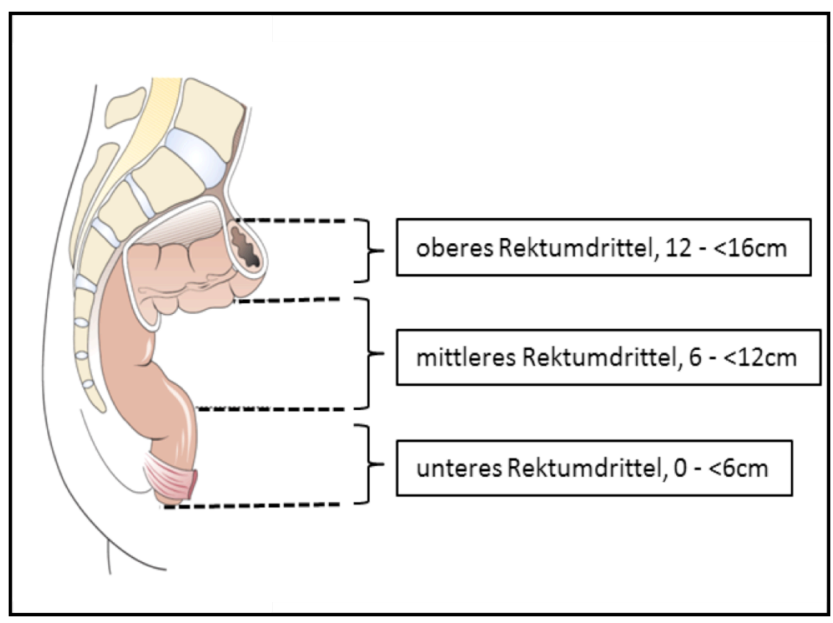

Abbildung 1: Einteilung des Rektums in oberes, mittleres und unteres Rektumdrittel: gemessen in $\mathrm{cm}$ ab Linea anocutanea (oberes Rektumdrittel: $12-16 \mathrm{~cm}$, mittleres Rektumdrittel: $6 \leq 12 \mathrm{~cm}$, unteres Rektumdrittel: $0 \leq 6 \mathrm{~cm}$ )

(Abbildung nach Liersch et al. 2007, S.48)

(Die Verwendung der Abbildung 1 erfolgt mit freundlicher Genehmigung durch Prof. Dr. med. T. Liersch, Klinik für Allgemein-, Viszeral- und Kinderchirurgie der UMG)

Prätherapeutisch erfolgt zunächst die UICC-Stadieneinteilung, die anhand der klinischen (c) Ergebnisse der Staging-Untersuchungen (cUICC) bestimmt wird. Das klinische Staging stellt die Grundlage für das weitere therapeutische Vorgehen dar. Neben Anamnese, körperlicher Untersuchung und der rektal-digitalen Untersuchung spielt dabei insbesondere die rektale Endosonographie ( $r E S$ ) eine bedeutende Rolle hinsichtlich der Klassifikation der Karzinominfiltration in die Rektumwand (uT-Status) und des regionären Lymphknotenbefalls (uN-Status) (Liersch et al. 2007). Das pathologische Staging beschreibt das Erkrankungsstadium nach TNM-Klassifikation (pUICC) und erfolgt postoperativ nach histopathologischer Begutachtung des chirurgisch entnommenen Resektats. Der T-Status beschreibt die Eindringtiefe des Tumors, der N-Status den Befall von regionären Lymphknoten (LK). Die Lymphbahnen verlaufen parallel zu den Venen, diese wiederum parallel zu den Arterien, die intraoperativ als Leit- und Zielstrukturen fungieren. Bei positivem Lymphknotenbefall sind im Rektum vor allem die Lymphbahnen im Bereich der Aa. rectales superiores, mediae und inferiores, der A. iliaca interna, der A. mesenterica inferior sowie 
sakrale Lymphknoten am Promontorium und laterale sakrale beziehungsweise präsakrale LK betroffen.

Beim KRK sollte eine histopathologische Begutachtung von mindestens 12 LK erfolgen, um ein sicheres histopathologisches Staging hinsichtlich des Nodalstatus zu erreichen (Wittekind und Meyer 2010, Hermanek 1995, Fuchs et al. 2014, Bruns et al. 2010). Der M-Status gibt an, ob bei einem Patienten Fernmetastasen vorliegen.

Das KRK metastasiert hämatogen je nach Tumorhöhe und der davon abhängigen Infiltrationen in das jeweilige Blut- und Lymphgefäßsystem vor allem in Lunge und Leber. Die benachbarten Organe wie Ovar, Harnblase und das Peritoneum stellen seltener "Fernmetastasierungsorte" dar sondern sind eher bei organüberschreitendem Tumorwachstum eines T4-Rektumkarzinoms per continuitatem betroffen (Wittekind und Meyer 2010).

\subsection{Epidemiologie des kolorektalen Karzinoms}

Mit steigender Inzidenz macht der Anteil kolorektaler Karzinome in den USA und Europa ungefähr 15\% aller Malignomerkrankungen aus. Mehr als 50\% der Patienten versterben aufgrund der Diagnose KRK. Pro Jahr erkranken in Deutschland daran ca. 60.000 Menschen unabhängig vom Geschlecht. Das KRK tritt dabei in knapp 90\% der Fälle ab dem 50. Lebensjahr auf, insbesondere Personen zwischen dem 60. und 75. Lebensjahr gelten als gefährdet (Liersch et al. 2007). Entscheidend für die Prognose ist das Stadium der Erkrankung bei Erstdiagnose: so beträgt die 5-JÜR im Stadium I und IIA etwa 85-93\%, bei vorhandenen Lebermetastasen liegt die 5-JÜR trotz ROResektion bei nur ca. 25-40\% (Schmiegel et al. 2010).

\subsection{Diagnosesicherung und Staging des kolorektalen Karzinoms}

Rektumkarzinome werden aufgrund ihrer mangelnden klinischen Symptomatik häufig erst dann erkannt, wenn sich erstmals Blutbeimengungen im Stuhl finden lassen. In der Regel sollte bei jedem Patienten mit peranalem Blutabgang eine komplette endoskopische Untersuchung des Kolorektums durchgeführt werden, da nicht selten ein begleitendes Hämorrhoidalleiden zu einer Bagatellisierung und Fehlinterpretation der Blutbeimengung führt (Liersch et al. 2007). Spätsymptome zeichnen sich bevorzugt durch Stuhlgewohnheitsänderungen mit Tendenz zu Obstipation und Diarrhoe sowie durch Gewichtsverlust und Tenesmen aus. Weiterhin kann eine Anämie oder ein Defäkationsschmerz bestehen, der möglicherweise durch einen obstruierenden Tumor bedingt ist. Um die Diagnose endgültig zu sichern, bedarf es einer im Rahmen der Rektoskopie erfolgten bioptischen Abklärung. 
Dabei sollten möglichst mehrere Proben aus verschiedenen Tumorarealen sowie aus gesunder Mukosa entnommen werden (Liersch et al. 2007).

Das prätherapeutische klinische Staging stellt die Grundlage jeder onkologischen Therapie hinsichtlich des weiteren therapeutischen Vorgehens dar (Liersch et al. 2007). Um den Höhensitz des distalen Tumoranteils ab Anokutanlinie zu bestimmen, wird eine starre Rektoskopie durchgeführt. Dabei wird, wie bereits erwähnt, das Rektumkarzinom durch einen Abstand bis einschließlich $16 \mathrm{~cm}$ ab Linea anocutanea definiert. Das klinische Staging umfasst weiterhin eine ausführliche Anamnese mit besonderer Berücksichtigung der Familienanamnese und die körperliche Untersuchung, bei der die rektal-digitale Untersuchung eine sehr wichtige Rolle spielt. Mit dieser Untersuchung können Tumoren bis 7-8 cm ab Anokutanlinie detektiert werden. Diese machen rund 30-40\% aller Rektumkarzinome aus (Gaedcke et al. 2011). Hinzu kommt die rektale Endosonographie (rES), die vorzugsweise vor einer Biopsieentnahme zur Vermeidung falsch-positiv diagnostizierter mesorektaler LK durchgeführt werden sollte. Sie stellt die zuverlässigste Untersuchung bezüglich des T-Status, also der Infiltrationstiefe des Tumors in die Rektumwand mit einer Sensitivität und Spezifität von $90 \%$ bei entsprechender Erfahrung des Untersuchers dar. Hinsichtlich des N-Status liegt die Sensitivität bei etwa $60 \%$ und ist somit geringer als beim T-Status. Die Beurteilung des regionären LK-Status mittels eines rES wird kontrovers diskutiert. Trotz einer geringer ausgeprägten Sensitivität und Spezifität stellt diese Untersuchung die Methode der Wahl zur Beurteilung des lokalen LK-Status dar, zumal die Untersuchung stark von der Erfahrung des Untersuchenden abhängig ist (Liersch et al. 2007, Bruns et al. 2010). Zusammenfassend bleibt zu sagen, dass die rektale Endosonographie in spezialisierten Kliniken inzwischen einen bedeutenden Einfluss auf die Wahl des operativen Verfahrens besitzt (Liersch et al. 2007). Das Staging wird durch eine kontrastmittelgestützte Computertomographie (CT) des Beckens / Abdomens beziehungsweise Magnetresonanztomographie (MRT) des Beckens ergänzt. Hierbei ist anzufügen, dass die CT-Diagnostik des Beckens und Abdomens im Grunde ein vollständiges abdominelles Staging abdeckt. Bezüglich der Tumorinfiltrationstiefe sind die rektale Endosonographie und die MRT des Beckens der CT jedoch überlegen. Deshalb ist die MRT in Schwerpunktzentren mittlerweile Methode der Wahl bei der Frage, ob ein Tumorkontakt zur mesorektalen Hüllfaszie besteht; hierbei wird von einem bildgebend positiven zirkumferentiellen Resektionsrand gesprochen. Auch hinsichtlich der Beurteilung der LK im mesorektalen Weichgewebe, der Levatormuskulatur, der puborektalen Schlinge und des analen Sphinkters hat sich die MRT etabliert (Gaedcke et al. 2011). Komplettiert wird das Staging durch eine Sonographie des Abdomens sowie eine Röntgen-Thorax-Aufnahme in zwei Ebenen zum Ausschluss hepatischer und pulmonaler Metastasen. Weiterhin erfolgt eine Restkolonabklärung vorzugsweise präoperativ beziehungsweise in Einzelfällen postoperativ, eine Überprüfung der Schließmuskelfunktion (Manometrie) und eine laborchemische Bestimmung des carcinoembryonalen Antigens (CEA). Der CEA-Wert ist als 
unabhängiger Prognosemarker anzusehen und dient als Verlaufsparameter, um indirekt auf ein mögliches Rezidiv hinzuweisen.

Die klinische Tumorklassifikation nach Mason ermöglicht eine manuelle Überprüfung der Tumorverschieblichkeit gegenüber der Rektumwand bis zu einer Höhe von $7-8 \mathrm{~cm}$ ab Linea anocutanea. Bei einer Tumorfixierung, die vor allem im cUICC-II/-III-Stadium auftritt, kann ein erfahrener Untersucher einschätzen, ob ein Sphinktererhalt im Rahmen einer onkologischen Rektumresektion realisierbar erscheint. Damit lässt sich eine erste klinische Aussage über das infiltrative Tumorwachstum treffen (Mason 1976, Liersch et al. 2007).

Aufgrund der zunehmenden Inzidenz des KRK im höheren Alter sollte ab dem 55. Lebensjahr eine komplette Koloskopie erfolgen. Dieses Verfahren hat die höchste Spezifität und Sensitivität zur Detektion von Adenomen beziehungsweise Karzinomen. Eine erneute Koloskopie sollte bei unauffälligem Befund nach 10 Jahren stattfinden. Bei Personen, die eine Koloskopie ablehnen, sollte ein jährlicher fäkaler okkulter Bluttest (FOBT; Guaiak-Test) durchgeführt werden; bei einem positiven Testergebnis ist daraufhin eine komplette Koloskopie indiziert. Mit der Einführung dieses Tests konnte die Sterblichkeit beim kolorektalen Karzinom signifikant gesenkt werden. Eine Koloskopie macht jedoch den FOBT hinfällig und stellt nach wie vor die Methode der Wahl zur Erkennung einer kolorektalen Neoplasie dar (Schmiegel et al. 2010).

Zusammenfassend lässt sich festhalten, dass das Staging von herausragender Bedeutung ist, da es die Grundlage für die Festlegung einer bestmöglichen individuellen stadiengerechten Therapie darstellt.

\subsection{Stadienabhängige Therapie des Rektumkarzinoms}

Mit der Einführung der neoadjuvanten Radiochemotherapie (RCT) sowie neuer operativer Verfahren hat es einen grundsätzlichen Wandel in der Therapie des Rektumkarzinoms innerhalb der letzten zwei Jahrzehnte gegeben (Gaedcke et al. 2011). Die Behandlung des Rektumkarzinoms erfolgt dabei multimodal und adaptiert an das Erkrankungsstadium. Diese Erkrankung stellt ein Krankheitsbild dar, das eine enge interdisziplinäre Kooperation zwischen Strahlentherapeuten, Chirurgen, Pathologen und Internisten zur Gewährleistung eines größtmöglichen Behandlungserfolges erfordert.

Für einen kurativen Therapieansatz bedarf es neben der Resektion des Primärtumors einer partiellen beziehungsweise totalen Entfernung des Mesorektums (Schmiegel et al. 2010). Die Resektion erfolgt dabei nach chirurgisch-onkologischen Prinzipien. Während der Präparation kommt es zur Anwendung einer No-Touch-Technik sowie einer En-bloc-Resektion von tumoradhärenten bzw. 
tumorinfiltrierten Organen (multiviszerale Resektion). Dadurch wird die Gefahr einer örtlichen Tumorzelldissemination reduziert (Liersch et al. 2007).

\subsubsection{Lokal begrenztes Rektumkarzinom (UICC-I-Stadium)}

Rektumkarzinome im cUICC-I-Stadium (cT1NOMO und cT2NOMO) werden durch eine alleinige Operation therapiert. Dabei werden die Tumoren bezüglich ihrer Differenzierung in "Low Risk"- (G12) und „High-Risk"-Karzinome (G3-4) unterteilt. Die gut differenzierten „Low Risk"-Tumoren werden bis maximal $3 \mathrm{~cm}$ Durchmesser ohne Lymphgefäßinvasion im Rahmen einer lokalen ROVollwandexzision durch die transanale lokale Exzision nach Parks oder die transanale endoskopische Mikrochirurgie (TEM) nach Buess behandelt. Eine RO-Resektion ist dabei durch einen histopathologischen Sicherheitsabstand von $\geq 1 \mathrm{~cm}$ als kurativ anzusehen (Liersch et al. 2007). Bei der lokalen Vollwandresektion bleibt der LK-Status weitgehend unberücksichtigt unter der Kenntnis, dass ein lokaler LK-Befall in diesem Stadium bei einer Wahrscheinlichkeit von 3-10 \% vergleichsweise gering ausfällt (Bruns et al. 2010). „High Risk“-cT1-Karzinome im schlecht differenzierten beziehungsweise undifferenzierten Zustand (G3-4) werden ebenso wie cT2-Karzinome mittels einer radikalen onkologischen Rektumresektion durch partielle mesorektale (PME) oder totale mesorektale Exzision (TME) therapiert (Gaedcke et al. 2011).

\subsubsection{Lokal fortgeschrittenes Rektumkarzinom (UICC-II/III-Stadium)}

Die multimodale Therapie umfasst beim Rektumkarzinom heutzutage die präoperative kombinierte Radiochemotherapie, die totale mesorektale Exzision (TME) als chirurgisches Verfahren sowie eine postoperative Chemotherapie (Gaedcke et al. 2011). Die multimodale Therapie zielt dabei auf einen kurativen Ansatz durch chirurgische Resektion, eine zytostatisch-medikamentöse Chemotherapie zur Sensibilisierung auf eine Strahlenexposition sowie eine Bestrahlung des kleinen Beckens ab. Die Operation stellt in dem Therapieregime den wichtigsten Prognose-limitierenden Faktor dar. Dabei bildet die TME die Basis der onkologischen Rektumchirurgie. Eine optimale TME kann als alleinige Maßnahme langfristig eine Senkung der Lokalrezidivrate bewirken und geht mit einer verbesserten Prognose einher (Gaedcke et al. 2011).

Rektumkarzinome im CUICC-II/III-Stadium, die sich im oberen Rektumdrittel $(>12 \mathrm{~cm}-16 \mathrm{~cm})$ befinden, werden nicht mittels präoperativer kombinierter RCT vorbehandelt, sondern primär im Rahmen der GAST-05-Studie randomisiert durch eine qualitätskontrollierte TME oder PME operiert. Die GAST-05Studie stellt dabei einen ersten Schritt in Richtung "Individualisierung“ der Therapie des Rektumkarzinoms anhand der Lokalisation des Tumors dar, die eine Überprüfung chirurgischer 
Operationsprinzipien sowie die Rücknahme der multimodalen RCT impliziert (Liersch et al. 2009). Rektumkarzinome im CUICC-II- und CUICC-III-Stadium werden einer multimodalen Therapie zugeführt, sofern sie im mittleren beziehungsweise im unterem Rektumdrittel lokalisiert sind. Unter der Einhaltung eines Stagings und der qualitätsgesicherten Chirurgie mittels TME zeigte die CAO/ARO/AIO-94-RCT-Studie der German Rectal Cancer Study Group (GRCSG) eine Senkung der 5Jahres-Lokalrezidivrate von $13 \%$ (primäre Operation + RT/CTx) auf $6 \%$ (präoperative RT/CTx+ Operation) (Sauer et al. 2004). Auch war nach neoadjuvanter RCT weder die postoperative Morbidität noch die 30-Tage-Letalität erhöht (Liersch et al. 2009). Die akute und chronische Toxizität zeigte sich unter der adjuvanten RCT signifikant höher und die Patientencompliance im Vergleich niedriger (Liersch et al. 2009). Gerade Patienten mit einem angestrebten Sphinktererhalt bei tief sitzendem Rektumkarzinom haben durch die neoadjuvante Therapie eine erhöhte Chance, kontinenzerhaltend operiert zu werden. So konnte in 19\% der Fälle ein Sphinktererhalt bei entsprechender Radiochemotherapie-induzierter Tumorregression durchgeführt werden, der initial aus chirurgisch-onkologischer Sicht nicht für möglich gehalten wurde (Liersch et al. 2009).

Etwa 15-20\% der Rektumkarzinompatienten haben bei Erstdiagnose ein nicht sicher R0resezierbares, fortgeschrittenes T4-Rektumkarzinom. Eine neoadjuvante RCT kann jedoch zu einem erheblichen Downsizing (Rückgang der Tiefeninfiltration) und zu einer erhöhten Resektabilität führen (Liersch et al. 2007, Sauer et al. 2004). Die neoadjuvante RCT sollte chemotherapeutisch 5Fluorouracil (5-FU) als Monotherapie beinhalten beziehungsweise mit Folinsäure kombiniert werden (Fuchs et al. 2014). Die CAO/ARO/AIO-04-Studie (Studiennummer: NCT00349076) zeigt durch die Zugabe von Oxaliplatin einen signifikanten Anstieg der pathological Complete Response ( $p C R$ ) bei 103 von 591 Patienten (17\%) mit einer intensivierten RCT gegenüber 81 von 606 Patienten (13\%) mit einer 5-FU-Monotherapie $(p=0,04)$ (Rödel et al. 2012). Die $p C R$ ist definiert durch eine Abwesenheit von vitalen Tumorzellen im Bereich des ehemaligen Primärtumors sowie in den Lymphknoten (урт0 pNO Status) nach neoadjuvanter Vorbehandlung. Als primärer Endpunkt der CAO/ARO/AIO-04-Studie wurde das dreijährige Disease Free Survival (DFS) herangezogen. Es zeigte sich, dass die Kombination von 5-FU mit Oxaliplatin zu einer signifikanten Verbesserung des DFS führte (71,2 vs. 75,9 Monate; $p=0,03$ ) (Rodel et al. 2014). Als Kontrollgruppe diente der ehemalige Prüfarm der CAO/ARO/AIO-94Studie, der eine 5-Fluorouracil-basierte neoadjuvante RCT, die TME als Operationstechnik und die postoperative viermonatige 5-FU-Chemotherapie beinhaltet.

\subsubsection{Metastasiertes Rektumkarzinom}

Eine etablierte Therapieleitlinie existiert bei Patienten mit einem Rektumkarzinom im cUICC-IVStadium aktuell nicht. Wichtig ist, dass bei Patienten mit einem hepatisch bzw. pulmonal 
metastasierten KRK vor Einleitung einer palliativen Chemotherapie eine Evaluation zur potentiell kurativen Metastasenresektion durch erfahrene Chirurgen und Onkologen (im Rahmen eines interdisziplinären Tumorboards) erfolgen sollte. Es hat sich gezeigt, dass eine erfolgreiche Metastasenresektion durch Leber- und/oder Lungenteilresektionen einen deutlichen Überlebensvorteil gegenüber einer alleinigen palliativen Chemotherapie bietet (Liersch et al. 2007). So liegt z.B. das 5-Jahres-Gesamtüberleben nach Lebermetastasenresektion bei 23-48 \% gegenüber weniger als $3 \%$ bei alleiniger Chemotherapie (Liersch et al. 2007). Nach einer Metastasenresektion können verschiedene Polychemotherapie-Regime (intravenöse Dauerinfusionsprotokolle) zum Einsatz kommen, wie z.B. Kombinationstherapien mit 5-FU+ Folinsäure+ Oxaliplatin/+ Irinotecan oder intraarterielle Chemotherapieapplikationen. Zudem sind auch innovative Target-Therapieformen (gegen CEA-exprimierende Tumorzellen) geprüft worden, wie z.B. der humanisierte, ${ }^{131}$ lod-markierte anti-CEA-Antikörper Labetuzumab im Rahmen einer Phase I/II-Radioimmuntherapiestudie (Liersch et al. 2005, Liersch et al. 2007).

In spezialisierten Zentren, die zu den Mitgliedern der German Rectal Cancer Study Group (GRCSG) zählen, wird ab Anfang 2015 unter randomisierten Bedingungen in Pilotstudien (CAO/ARO/AIO-012Studie; EudraCT-Nummer: 2011-006310-13) eine präoperative RCT mit nachfolgender Chemotherapie (FOLFOX-Regime) oder eine alleinige präoperative Induktionschemotherapie mit anschließender RCT vor der Multiviszeralresektion im cUICC-IV-Stadium als potentiell kurative Therapieoption geprüft (Gaedcke et al. 2011).

Patienten, bei denen ein kurativer Therapieansatz möglich erscheint, sollten präoperativ eine maximal remissionsinduzierende Therapie erhalten. Eine intensive Primärtherapie sollte auch bei Patienten (ECOG 0-2) mit hoher Tumorlast, rascher Progredienz, tumorbedingter klinischer Symptomatik und drohenden Organkomplikationen erfolgen (Fuchs et al. 2014).

\subsection{Prognose und Nachsorge}

Diagnostik und Behandlung von Lokalrezidiven, Metastasen und Zweittumoren sind beim KRK im Gegensatz zu anderen gastrointestinalen Tumoren durch eine engmaschige Nachsorge am besten zu verwirklichen und haben eine prognostische Bedeutung. Dabei besteht innerhalb der ersten fünf Jahre nach kurativer Therapie eines KRK ein erhöhtes Risiko für lokoregionäre Rezidive (3-24\%), von Fernmetastasen (>25\%) oder für ein metachrones Zweitkarzinom (1,5-10\%) (Schmiegel et al. 2010). Wichtig für die Prognose ist die frühzeitige Detektion des Lokalrezidivs mit histologischer Sicherung. Möglicherweise sind erhöhte Tumormarker, die Magnetresonanztomographie (MRT), die Computertomographie (CT), die Rektoskopie sowie die Endosonographie für die weitere Therapie richtungsweisende Untersuchungsmethoden. 
Außerdem spielt die Fluordesoxyglucose-Positronenemissionstomographie (FDG-PET) bei der Diagnostik eines Lokalrezidivs eine zunehmende Rolle, zumal mit dieser Untersuchung auch stoffwechselaktive Metastasen detektiert werden können (Bruns et al. 2010).

Von hoher Bedeutung ist die Behandlung von Beeinträchtigungen, die durch die Therapie erst entstanden sind, wie z.B. Harninkontinez, Blasenentleerungsstörungen, Versorgungsprobleme bei Stomapatienten und sexuelle Dysfunktion. Patienten mit einem UICC-I-Stadium nach RO-Resektion müssen aufgrund der sehr guten Prognose nicht regelmäßig zur Nachsorge, können aber bei erhöhtem CEA-Wert, pT2-Tumoren oder schlechtem Differenzierungsgrad G3-4 auch engmaschiger kontrolliert werden. Gelegentlich wird bei einem Rektumkarzinom im Stadium pT2pNOMO eine jährliche diagnostische Nachsorge in Form von CEA-Bestimmung, postoperativer CT, Röntgen-Thorax, Koloskopie alle 3-5 Jahre, Rektoskopie und Sonographie des Abdomens empfohlen, da die Inzidenz einer Progression beim Rektumkarzinom im Stadium UICC-I mit 14\% gegenüber dem UICC-I-Stadium des Kolonkarzinoms mit 4,5\% signifikant erhöht ist (Bruns et al. 2010). Patienten mit einem pT2Tumor (UICC Ib) erleiden mit 13\% dabei deutlich häufiger ein Rezidiv als Patienten mit einem pT1Tumor (UICC la) (4\%). Alles in allem ist das Langzeitüberleben im Stadium UICC I mit 86\% sehr gut und erfordert keine standardisierte engmaschige Nachsorge wie bei einem Patienten mit einem Rektumkarzinom im UICC-Stadium II und III. Das Nachsorgeprogramm umfasst auch hier im Rahmen von halbjährlichen Untersuchungsintervallen Anamnese, körperliche Untersuchung, CEABestimmung, Koloskopie, Abdomensonographie, Rekto-/Sigmoidoskopie, Computertomographie und Röntgen-Thorax. Nach Abschluss der Nachsorge sollte lebenslang alle 3-5 Jahre eine Koloskopie erfolgen, um Zweittumoren im Kolon frühzeitig zu detektieren (Bruns et al. 2010). Aufgrund der Tatsache, dass rund $80 \%$ aller Metastasen in der Leber auftreten, sollte eine regelmäßige Abdomensonographie im Abstand von 3-6 Monaten erfolgen. Außerdem ist die Optimierung der Lebensgewohnheiten auch posttherapeutisch von hoher Bedeutung. Dazu zählen insbesondere körperliche Aktivität, Einstellen des Rauchens, gemäßigter Alkoholkonsum, das Einhalten eines natürlichen Körpergewichts sowie ausgewogenes Ernährungsverhalten (Schmoll et al. 2012).

\subsection{Biomarker in der Therapie für das Rektumkarzinom}

Bis heute ist es nicht gelungen, einen einzelnen prädiktiven Biomarker hinsichtlich des Therapieansprechens $\mathrm{zu}$ finden, der verlässlich das Outcome beim lokal fortgeschrittenen Rektumkarzinom unter neoadjuvanter Radiochemotherapie beschreibt. Auch ein prognostischer Biomarker hinsichtlich des Langzeitverlaufs konnte bislang nicht detektiert werden. Eine Metaanalyse von Kuremsky et al. (2009) wertete sechs verschiedene Marker aus, die zuvor in mindestens fünf Studien als relevant beschrieben wurden. Dabei handelt es sich um p53, p21, 
Thymidylatsynthase, Epidermal Growth Factor Receptor (EGFR), Ki-67 und bcl-2/bax. Vor allem EGFR scheint eine vielversprechende Rolle als Biomarker einzunehmen (Kuremsky et al. 2009). Die Tyrosinkinase SRC dient als wichtiger Interaktionspartner im EGFR-Pathway. Somit könnte die Expression von SRC möglicherweise eine Bedeutung als Biomarker hinsichtlich der Prädiktion oder der Prognose haben. Eine ausführlichere Diskussion der Metaanalyse von Kuremsky et al. (2009) erfolgt unter dem Punkt 4.3 Weitere Biomarker beim kolorektalen Karzinom in der Übersicht. Anzumerken ist, dass es nicht auf einen einzelnen Biomarker allein ankommt, sondern vielmehr auf einen Markerpanel, dem vermutlich eine prädiktive und/oder prognostische Bedeutung zukommt.

\subsection{Die Tyrosinkinase SRC - Entdeckung und Bedeutung}

1976 wurde von den amerikanischen Forschern J.M. Bishop und H.E. Varmus das SRC-Gen, das zur Gruppe der SRC-Tyrosinkinasen-Familie (SFK) gehört, entdeckt. Dieses Gen war gleichzeitig das erste Protoonkogen, das identifiziert werden konnte. Die Entdeckung des SRC-Gens wurde mit dem Nobelpreis für Medizin und Physiologie im Jahre 1989 ausgezeichnet (Sen und Johnson 2011). SRC codiert für eine gleichnamige Tyrosinkinase, die bei Aktivierung an Angioneogenese, Zellproliferation, Zellüberleben sowie Zellmigration beteiligt ist. Bei entarteter Zellregulation stellen diese Vorgänge vier der sechs "Hallmarks Of Cancer" dar (Aleshin und Finn 2010, Hanahan und Weinberg 2000). Die "Hallmarks Of Cancer" wurden erstmalig 2000 in einem Artikel im Cell Journal veröffentlicht, in dem die Autoren die Komplexizität der Krebsentstehung auf eine kleine Anzahl von Grundprinzipien reduzieren. Zu diesen zählen: Unabhängigkeit von Wachstumssignalen, Unempfindlichkeit auf wachstumshemmende Signale, unbegrenztes Wachstumspotenzial, mangelnde Fähigkeit zur Apoptose, Versorgung des Tumors durch Angiogenese und Metastasenbildung (Hanahan und Weinberg 2000).

Eine Überexpression von SRC wurde bereits in vielen verschiedenen Karzinomentitäten festgestellt, darunter beim Mamma-, Bronchial-, Ovarial-, Prostata- und Pankreaskarzinom (Summy und Gallick 2003, Dehm und Bonham 2004). Vor allem bei gastrointestinalen Tumoren scheint eine vermehrte SRC-Aktivität mit einem fortgeschrittenen Tumorstadium und/oder der Progression der Erkrankung verbunden zu sein. Auch eine Resistenz gegenüber Chemotherapeutika wie Trastuzumab oder Gemcitabine wird derzeit diskutiert (Zhang et al. 2011, Talamonti et al. 1993, Shah und Gallick 2007, Duxbury et al. 2004). 


\subsection{Strukturelle Eigenschaften von SRC}

Die Tyrosinkinase SRC besitzt ein Molekulargewicht von 60 Kilodalton (60 kDa) und besteht aus verschiedenen Domänen, die intramolekular wiederum unterschiedliche Aufgaben übernehmen. Am $\mathrm{N}$-Terminus des Moleküls befindet sich eine an der SH4-Domäne gekoppelte Myristoylierungsgruppe, nach c-terminal folgen eine sogenannte Unique Domain, die SH3- und SH2-Domäne, eine Linker Domain, die als SH1-Domäne bekannte Tyrosinkinasendomäne und der negativ regulatorische CTerminus (Sen und Johnson 2011). Das Enzym liegt überwiegend im Zytosol vor, die Myristoylierungsgruppe der SH4-Domäne besitzt jedoch die Funktion, das Molekül mit der Zellmembran zu assoziieren sowie andere Zellen zu transformieren (Roskoski 2004). Der Unique Domain werden spezifische Funktionen nachgesagt, die je nach Mitglied der SRC-TyrosinkinasenFamilie (SFK) variieren. Die SH3-Domäne wiederum scheint bei der Interaktion von Proteinen für das Bereitstellen und die Lokalisierung von Substraten verantwortlich zu sein (Thomas und Brugge 1997). Die SH2-Domäne, die je nach SFK-Mitglied unterschiedliche Affinitäten zu verschiedenen Bindungspartnern besitzt, kann phosphorylierte Tyrosinreste an die eigene c-terminale regulatorische Domäne binden (Sen und Johnson 2011, Waksman und Kuriyan 2004).

Bei der Linkerdomäne handelt es sich um eine Domäne, die intramolekular mit der SH3-Domäne interagiert, die Kinaseaktivität reguliert und zwischen SH2- und SH1-Domäne lokalisiert ist. Die als SH1-Domäne bekannte katalytische Tyrosinkinasendomäne besteht aus zwei durch einen katalytischen Spalt getrennte Untereinheiten. In diesem Spalt befindet sich sowohl die Substratbindungsstelle als auch ein Adenosin-5'-Triphosphat (ATP)-Molekül, wobei ein Austausch von Phosphat erfolgt. Dieser Spalt bildet eine Aktivierungsschleife, die das sogenannte Tyrosin419 (Tyr419) enthält, das eine positiv regulatorische Stelle für eine vermehrte Kinaseaktivität repräsentiert (Brown und Cooper 1996). Eine Phosphorylierung des negativ regulatorischen Tyrosinrests 530 (Tyr530) führt zu einer intramolekularen Interaktion des phosphorylierten Tyr530 mit der SH2-Domäne, wodurch das Enzym eine geschlossene Konformation einnimmt und in einen inaktiven Zustand übergeht. Eine Autophosphorylierung von Tyr419 innerhalb der SH1-Domäne sowie eine Dephosphorylierung von Tyr530 führt hingegen zu einer Aktivierung des SRC-Moleküls (Aleshin und Finn 2010).

Zu der Regulation des SRC-Proteins wird noch im Kapitel 2.7 Funktion des Zielantigens Stellung genommen. 


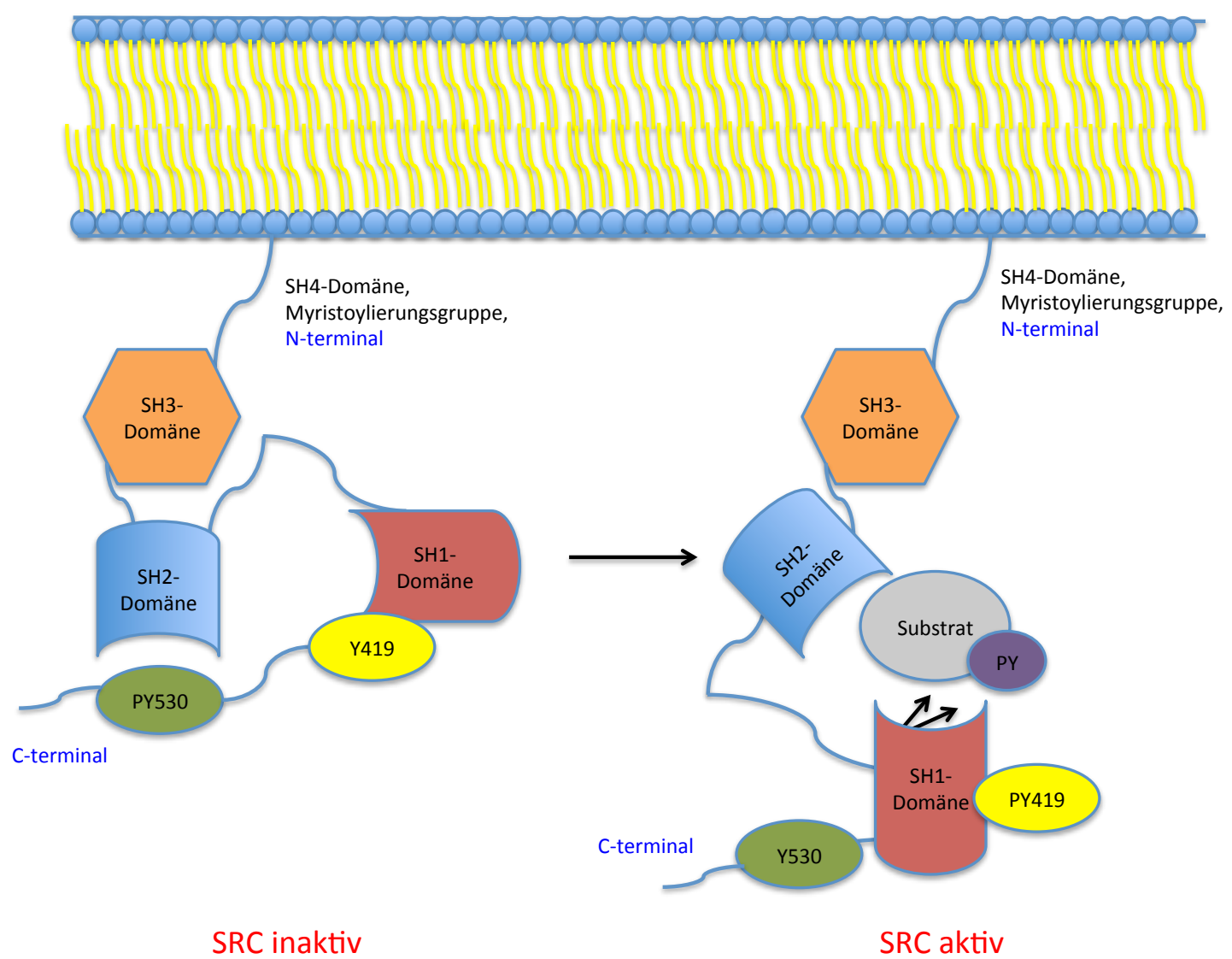

Abbildung 2: Übersicht über Struktur und Aktivierung von SRC: Das Protein besteht aus vier unterschiedlichen homologen Domänen. Die SH4-Domäne am N-terminalen Ende ermöglicht durch die Myristoylierungssequenz eine Verbindung zur Zellmembran. Die SH3-Domäne interagiert mit anderen Proteinen oder SRC selbst. Die SH2-Domäne kann phosphorylierte Tyrosinreste entweder an die eigene c-terminale regulatorische Domäne oder auch an diese anderer Proteine binden. Die SH2-Linkerdomäne befindet sich zwischen SH2- und SH1-Domäne, kann die SRC-Aktivität regulieren und interagiert mit der SH3-Domäne. Die SH1-Domäne stellt die Tyrosinkinasendomäne dar und enthält den Tyrosinrest419 (Tyr419, auch Y419), der durch die Kinasedomäne phosphoryliert werden kann. Am C-terminalen Ende befindet sich der negativ regulatorische Tyrosinrest530 (Tyr530, auch Y530).

Wird Y530 durch die C-terminale SRC-Kinase phosphoryliert, bindet sich der C-Terminus an die SH2-Domäne und hemmt dadurch die SRC-Aktivierung durch eine Konfigurationsänderung der SH2- und SH3- und SH2-Linkerdomäne. Die gesamte Konfiguration wird dadurch geschlossen und inaktiv.

Eine Dephosphorylierung von Y530 durch Phosphatasen sowie eine Autophosphorylierung von Y419 ermöglicht den SH1-, SH2- und SH3-Domänen eine Öffnung, wodurch SRC in einen aktiven Zustand übergeht.

(Abbildung modifiziert nach Kim et al. 2009, S.589)

\subsection{Molekulare SRC-Interaktionen}

Das SRC-Molekül besitzt eine Vielzahl an Interaktionspartnern und spielt in mehreren molekularen Pathways eine wichtige Rolle. Dabei ist SRC unter anderem für die Anordnung von Zell-Zellbeziehungsweise Zell-Matrix-Adhäsionen (Yeatman 2004) essenziell. Das mit der Zellmembran assoziierte und aktivierte SRC lagert sich der zytoskelettalen-membranösen Kontaktfläche an und begünstigt dadurch eine Abnahme von Zell-Zell- und Zell-Matrix-Kontakten (Bjorge et al. 2000). Für die Aufrechterhaltung von diesen Verbindungen sind insbesondere E-Cadherin-Moleküle 
verantwortlich. In KRK-Zelllinien korrelierte eine vermehrte SRC-Aktivität mit einer verminderten Zell-Zell-Adhäsion sowie einer geringeren E-Cadherin-Expression (Irby und Yeatman 2002, Nam et al. 2002). SRC kann weiterhin durch Phosphorylierung Untereinheiten von Integrinmolekülen hemmen, die ebenfalls bei der Verknüpfung von Zellen zur extrazellulären Matrix eine Rolle spielen (Sakai et al. 2001, Datta et al. 2002). Bei Krebsleiden führen fehlregulierte Zell-Matrix-Kontakte zu einer erhöhten Wahrscheinlichkeit der Metastasenbildung und somit zu einem verkürzten Überleben der Patienten (McLean et al. 2005).

Die SRC-Aktivität wird außerdem durch verschiedene Rezeptor-Tyrosinkinasen (RTK) in Form von Wachstumsfaktoren wie beispielsweise EGFR (epidermal growth factor receptor), VEGFR (vascular endothelial growth factor receptor), PDGFR (platelet-derived growth factor receptor), fibroblast growth factor receptor und HER-2 (human epidermal growth factor receptor 2) reguliert (Parsons und Parsons 1997).

Epitheliale und fibroblastische Zelllinienexperimente zeigten ein synergistisches Zusammenspiel zwischen SRC und EGFR (auch ErbB-1) hinsichtlich der Zellinvasion und der Proliferation. SRC scheint also eine wichtige Rolle im EGFR-Pathway zu spielen. Durch Phosphorylierung von EGFR durch SRC konnten auch weitere Signalkaskaden wie Jak-Signal Transducers And Activators Of Transcription (STAT5B) und die Mitogen-Activated Protein Kinase (MAPK) aktiviert werden, was wiederum zu einer verstärkten Angioneogenese und Zellproliferation führte (Lieu und Kopetz 2010, Kloth et al. 2003, Biscardi et al. 1998). Auch eine Rolle von vermehrt exprimiertem SRC bei der EGFRAntikörperresistenz wird diskutiert. In KRK-Zelllinien mit einer Resistenz gegen den EGFR-Antikörper Cetuximab zeigte sich eine verstärkte SRC-Aktivität. Mit einer SRC-Inhibition konnte die Resistenz von Cetuximab induzierter Apoptose aufgelöst werden, wobei diese Hemmung keinen Einfluss auf die Expression von EGFR in den Zellen hatte (Lu et al. 2007). Eine Überexpression von SRC erhöhte zudem die Heterodimerisierung von HER-2 (ErbB-2) und HER-3 (ErbB-3), die wie EGFR zu den Mitgliedern der ErbB-Familie gehören, und ermöglichte dadurch einen Upstream-Mechanismus mit vermehrter biologischer Aktivität im Signalweg dieser Moleküle (Ishizawar et al. 2007).

Die Angioneogenese wird durch eine Vielzahl von Zytokinen reguliert, wodurch eine zelluläre Kaskade ausgelöst und eine verstärkte Endothelzellproliferation begünstigt wird. Häufig ist die Gefäßneubildung bei Vorliegen von Karzinomen fehlreguliert. Medikamentöse Angiogenesehemmer sind daher fester Bestandteil onkologischer Therapien im klinischen Alltag. Eine SRC-Aktivierung ist mit einer vermehrten Expression von proangiogenetischen Zytokinen wie Interleukin 8 (IL-8) und VEGF assoziiert. Dabei kann SRC die Expression von angiogenetischen Wachstumsfaktoren und Zytokinen durch deren Genexpressionsregulierung kontrollieren (Kanda et al. 2007). Vor allem die antineogenetischen Effekte von SRC-Inhibitoren scheinen vielversprechend für den Einsatz in der 
Tumortherapie. In Pankreaskarzinomzelllinien konnte bereits ein Rückgang der IL-8-Expression durch SRC-Inhibition nachgewiesen werden (Trevino et al. 2005).

Außerdem spielt SRC eine wichtige Rolle im Knochenstoffwechsel. Knochenmetastasen kommen vorwiegend bei Bronchial-, Prostata- und Mammakarzinomen vor, aber auch beim KRK können sie auftreten. In Tiermodellen zeigte sich ein erhöhtes SRC bei funktionsfähigen Osteoklasten, ein unterbrochener SRC-Signalweg hingegen verhinderte eine Migration der Osteoklasten und eine Aufnahme dieser in den Knochen. Im Mausmodell entwickelten SRC-überexprimierende Brustkrebszellen vorzugsweise die Bildung von Knochenmetastasen. In einem ähnlichen Brustkrebsmodell führte die SRC-Inhibition zu verminderten Knochenmetastasen, zu einer geringeren Gesamtletalität und Produktion der Osteoklastenaufnahme im Knochen sowie zu einer verstärkten Osteoblastenfunktion in vitro (Horne et al. 1992, Miyazaki et al. 2006, Myoui et al. 2003, Rucci et al. 2006).

Zusammenfassend lässt sich sagen, dass eine vergleichsweise hohe SRC-Expression mit Zellproliferation, Angiogenese, Zellmigration, Zellwachstum und Bildung von Metastasen all das begünstigt, was die Tumorentwicklung beziehungsweise das Tumorwachstum fördert. Genau die entgegengesetzten Effekte werden sich beim klinisch-therapeutischen Einsatz von SRC-Inhibitoren erhofft.

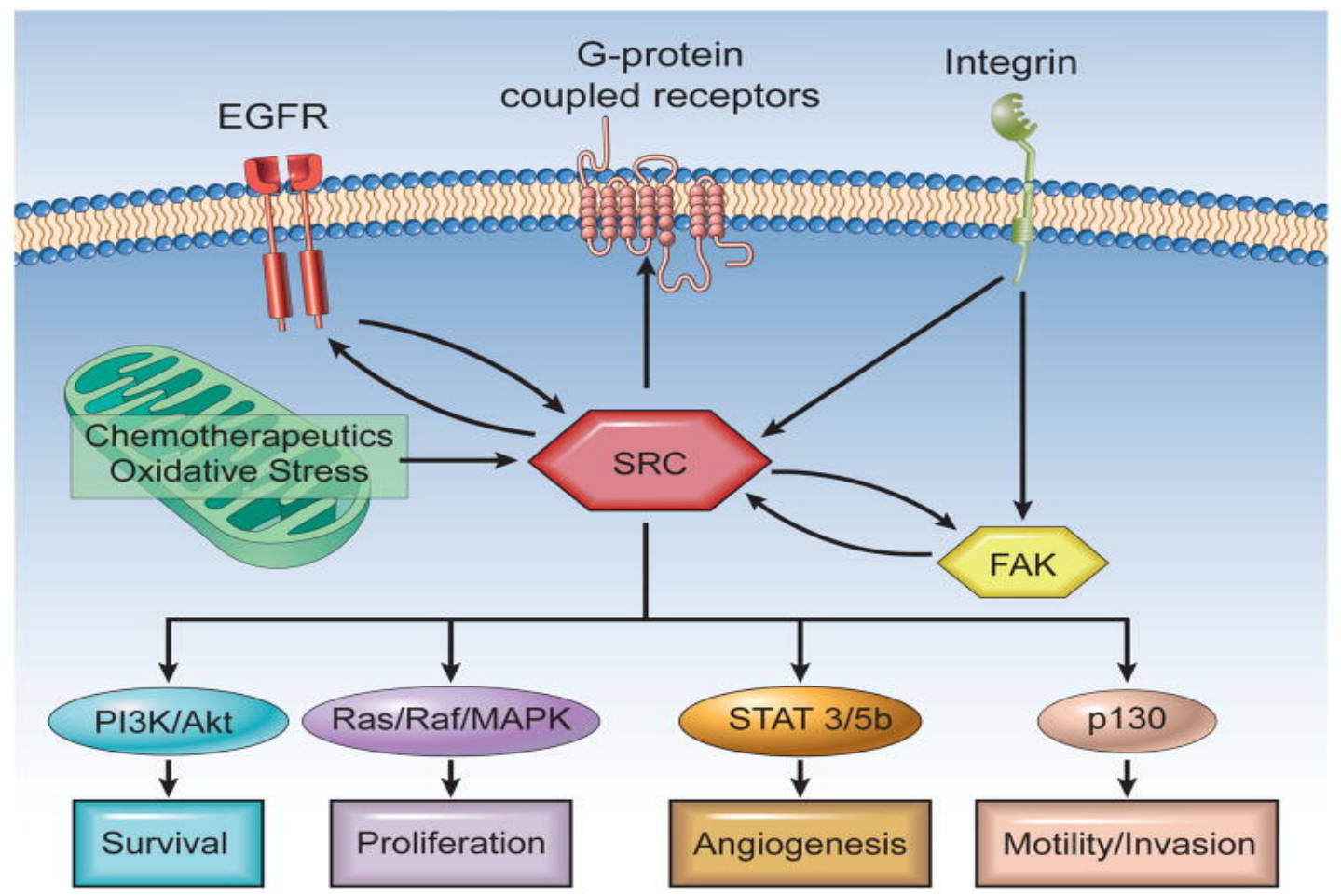

Abbildung 3: Übersicht über molekulare SRC-Interaktionspartner: Von besonderem Interesse ist dabei die Rolle von SRC im EGFR-Pathway.

(Abbildung nach Lieu und Kopetz, 2010, S.12)

(Die Verwendung der Abbildung 3 erfolgt mit freundlicher Genehmigung durch Prof. S. Kopetz, University of Texas MD Anderson Cancer Center, Houston, TX, USA) 


\subsection{SRC-Inhibitoren als zukünftige Therapieoption}

Angesichts der Tatsache, dass das Fortschreiten von Karzinomen in mehreren Tumorentitäten durch SRC-Inhibitoren bereits vermindert werden konnte, könnte eine selektive Hemmung der SRCAktivierung möglicherweise bei der Prävention von Metastasen nützlich sein (Nam et al. 2002).

Die drei bisher am häufigsten untersuchten SRC-Inhibitoren sind Dasatinib (Sprycel), Bosutinib (SKI606) und Saracatinib (AZD530). Diese werden alle im Rahmen von klinischen Studien derzeit in den verschiedendsten Entitäten (beispielsweise fortgeschrittenes metastasiertes Mammakarzinom, Prostata-/Mammakarzinom mit Knochenmetastasen, ausgedehntes kleinzelliges Bronchialkarzinom, metastasiertes Pankreaskarzinom) erprobt. Dasatinib ist ein SRC/ABL-Inhibitor, dessen antiproliferative und antitumoröse Wirkung sich in einigen soliden und hämatologischen Tumorzelllinien gezeigt hat (Chang et al. 2008). Außerdem zeigten Studien in Kolonkarzinomzelllinien eine Zelladhäsionshemmung sowie eine geringere Zellmigration und Zellinvasion. In EGFRüberexprimierenden Brustkrebszelllinien hemmte Dasatinib Zellwachstum, Zellinvasion und Angiogenese und förderte gleichzeitig die Apoptose (Nautiyal et al. 2009). Bosutinib zeigte im Brustkrebsmodell eine signifikant verminderte Anzahl an Lungen- und Lebermetastasen und wird klinisch derzeit beim Mammakarzinom sowie weiteren soliden Tumoren und Leukämien eingesetzt. Saracatinib ist ein dualspezifischer SRC/ABL-Inhibitor, der in Brustkrebszelllinien mit mutiertem Östrogenrezeptor in Kombination mit Tamoxifen zu einer synergistischen SRC-Hemmung führte (Herynk 2006).

Es stellt sich dabei die Frage, ob diese Inhibitoren als Monotherapie eingesetzt werden sollten oder ob eine Kombinationstherapie sinnvoll erscheint. Da Mutationen im SRC-Molekül nicht der vorherrschende Mechanismus sind, um eine SRC-Aktivierung herbeizuführen, scheint eine alleinige Monotherapie mit SRC-Antagonisten nur wenig erfolgversprechend zu sein. Schon die präklinischen Daten zeigten einen nur sehr geringen Einfluss von SRC-Inhibitoren auf die Zellproliferation in KRKZelllinien (Jones et al. 2002). Daher scheint eine Kombinationstherapie mit Zytostatika vielversprechender zu sein. In Pankreasadenokarzinomzellinien korrelierte die SRC-Aktivität mit einer Chemoresistenz gegenüber Gemcitabin. Nach Zugabe von Tyrosinkinaseninhibitoren (TKI) zeigte sich ein geringeres Tumorwachstum sowie eine Verhinderung der Metastasenbildung in vivo (Duxbury et al. 2004). Auch in Zelllinien von Ovarialkarzinomzellen konnte eine SRC-Hemmung die Tumorzellen für Docetaxel und Cisplatin sensibilisieren (Pengetnze et al. 2003, Han et al. 2006). Derzeit wird eine kombinierte EGFR- und SRC-Inhibition bestehend aus Cetuximab und Dasatinib im Rahmen von klinischen Studien erprobt. Bisher erfolgt der kombinierte Einsatz von EGFR-und SRCInhibitoren jedoch überwiegend bei Patienten mit Kopf-Hals-Tumoren, weswegen über die Wirksamkeit dieser Hemmstoffe beim KRK nur spekuliert werden kann (Argiris et al. 2012). 
In einer Phase-II-Studie (Studiennummer: NCT00504153) konnte bei Patienten mit einem vorbehandelten metastasierten KRK nachgewiesen werden, dass Dasatinib als Monotherapie keine Wirksamkeit zeigte (Sharma et al. 2012). In einer aktuell andauernden Phase-I-/II-Studie (Studiennummer: NCT00501410) wird überprüft, ob und inwieweit die Inhibition von EGFR und SRC durch Cetuximab und Dasatinib in Kombination mit dem FOLFOX-Schema einen Einfluss auf das Outcome bei Patienten mit einem metastasierten kolorektalen Karzinom hat. Die Studie wird voraussichtlich im April 2015 abgeschlossen sein (ClinicalTrials.gov 2007). Eine weitere Phase-IIStudie (Studiennummer: NCT00277303), die den Einfluss von XL999, einem multiplen TKIChemotherapeutikum, welches unter anderem PDGFR, VEGFR und SRC inhibiert, bei Patienten mit einem metastasierten KRK untersuchte, musste aufgrund von kardiotoxischen Nebenwirkungen abgebrochen werden (ClinicalTrials.gov 2006).

Es bleibt festzuhalten, dass SRC-Antagonisten neue therapeutische Möglichkeiten darstellen, die sich derzeit schon in der klinischen Erprobung befinden.

Allerdings sind noch zahlreichere klinische Evaluierungen notwendig, um eine gesicherte Aussage darüber treffen zu können, ob und inwieweit SRC-Inhibitoren tatsächlich von klinischer Relevanz sein könnten.

Aufgrund der Tatsache, dass bisher kaum relevante Daten zum KRK und speziell zum Rektumkarzinom vorliegen, ist in dieser Untersuchung die Expression von SRC ausschließlich an Patienten mit einem Rektumkarzinom durchgeführt worden.

\subsection{Zielsetzung und Fragestellung}

Die Untersuchung des Patientenkollektivs mittels der immunhistochemischen Auswertung erfolgte durch das Teilprojekt 5 (Leiter: Prof. Dr. T. Liersch) der Klinischen Forschergruppe 179 (KFO 179; Leiter: Prof. Dr. B. M. Ghadimi): „Biological Basis Of Individual Tumor Response In Patients With Rectal Cancer" der Universitätsmedizin Göttingen (siehe www.kfo179.de). Alle Teilprojekte dieser Forschergruppe werden durch die Deutsche Forschungsgemeinschaft (DFG) gefördert.

Sämtliche Patienten, die in diese Untersuchung eingeschlossen wurden, sind in Phase II-/III-Studien der German Rectal Cancer Study Group (GRCSG) oder analog dieser Protokolle in der Klinik für Allgemein-, Viszeral- und Kinderchirurgie der Universitätsmedizin Göttingen (UMG) therapiert worden. Bei allen Patienten mit einem Rektumkarzinom im klinischen UICC-II- und III-Stadium wurde eine neoadjuvante RCT durchgeführt.

Folgende Fragen sollten in der vorliegenden Arbeit durch diese Untersuchung beantwortet werden: 
1) Kann eine SRC-Expression in der Biopsie bzw. im Resektat bestimmt werden und gibt es womöglich einen Shift (Hoch-/Herunterregulation) durch die neoadjuvante RCT?

2) Hat die Expression von SRC aus prätherapeutischen Biopsien einen prädiktiven Wert hinsichtlich des Ansprechens auf die Radiochemotherapie (gemessen anhand klinischpathologischer Daten und des Tumorregressionsgrades)?

3) Spielt die Expression von SRC aus prätherapeutischen Biopsien und residuellen Resektaten eine prognostische Rolle bezüglich des krankheitsfreien Überlebens (Disease Free Survival, DFS) beziehungsweise bezüglich des karzinomspezifischen Überlebens (Cancer Specific Survival, CSS)?

4) Kann aus der Beantwortung dieser Fragen ein klinischer Nutzen vermutet werden, der künftig neue Therapieformen ermöglicht (beispielsweise SRC als Target)?

5) Wie lassen sich die Ergebnisse dieser Untersuchung in den Kontext der bisher verfügbaren Literatur einordnen? 


\section{2) Patientenkollektiv, Material und Methoden}

\subsection{Patientenkollektiv}

In diese Untersuchung wurde ein Patientenkollektiv von 186 Patienten eingeschlossen, die an einem lokal fortgeschrittenen CUICC-II/III Rektumkarzinom erkrankt sind. Bei allen Patienten erfolgte eine eine multimodale Therapie, die sich an den aktuellen Therapierichtlinien bzw. Protokollen klinischer Studien in Zusammenarbeit mit der Klinik für Strahlentherapie und Radioonkologie (Direktor Univ.Prof. Dr. Dr. C. F. Hess) der Universitätsmedizin Göttingen orientierte. Jeder dieser Patienten ist in der Klinik für Allgemein-, Viszeral- und Kinderchirurgie der Universitätsmedizin Göttingen (Ärztliche Leitung: Univ.-Prof. Dr. H. Becker bis 03/2012, seit dem 01.04.2012: Univ.-Prof. Dr. B. M. Ghadimi) im Zeitraum vom 20.05.1998 bis 24.02.2010 operiert worden.

Alle Patienten, die in diese Studie eingeschlossen wurden, wurden ausführlich über den Inhalt und die Ziele dieser Untersuchung aufgeklärt. Dabei lag von jedem Patienten eine schriftliche Einverständniserklärung über die Evaluierung seiner klinischen Befunde, die immunhistochemische Auswertung des entnommenen und archivierten Biomaterials sowie die Erlaubnis zur Erhebung weiterer Daten im Rahmen der Follow-Up-Untersuchung durch die KFO 179 vor (www.kfo179.de).

Die histopathologische Diagnostik, die Beurteilung der Resektate sowie die Bestimmung des Tumorregressionsgrades erfolgte nach etablierten Verfahren im Institut für Pathologie (Direktor: Prof. Dr. P. Ströbel, OÄ Dr. med. H. Rothe, Dr. J. Kitz).

Das Durchschnittsalter der Patienten betrug zum Zeitpunkt der Operation 64 Jahre $(63,7+/-9,6$ Jahre; von 35 - 83 Jahre). In dieser Studie waren von insgesamt 186 Patienten 130 (69,9\%) männlich und $56(30,1 \%)$ weiblich. Die Operationsverfahren wurden standardisiert und leitliniengerecht anhand onkologischer Operationsmethoden inklusive einer TME durchgeführt. Das therapeutische Vorgehen richtete sich dabei nach Protokollen randomisierter prospektiver Phase-II- und III-Studien (CAO/ARO/AIO-94; Sauer et al. 2004, CAO/ARO/AIO-04; Rödel et al. 2012). Insgesamt gab es in diesem Patientenkollektiv drei verschiedene Behandlungsgruppen. Eine Gruppe ( $n=27,14,5 \%$ ) wurde im Rahmen der CAO/ARO/AIO-94-Studie primär operiert und erhielt im Anschluss eine adjuvante RCT. Diese Gruppe stellt die Kontrollgruppe dar. Die beiden anderen Gruppen erhielten eine neoadjuvante Therapie $(n=159,85,5 \%)$. Die eine Gruppe $(n=56,30,1 \%)$ wurde im Rahmen der CAO/ARO/AIO-04-Studie mit einer innovativen, intensivierten neoadjuvanten Radiochemotherapie behandelt, die sich aus der Radiatio (Gesamtdosis: 50,4 Gy) und den Radiosensitizern 5-Fluorouracil (5-FU) und Oxaliplatin zusammensetzt. Die andere Behandlungsgruppe ( $n=103,55,4 \%$ mit neoadjuvanter Vorbehandlung bekam eine als Radiosensitizer-dienende systemische 5-FUMonotherapie mit zusätzlicher Radiotherapie ( $n=103,55,4 \%)$. 
Prätherapeutisch wiesen 176 der 186 Patienten ein Rektumkarzinom im cUICC-Stadium II/III und damit eine lokal fortgeschrittene Tumorerkrankung auf $(94,6 \%)$. Sieben $(3,8 \%)$ Patienten befanden sich in einem bereits metastasierten Zustand (cUICC IV).

Bei 94 Patienten (50,5\%) wurde der Tumor im mittleren Drittel lokalisiert $(6-<12 \mathrm{~cm})$, bei 14 Patienten $(7,5 \%)$ wiederum befand sich das Karzinom im oberen Rektumdrittel $(12-16 \mathrm{~cm})$. Bei 78 Patienten $(42,0 \%)$ wurde eine Tumorlokalisation im unteren Drittel $(0-<6 \mathrm{~cm})$ ermittelt.

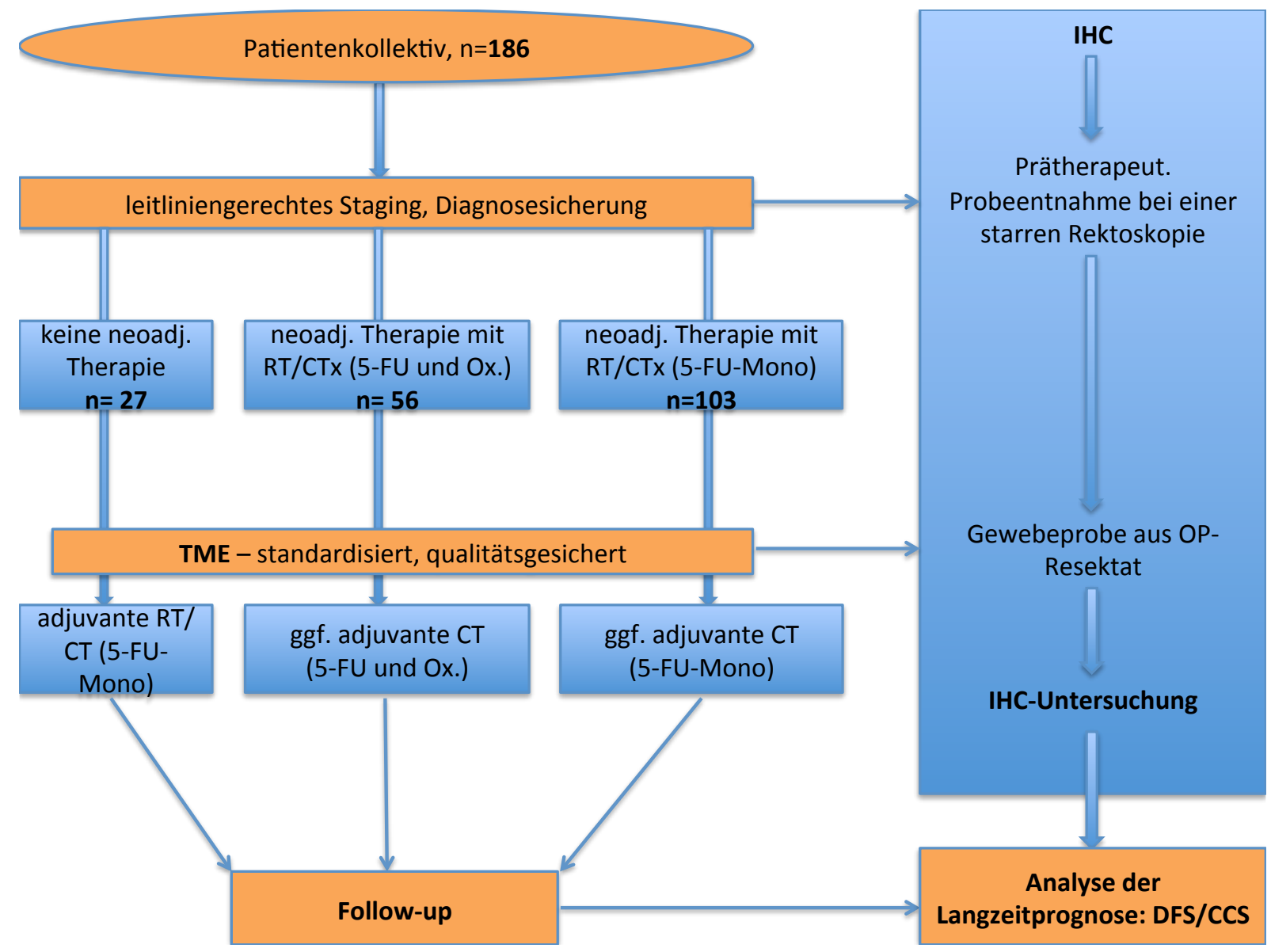

Abbildung 4: Studiendesign und Ablauf der Therapie; das Staging besteht aus einer ausführlichen Anamnese, der rektalen Endosonographie, einer starren Rektoskopie, einem Röntgen-Thorax und ggf. einer MRT/CT-Untersuchung. Dabei wurden alle Patienten im Rahmen einer multimodalen Therapie in der Universitätsmedizin Göttingen therapiert. Das Patientenkollektiv $(n=186)$ besteht dabei aus drei verschiedenen Behandlungsgruppen.

5-FU - 5-Fluorouracil, Ox. - Oxaliplatin, CTx - Chemotherapie, RT - Radiotherapie, TME - Totale Mesorektale Exzision, DFS - Disease Free Survival, CCS - Cancer Specific Survival, 


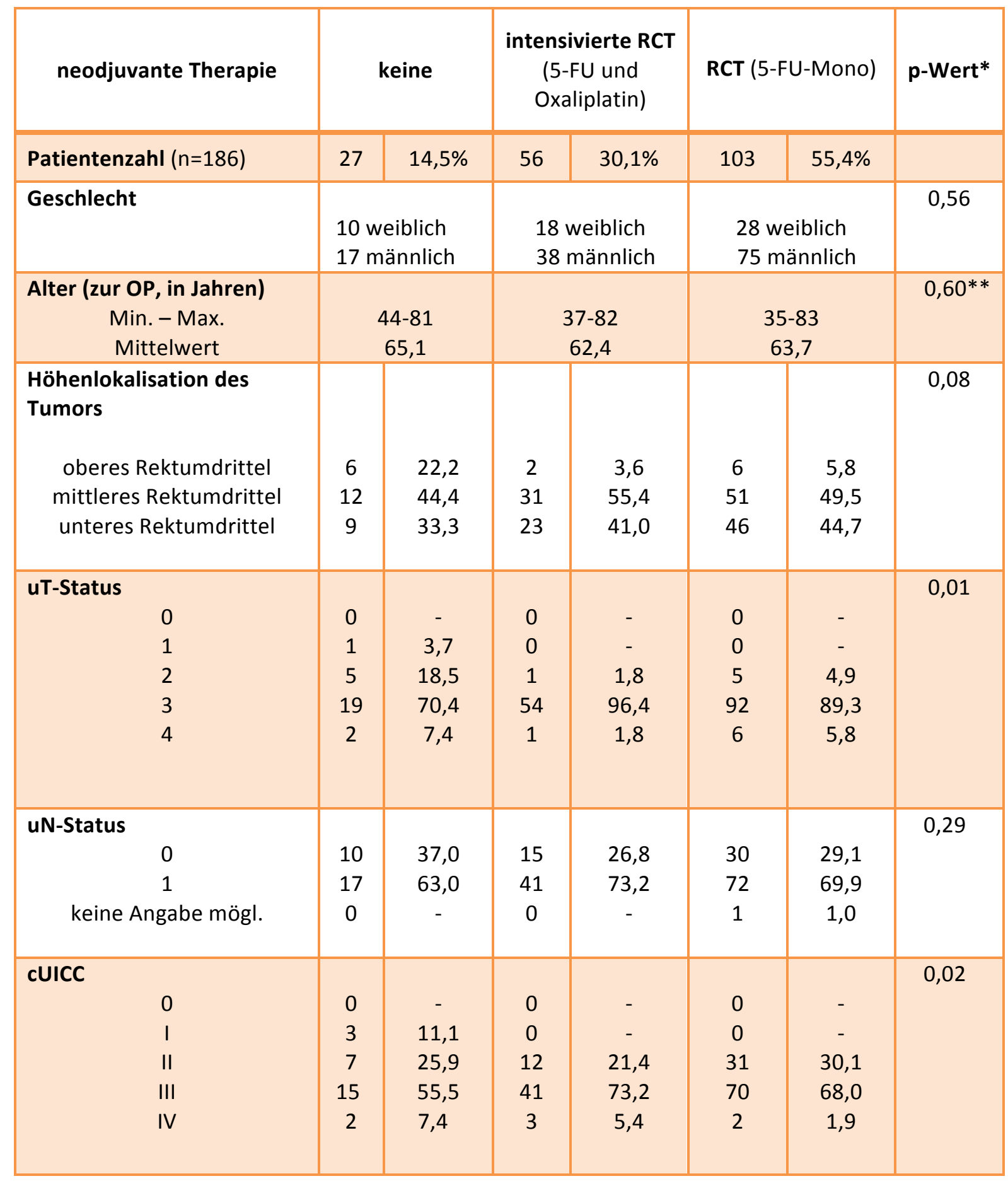

Tabelle 1: Übersicht über die klinischen Daten des Patientenkollektivs; darin wurden insgesamt 186 Patienten eingeschlossen. Diese verteilen sich auf drei Behandlungsgruppen, die sich hinsichtlich ihrer neoadjuvanten Vorbehandlung unterscheiden. Die Tabelle stützt sich auf diejenigen Daten, die zum Zeitpunkt der Untersuchungen vorlagen.

*p-Wert-Berechnung mit Chi-Quadrat-Test

** p-Wert-Berechnung mit Kruskal-Wallis-Test 


\subsection{Perioperative Qualitätsüberprüfung des Tumorresektats}

Gemäß der gültigen S3-Leitlinie wird das Adenokarzinom des Rektums im lokal fortgeschrittenen Stadium im Rahmen einer multimodalen Therapie behandelt. Dabei stellt der chirurgische Anteil eine bedeutende Komponente im interdisziplinären Therapiekonzept dar (Liersch et al. 2009).

Damit dieser entscheidende Therapieschritt nach onkologischen Operationsprinzipien nachhaltig auf höchstem Niveau beibehalten werden kann, bedarf es einer Qualitätsüberprüfung des entnommenen Rektumresektats.

Bei Karzinomen im unteren Rektumdrittel $(0-<6 \mathrm{~cm}$ ab Anokutanlinie) und im mittleren Rektumdrittel (6-<12 cm ab Linea anocutanea) stellt die totale mesorektale Exstirpation (TME) das etablierte Operationsverfahren dar. Bei Tumoren, die sich im oberen Rektumdrittel (>12 cm ab Anokutanlinie) befinden, ist bis zum gegenwärtigen Zeitpunkt noch nicht klar, ob eine partielle mesorektale Exstirpation (PME) der TME onkologisch gleichwertig und in Bezug auf Organfunktionalität überlegen ist. Diese Frage wird derzeit anhand der prospektiv randomisierten, multizentrischen Phase-II-Studie (GAST 05-Studie; Studiennummer: ISRCTN35198481) überprüft.

Unmittelbar nach der Resektatentnahme erfolgt die erste standardisierte Qualitätskontrolle zur Sicherung der Qualität der mesorektalen Exzision (Liersch et al. 2005, Sterk et al. 2000). Hierbei wird die Intaktheit der mesorektalen Hüllfaszie mithilfe einer verdünnten Methylenblaulösung untersucht. Dazu wird im Resektat die Arteria mesenterica inferior aufgesucht, freipräpariert und knopfkanüliert. Nach der Fixierung der Kanüle werden 20 ml einer Methylenblaulösung injiziert, dabei kommt es zu einer Anfärbung des Präparats. Läsionen an der Hüllfaszie des Mesorektums werden durch den Farbstoffaustritt sichtbar gemacht. Anhand des Austritts des Farbstoffes kann unmittelbar am nativen Präparat eine Aussage über die Qualität der TME zusätzlich zum späteren histopathologischen Befund getroffen werden (Sterk et al. 2000, Hermanek et al. 2003, Liersch et al. 2005).

Anschließend erfolgt die Dokumentation der Durchführung und des Resultats der Qualitätssicherung. Das Präparat wird daraufhin unmittelbar dem Institut für Pathologie der Universitätsmedizin Göttingen übergeben. Hier erfolgt die histopathologische Beurteilung des karzinominfiltrierten Gewebes. 


\subsection{Postoperative histopathologische Beurteilung des Resektats}

Zunächst werden makroskopisch die Hüllfaszien auf Vollständigkeit und Intaktheit überprüft. Außerdem erfolgt eine Begutachtung der kompletten mesorektalen Oberfläche als nächster Qualitätssicherungsschritt. Dabei werden etwaige Läsionen und Penetrationen sorgfältig festgehalten. Die Qualität der TME richtet sich nach den sogenannten MERCURY-Kriterien (M.E.R.C.U.R.Y. 2002). Dabei werden insgesamt drei verschiedene Qualitätsgrade differenziert: Grad 1 entspricht der kompletten Resektion des Mesorektums mit einer intakten mesorektalen Hüllfaszie und nur geringgradigen Defekten. Resektate mit Qualitätsgrad 2 beschreiben Unebenheiten an der Oberfläche, allerdings ist die Muscularis propria des Rektums nicht einsehbar. Qualitätsgrad 3 entspricht Resektaten mit größeren Läsionen und einer einsehbaren Muscularis propria. Dieser Grad ist zumeist mit einem flächenhaften Methylenfarbstoffaustritt assoziiert.

Im Rahmen einer standardisierten Aufarbeitung wird zunächst das abgesetzte Rektumgewebe sowie der longitudinale und transversale Durchmesser des Tumors ohne Zug auf das Präparat ausgemessen und der Abstand zu den Resektionsrändern nach oral, aboral und zirkumferentiell bestimmt.

Anschließend erfolgt die Dokumentation der Lokalisation des Tumors bezüglich der peritonealen Umschlagsfalte. Danach wird das native Präparat ober- und unterhalb des tumorinfiltrierten Gewebes eröffnet. Zur Stabilisierung der Tumorregion wird eine endoluminale Tamponade eingeführt. Das Resektat wird in diesem Zustand aufgespannt und in vierprozentiger, gepufferter Formalinlösung über mindestens 24 Stunden fixiert. Nach durchgeführter Fixierung kommt es zur Anfärbung der mesorektalen Oberfläche und zur Anfertigung lamellierender Querschnitte, um relevante Tumoranteile und umgebendes Mesorektum in Paraffin einzubetten. Die Paraffineinbettung erfolgt dabei nach standardisierten und automatisierten Methoden.

Die Gewebsschnitte werden aus dem in Paraffin eingebetteten Tumormaterial hergestellt. Diese lassen eine histopathologische Begutachtung zu, die anhand der aktuell gültigen TNM/UICCRichtlinien (RKI und GEKID 2010) durchgeführt wird. Die Stadienzuordnung der Tumorerkrankung basiert auf der umfassenden und exakten Untersuchung des Tumorgewebes, wodurch sich leicht ableiten lässt, wie wichtig eine ausführliche Begutachtung letztlich auch für die Therapieentscheidung ist.

Dabei werden folgende Parameter begutachtet:

- Tumorlokalisation, Lokalisation zur peritonealen Umschlagsfalte (ober- oder unterhalb gelegen)

- Histologischer Tumortyp nach Klassifikation der World Health Organization (WHO)

- $\quad$ PT-Status - Tumorinfiltrationstiefe (T1-4) 
- pN-Status - regionärer Lymphknotenstatus mit Angabe der Anzahl aller untersuchten Lymphknoten (NO-2)

- $\quad$ pM-Status - Bestehen von Fernmetastasen (M0/1)

- $\quad$ Grading - Differenzierungsgrad des Tumorgewebes (0-4)

- R-Klassifikation - Beurteilung der Tumorresektionsränder nach mikroskopischem oder makroskopischem Nachweis maligner Zellen mit Angabe des Abstands zwischen Resektionsrand und Tumor (RO-2)

- $\quad$ CRM - circumferentieller Resektionsrand negativ, wenn Sicherheitsabstand $\geq 1 \mathrm{~mm}$; positiv, wenn circumferentieller Sicherheitsabstand < $1 \mathrm{~mm}$ (CRM negativ/positiv)

- $\quad$ Lymph-/Blutgefäßinvasion (L 0/1; V 0/1)

- Beurteilung des Tumorregressionsgrades (TRG) bei erfolgter neoadjuvanter Radio/Chemotherapie (TRG 0-4)

Dem Tumorregressionsgrad kommt dabei ein großer prognostischer Stellenwert zu. Er wird histopathologisch ermittelt und beschreibt das Ansprechen des Tumors auf die präoperative Radiochemotherapie. Dabei erfolgt das Tumorregressionsgrading in fünf verschiedene Stufen (siehe Tabelle 2) (Dworak et al. 1997, Gavioli et al. 2000, Wittekind und Tannapfel 2003). Kriterien sind nach erfolgter RCT unter anderem das residuelle Tumorvolumen im Gewebe, Nekrosen, Fibrosen und Granulationsgewebe (Dworak et al. 1997, Bruns et al. 2010).

\begin{tabular}{|c|c|}
\hline \multicolumn{2}{|r|}{ Tumorregressionsgrad nach Dworak } \\
\hline TRG 0 & keine Fibrose; keine Tumorregression \\
\hline TRG 1 & $\begin{array}{l}\text { Minimale Regression; Tumor dominiert, bei }<25 \% \text { der Tumormasse eindeutige Zeichen radiogener } \\
\text { fibrotischer Veränderungen/Vaskulopathie }\end{array}$ \\
\hline TRG 2 & $\begin{array}{l}\text { Leicht zu identifizierende Tumorzellnester, Überwiegen der Fibrose; Regression bei } 25-50 \% \text { der } \\
\text { Tumormasse }\end{array}$ \\
\hline TRG 3 & $\begin{array}{l}\text { Gute Regression bei }>50 \% \text { Tumormasse; sehr wenige, vereinzelte Tumorzellen sind mikroskopisch } \\
\text { schwer nachzuweisen bei nahezu vollständig radiogen fibrotischem Gewebe }(>80 \%) \text { mit oder ohne } \\
\text { Schleimbildung }\end{array}$ \\
\hline TRG 4 & Kein Nachweis vitaler Tumorzellen, vollständige Fibrose; komplette Regression \\
\hline
\end{tabular}

Tabelle 2: Klassifikation des Tumorregressionsgrades (TRG) nach neoadjuvanter Radio-/Chemotherapie. Der TRG hilft bei der Einschätzung eines Therapieansprechens auf die neoadjuvante RCT und wird dazu in Korrelation mit den klinischen Daten genutzt (nach Dworak et al. 1997 und Gavioli et al. 2000). Der TRG wird histopathologisch im residuellen Rektumresektat bestimmt. 


\subsection{Material und Gewebeproben}

Für die immunhistochemische Auswertung wurden mehrere Gewebeproben jeweils eines Patienten entnommen, wobei die Gewinnung von Tumorgewebe zu zwei verschiedenen Zeitpunkten erfolgte (siehe Abbildung 4, S.20). Die erste Probeentnahme wurde prätherapeutisch mittels starrer Rektoskopie zur histologischen Sicherung der Diagnose durchgeführt. Bei der zweiten Gewebeprobe handelte es sich um das Tumorgewebe, welches im Rahmen der Operation reseziert wurde.

In Zusammenarbeit mit dem Institut für Pathologie der Universitätsmedizin Göttingen wurde für die immunhistochemische Untersuchung das entsprechende Tumormaterial formalinfixiert und in Paraffin eingebettet.

Für die Auswertung lagen von 129 Patienten (69,3\%) sowohl die Biopsie als auch das Resektat vor. Bei 34 Patienten (18,3\%) stand lediglich das Tumormaterial des Resektats zur Verfügung, da die Gewinnung der Biopsie zum Teil außerhalb der Universitätsmedizin Göttingen erfolgte bzw. das vorhandene Material nicht ausreichend Tumorzellen enthielt. Bei 23 Patienten $(12,4 \%)$ konnte nur das Tumorsample der Biopsie immunhistochemisch aufgearbeitet werden. Tumormaterial, das beispielsweise aufgrund einer effektiven Tumorregression zu wenige maligne Zellen enthielt, wurde nicht in die statistische Analyse einbezogen.

\subsection{Immunhistochemie und Herstellung von Gewebeschnitten}

\subsubsection{Immunhistochemische Anfärbung von Geweben}

Die immunhistochemische Gewebeanfärbung basiert auf einer spezifischen Antigen-AntikörperReaktion. Dabei besitzt der Antikörper (AK) eine Affinität zu seinem Epitop, welches den Bereich des Antigens widerspiegelt, an dem die Bindung des AK erfolgt. Um an dem Ort der Immunreaktion ein sichtbares Signal zu erzeugen, bedarf es einer Koppelung des AK mit einem Detektionssystem (Lang 2006).

In der Immunhistochemie (IHC) wird zwischen der direkten und der indirekten Methode unterschieden. Die direkte Methode ist heutzutage aufgrund einer geringeren Sensitivität - vor allem bei einer niedrigen Nachweismenge an Antigenen - weitesgehend obsolet. In dieser Arbeit wird daher die Zwei-Schritt-Methode im Rahmen der indirekten Methode angewandt. Dabei bindet zunächst ein unkonjugierter Primärantikörper an das entsprechende SRC-Antigen (Lang 2006). In einem zweiten Schritt richtet sich der mit dem Detektionssystem gekoppelte unspezifische Sekundärantikörper an den Primärantikörper. Hierbei können mehrere Sekundärantikörper an einen Primärantikörper binden, was zu einer intensiveren Färbung und dadurch auch zu einer erhöhten Sensitivität führt. Bei dem Sekundärantikörper handelt es sich hierbei um das Multimer-lg_DAB. An 
dieses wird das Enzym Peroxidase konjugiert, das als Detektionssystem fungiert, indem es mit Hilfe des Substrates Wasserstoffperoxid das Chromogen Diaminobenzidin (DAB) oxidiert und in ein bräunliches Farbstoffprodukt umwandelt. Somit wird das Zielantigen farblich markiert. Um eine Farbintensivierung zu erreichen, wurde noch eine Kupferlösung (Copper) hinzugegeben, welche als metallischer Farbverstärker für das entsprechende Chromogen diente (Lang 2006).
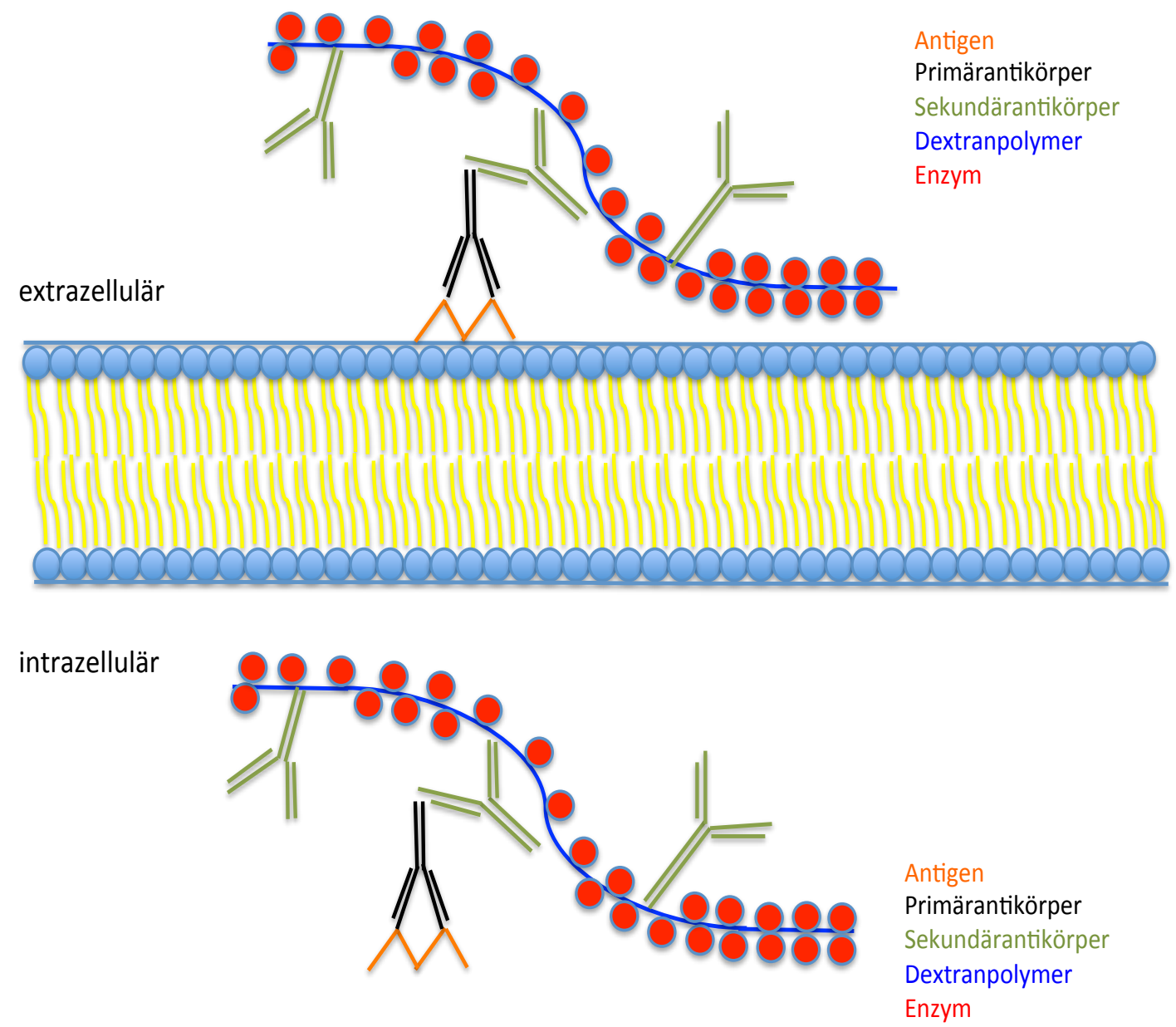

Abbildung 5: Schema der Immunhistochemie: Das SRC-Antigen befindet sich sowohl im Zytosol als auch in der Zellmembran. Der unkonjugierte Primärantikörper bindet zunächst an das Antigen. Im Anschluss richtet sich der mit einem Detektionssystem ausgestattete Sekundärantikörper an den Primärantikörper. Es erfolgt die Konjugation des Enyzms am Sekundärantikörper, wobei das Chromogen Diaminobenzidin oxidiert und in ein bräunliches Farbstoffprodukt umgewandelt wird. Es kommt zu einer farblichen Markierung des Zielantigens.

(Abbildung modifiziert nach Lang 2006, S. 279) 


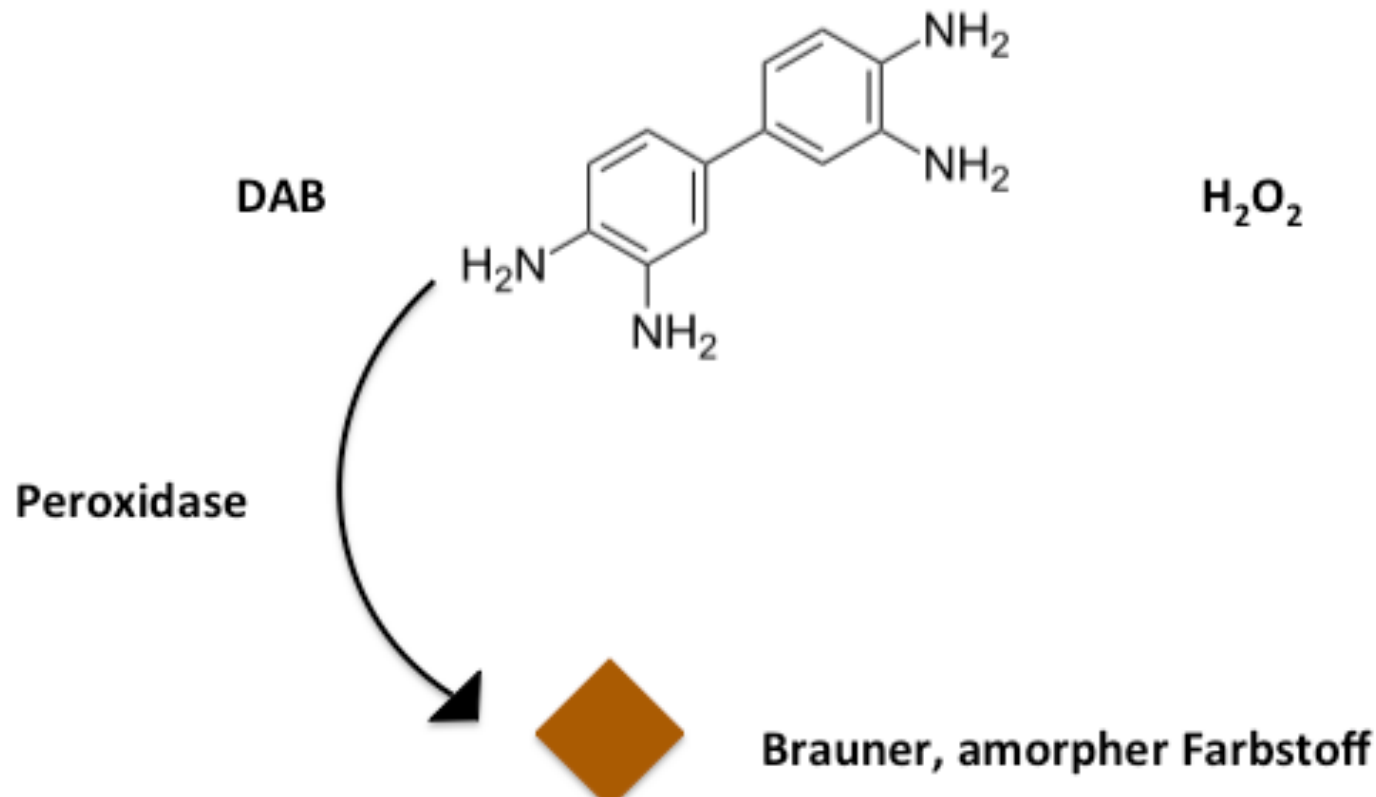

Abbildung 6: Anfärbung des Zielantigens: Das Chromogen Diaminobenzidin wird durch das Enzym Peroxidase mithilfe des Substrates Wasserstoffperoxid $\left(\mathrm{H}_{2} \mathrm{O}_{2}\right)$ oxidiert. Es erfolgt eine bräunliche Anfärbung des SRC-Antigens.

(Abbildung modifiziert nach Lang 2006, S. 266)

\subsubsection{Anfertigung von Schnitten}

Als Untersuchungsmaterial dienten die Tumor-tragenden Paraffinblöcke, deren histopathologische Anfertigung und Begutachtung in der Abteilung Pathologie der UMG erfolgte. Dort wurde das Tumormaterial über 24 Stunden mit vierprozentiger, gepufferter Formaldehydlösung fixiert und anschließend in Paraffinblöcke eingebettet. Das zu untersuchende Patientenmaterial bestand einerseits aus prätherapeutisch entnommenen Biopsien und andererseits aus residuellem Tumor, der intraoperativ im Rahmen einer Rektumresektion und entfernt wurde. Mithilfe eines Schlittenmikrotoms wurden aus den tumorenthaltenden Paraffinblöcken ca. $2 \mu \mathrm{m}$ dicke Schnitte hergestellt, die anschließend auf Adhäsiv-Objektträger in einem Wasserbad aufgetragen wurden. Es erfolgte eine Inkubation bei $37^{\circ} \mathrm{C}$ über einen Zeitraum von zwölf Stunden in einem Brutschrank.

\subsubsection{Automatisierte Färbung}

Die Färbung erfolgte anhand eines etablierten Verfahrens durch den Immunofärbeautomaten BenchMark XT der Firma Ventana (Sitz in Sunnyvale, CA, USA). Dieser standardisierte Färbeprozess hat den Vorteil, dass alle Präparate nach demselben Procedere gefärbt werden und somit ein Grad der Vergleichbarkeit erreicht wird, der unter manuellen Bedingungen kaum möglich ist. Daher liegen alle Präparate auf einem Qualitätsniveau, eine Streuung der Farbintensität wird somit weitestgehend vermieden. Damit der Primärantikörper an dem Zielantigen bindet, bedarf es einer sogenannten 
Demaskierung des Antigens. Das bedeutet, dass die fixierungsbedingten Proteinvernetzungen des Antigens in diesem Fall durch Hitze gelockert werden, die Gewebspermeabilität steigt. Alle Präparate werden dabei im Rahmen einer Vorbehandlung über einen Zeitraum von 60 Minuten auf $100^{\circ} \mathrm{C}$ erhitzt. Hierbei wird ein sogenannter Cell Conditioner (CC1) der Firma Ventana verwendet. Dieser stellt eine Antigen-Retrieval-Lösung mit EDTA-Puffer (Tris-Borat-EDTA; pH 9,6) dar. Der Antikörper SRC (Klon 36D10) Rabbit mAb (siehe Tabelle 5, S.32) der Firma Cell Signaling Technology ${ }^{\circledR}$ mit einem Molekulargewicht von 60 kDa ist ein monoklonaler Kaninchenantikörper, der in einer Verdünnung von 1:2000 aufgetragen und für 32 Minuten bei $37^{\circ} \mathrm{C}$ inkubiert wird. Nach der Bindung des Primärantikörpers an das Antigen wird nun der mit dem Detektionskit gekoppelte Sekundärantikörper hinzugegeben. Dieser Sekundärantikörper richtet sich hochspezifisch gegen den Primärantikörper. Wenn der Färbevorgang abgeschlossen ist, werden die Präparate durchgespült und mithilfe von Alkohol entwässert. Abschließend werden die Objektträger mit einem Deckglas behaftet.

\subsubsection{Auswertung der immunhistochemischen Färbungen}

Bei SRC handelt es sich um ein Protein, das überwiegend im Zytosol lokalisiert ist. Allerdings ist die Tyrosinkinase auch über eine Domäne mit der Zellmembran assoziiert. Daher ist sowohl die zytoplasmatische, als auch die Membranfärbung von Interesse. Eine Färbung von tumorfreiem Gewebe wurde nicht berücksichtigt. Die Beurteilung der Präparate wurde durch verschiedene Kriterien festgelegt: Bei der Auswertung der zytosolischen Färbung wurden die Färbeintensitäten Zytosol 0, Zytosol I, Zytosol II und Zytosol III (siehe Tabelle 3, S.29) unterschieden. Bei der Färbeintensität 0 ist keine Anfärbung des Zytosols zu erkennen, bei Intensität I hingegen eine leichte Anfärbung. Intensität II stellt eine starke Anfärbung dar, während Intensität III eine äußerst stark ausgeprägte Färbung charakterisiert. Bei der Membranfärbung wurden ebenfalls vier Intensitäten festgelegt (siehe Tabelle 4, S.29): Membranintensität 3 bedeutet, dass die einzelnen Zellmembranen bis zu einer 5-fachen Vergrößerung voneinander abzugrenzen waren, bei Intensität 2 war die Abgrenzung erst bis zu einer 20-fachen Vergrößerung möglich. Intensität 1 lieferte erst bei einer 40fachen Vergrößerung eine Differenzierung. Bei der Intensität 0 konnte selbst bei maximaler Vergrößerung keine Unterscheidung vorgenommen werden. War bestimmtes Tumorgewebe unterschiedlich stark angefärbt, wurde den einzelnen Intensitäten ein prozentualer Anteil zugesprochen. Die Zuordnung zu den verschiedenen Intensitäten geschah verblindet ohne jegliches Wissen über pathologische bzw. klinische Daten. Die Auswertung am Mikroskop wurde ein weiteres Mal vorgenommen und von den Kollegen der Pathologie gegenkontrolliert. Alle Präparate wurden 
unabhängig von zwei verschiedenen Untersuchern evaluiert. Bei der Intraobservervariabilität sowie bei der Interobservervariabilität wurde der Mittelwert berechnet.

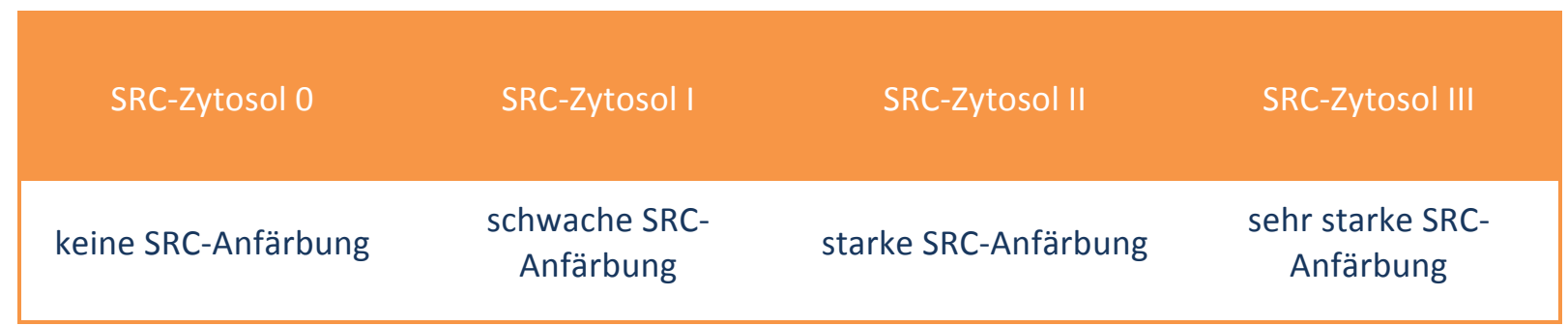

Tabelle 3: Einteilung der Zytosolanfärbung in vier unterschiedliche Färbeintensitäten: dabei stellt die Farbintensität 0 die schwächste und die Farbintensität 3 die stärkste Anfärbung dar (siehe Abbildung 7, S.30).

\begin{tabular}{|c|c|c|c|}
\hline SRC-Membran 0 & SRC-Membran 1 & SRC-Membran 2 & SRC-Membran 3 \\
\hline $\begin{array}{c}\text { Abgrenzung bis zu } \\
\text { 5facher Vergrößerung } \\
\text { möglich }\end{array}$ & $\begin{array}{c}\text { Abgrenzung bis zu } \\
\text { 20facher Vergrößerung } \\
\text { möglich }\end{array}$ & $\begin{array}{c}\text { Abgrenzung bis zu } \\
\text { 40facher Vergrößerung } \\
\text { möglich }\end{array}$ & $\begin{array}{l}\text { auch bei 40facher } \\
\text { Vergrößerung keine } \\
\text { Abgrenzung möglich }\end{array}$ \\
\hline
\end{tabular}

Tabelle 4: Einteilung der Membrananfärbung in vier unterschiedliche Intensitäten: die Intensität 0 ermöglicht dabei bereits bei bis zu 5 facher Vergrößerung eine Identifizierung der Zellmembranen. Bei der Intensität 3 war selbst bei der größtmöglichen 40fachen Vergrößerung keine Identifizierung der Zellmembranen möglich (siehe Abbildung 8, S.31).

\subsubsection{Probleme und Nachteile der quantitativen Immunhistochemie}

Die Immunhistochemie ist nicht nur eine etablierte Methode für die Forschung, sondern auch in zunehmendem Maße von Bedeutung für die Diagnostik und die Beurteilung therapeutischer Biomarker (Walker 2006). Allerdings existiert bisher wenig Standardisierung hinsichtlich Färbemethodik und Auswertung von Ergebnissen (Seidal et al. 2001). Dabei treten insbesondere Bedenken hinsichtlich der Validierung der entsprechenden Reagenzien, der generellen Reproduzierbarkeit der Färbemethodik sowie der Interpretation der Ergebnisse auf. Hierbei geht es nicht um die bloße Tatsache, ob ein positives Färbeergebnis vorliegt oder nicht, sondern auch um eine Quantifizierung des Färbeergebnisses, also welches Expressionslevel des Antigens tatsächlich erreicht wird (Taylor 2006). Für eine Standardisierung der Immunhistochemie bedarf es einer Optimierung und/oder Vereinheitlichung insbesondere der Gewebserfassung, Fixierung, Schnittdicke, des Färbeprozesses, der Bilddigitalisierung sowie der Bildanalyse. Dabei wird insbesondere auch die Entwicklung von einer deskriptiven zu einer quantitativen Analyse eingefordert, also von einem Übergang der Nutzung des okularen Mikroskops zu einer Nutzung Bildschirm-gestützter Systeme (Dunston et al. 2012). Die deskriptive Analyse wird vor allem wegen 
ihres hohen Aufwands und der ausgeprägten Subjektivität kritisiert. In Versuchsreihen mit immunhistochemischen Ovarialkarzinompräparaten konnte gezeigt werden, dass computergestützte Methoden zur Klassifizierung von tumorösen Bereichen und zur Quantifizierung immunhistochemischer Färbeintensitäten sehr ähnliche Daten verglichen mit einer visuellen Analyse eines Pathologen lieferten (Rizzardi et al. 2012, Posern 2013). Zur Veranschaulichung wurden digitale Fotografien ausgewählter, besonders aussagekräftiger Präparate angefertigt:

A
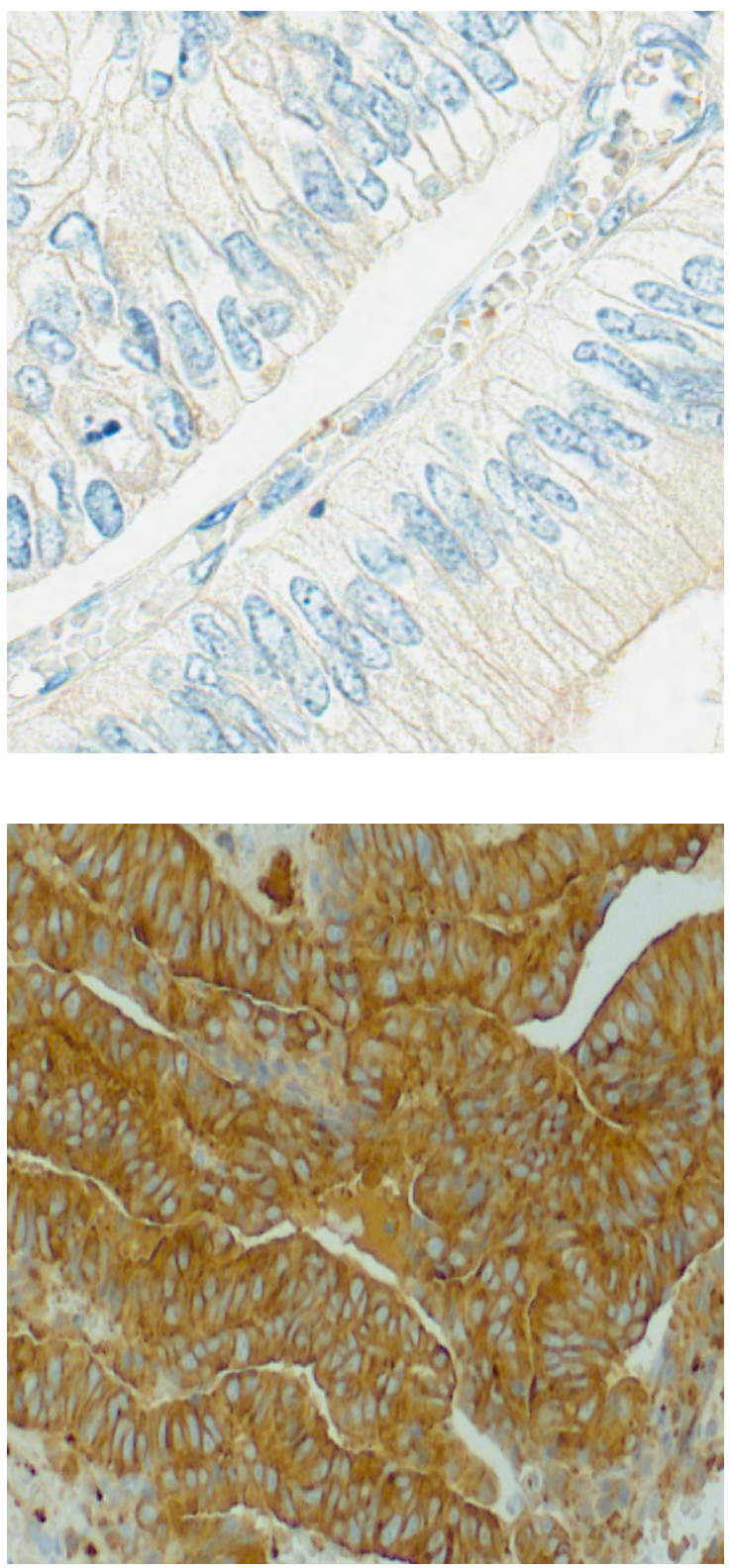

B
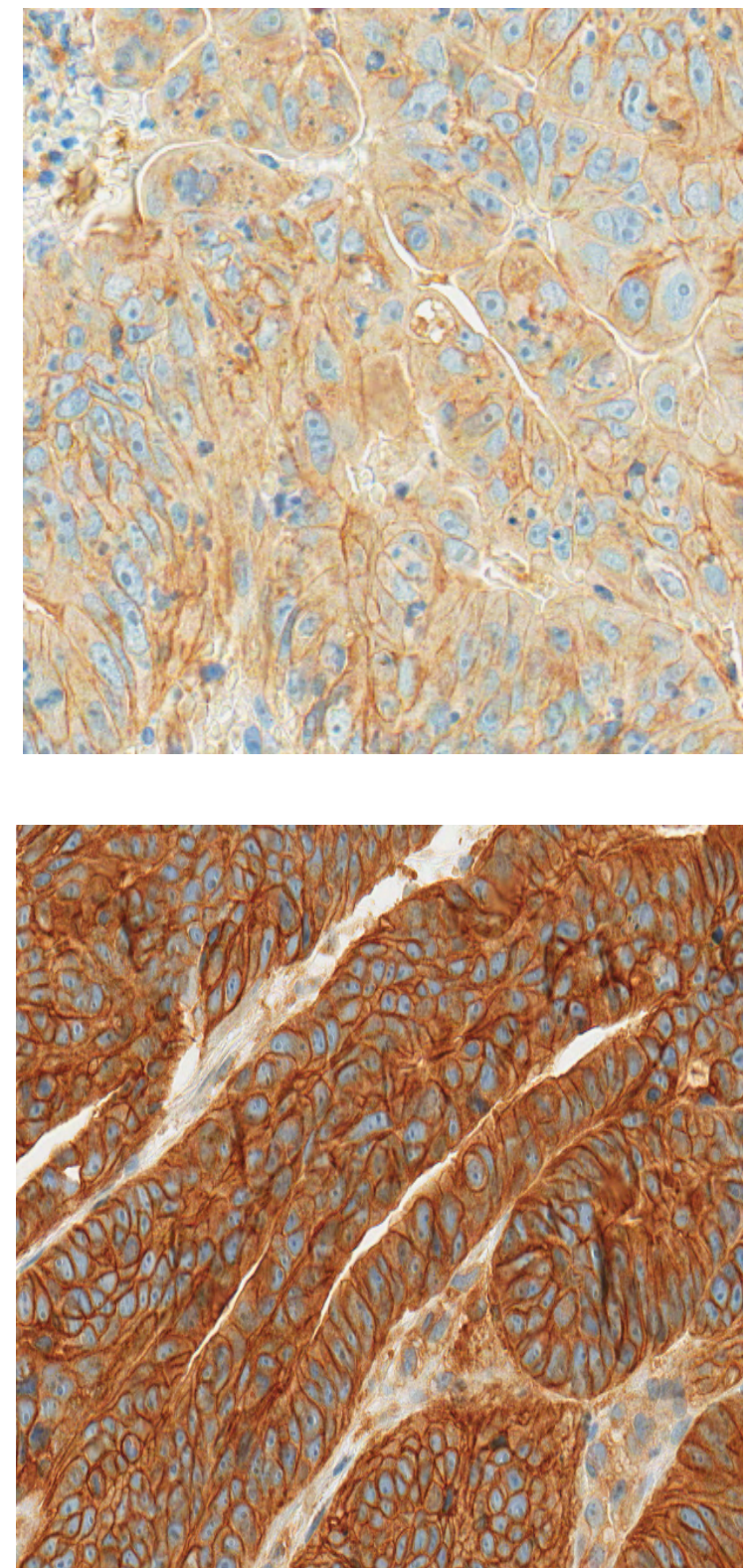

D

\section{C}

Abbildung 7: Digitale Immunhistochemieaufnahmen in der Zytosolfärbung: A SRC-Zytosol 0 in 40x Vergrößerung, B SRC-Zytosol I in 20x Vergrößerung, C SRC-Zytosol II in 10x Vergrößerung, D SRC-Zytosol III in 20x Vergrößerung 
A
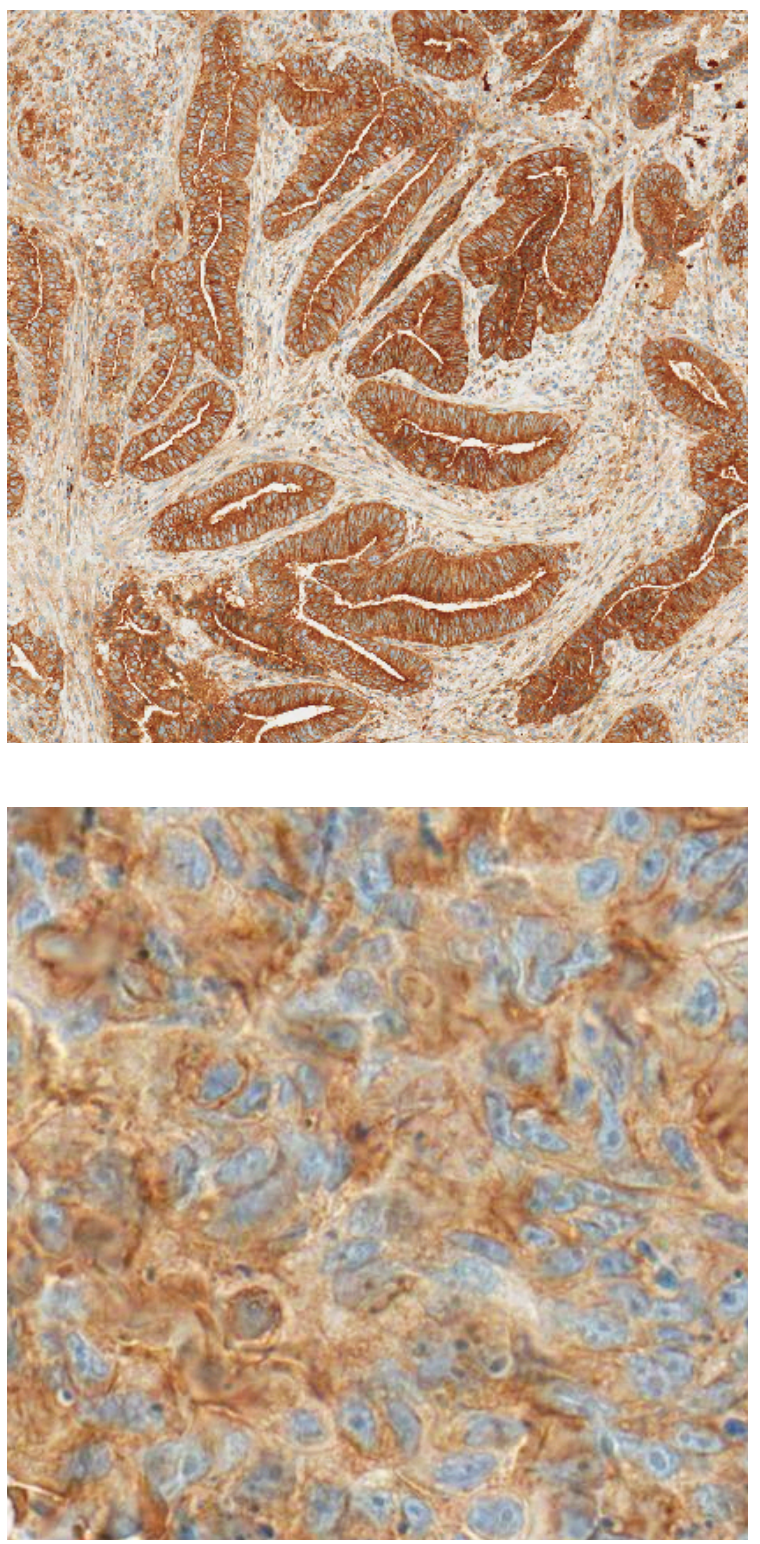

C
B
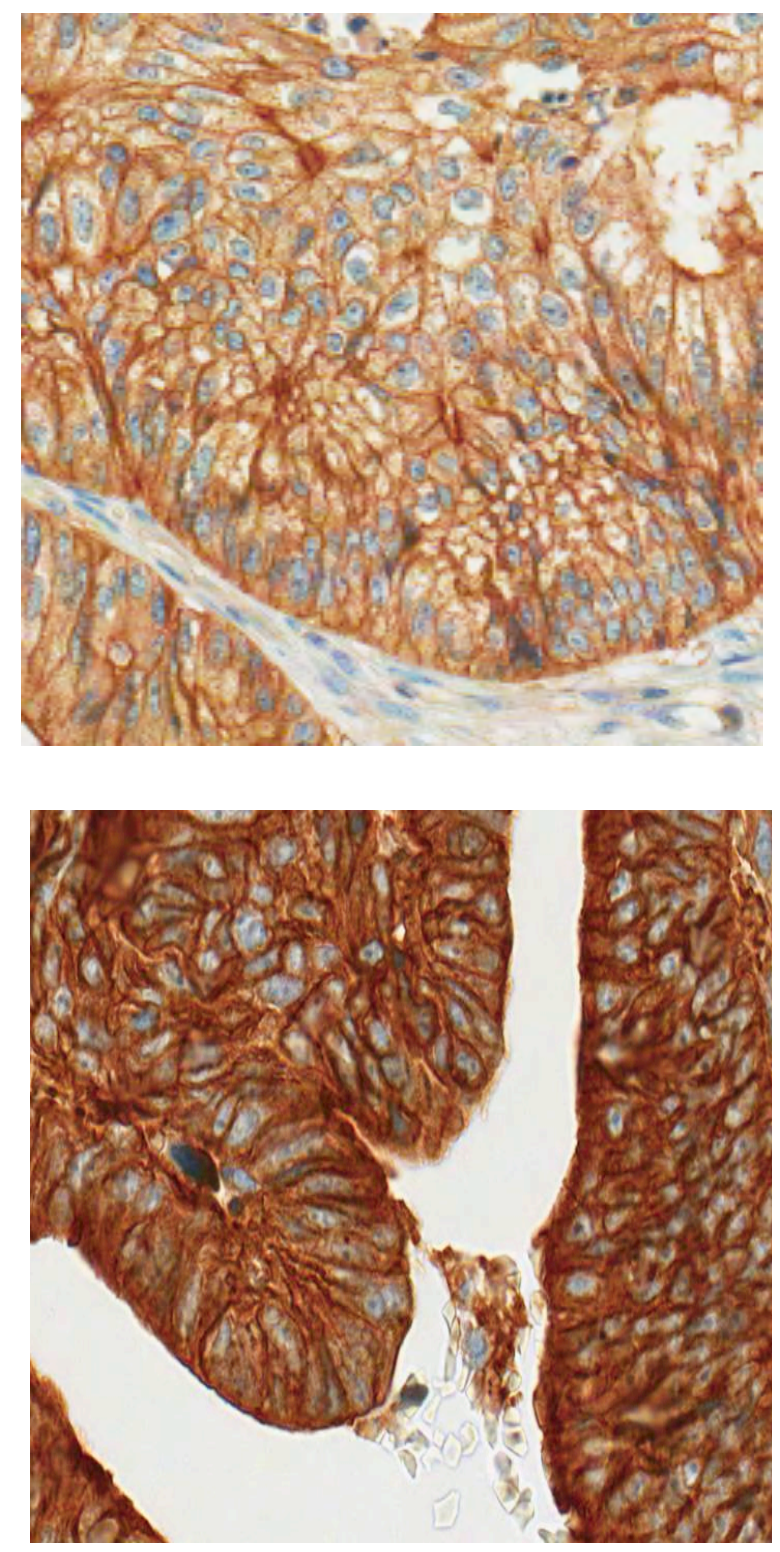

D

Abbildung 8: Digitale Immunhistochemieaufnahmen in der Membranfärbung: A SRC-Membran 0 in $5 x$ Vergrößerung, B SRC-Membran I in 20x Vergrößerung, C SRC-Membran II in 40x Vergrößerung, D SRC-Membran III in 40x Vergrößerung 


\subsection{Verwendete Materialien}

\begin{tabular}{|c|c|}
\hline Verwendete Marterialien & Firma, Hersteller, etc. \\
\hline Adhäsive Objektträger Starfrost & $\begin{array}{l}\text { Engelbrecht Medizin \& Labortechnik GmbH, } \\
\text { Edermünde, Deutschland }\end{array}$ \\
\hline Deckgläser & Gerhard Menzel GmbH, Braunschweig, Deutschland \\
\hline Ethanol 99\% & Chemie Vertrieb, Hannover, Deutschland \\
\hline Färbeautomat BenchMark XT & Ventana Medical Systems, Tucson, Arizona, USA \\
\hline Mikroskop Axio Imager II & Carl Zeiss Microlmaging GmbH, Deutschland \\
\hline Mikrotomklingen & pfm, Köln, Deutschland \\
\hline Monoclonal Rabbit Anti-Human SRC (Klon 36D10) & Cell Signal, Boston, Massachusetts, USA \\
\hline Schlittenmikrotom Microm HM 430 & MICROM International, Walldorf, Deutschland \\
\hline $\begin{array}{l}\text { Substanzen für den Färbeautomat BenchMark XT: } \\
\text { - EZ Prep } \\
\text { - LCS } \\
\text { - Reaction Buffer } \\
\text { - CC1 (Cell Conditioner) } \\
\text { - Antibody Diluent } \\
\text { - Hämatoxilin II } \\
\text { - Bluing Reagent }\end{array}$ & Ventana Medical Systems, Tucson, Arizona, USA \\
\hline $\begin{array}{l}\text { ultraView Universal DAB Detection Kit, enthält: } \\
\text { - Inhibitor } \\
\text { - Multimer Ig } \\
\text { - DAB } \\
\text { - } \mathrm{H}_{2} \mathrm{O}_{2} \\
\text { - Copper }\end{array}$ & Ventana Medical Systems, Mannheim, Deutschland \\
\hline Ventana VIAS Image Analysis System & Ventana Medical Systems, Tucson, Arizona, USA \\
\hline Vitro Clud - Eindeckmittel & $\begin{array}{l}\text { R. Langenbrinck- Labor-und Medizintechnik, } \\
\text { Emmendingen, Deutschland }\end{array}$ \\
\hline Wärmeschrank & Memmert GmbH, Schwabach, Deutschland \\
\hline Xylol & Mallinckrodt Baker B.V., Deventer, Niederlande \\
\hline
\end{tabular}

Tabelle 5: Auflistung der verwendeten Materialien und Substanzen mit Angabe des Herstellers 


\subsection{Funktion des Zielantigens}

Im Kapitel 1.9 Strukturelle Eigenschaften von SRC wurde bereits auf die einzelnen strukturellen Bestandteile des SRC-Moleküls eingegangen. Nachfolgend soll nun die Regulation der Tyrosinkinase diskutiert werden. Dabei ist zu beachten, dass es verschiedene Wege gibt, die SRC-Kinaseaktivität zu beeinflussen und dass jeder dieser Wege möglicherweise zu einer Aktivierung von SRC in Tumorzellen führt. Die Regulation erfolgt einerseits über die Phosphorylierung des Tyrosinrestes 530 (Tyr530), die Mutation bzw. die Deletion der C-terminalen regulatorischen Region, die durch intramolekulare Interaktionen bedingte Verlagerung der SH3- und SH2-Domäne sowie andererseits über eine Phosphorylierung des Tyrosinrestes 419 (Tyr419). Hierbei spielen insbesondere Interaktionen zwischen der SH2-Domäne und dem Tyr530 des C-terminalen Endes, aber auch zwischen der SH2-Kinase-Linkerund der SH3-Domäne eine wichtige Rolle, indem über diese molekularen Mechanismen die SRCAktivität moduliert werden kann (Gonfloni et al. 2000). Die Regulation der Phosphorylierung von Tyr530 wird dabei durch Kinasen und Phosphatasen bewerkstelligt. Bei den Kinasen sind insbesondere die c-Src-Kinase (Csk) sowie die Csk-homologe-Kinase (Chk) zu erwähnen. Beide Tyrosinkinasen sind in der Lage, Tyr530 zu phosphorylieren und dadurch SRC zu inaktivieren (Okada und Nakagawa 1989, Cooper et al. 1986, Zrihan-Licht et al. 1997). Eine verminderte Expression von Csk könnte bei der Aktivierung von SRC in Tumorgewebe eine Rolle spielen. Bei Patienten mit einem hepatozellulären Karzinom (HCC) zeigte sich eine geringere Csk-Expression als im gesunden Lebergewebe, wobei eine verminderte Expression mit einer verstärkten SRC-Aktivität einherging (Masaki et al. 1999). Vieles weist darauf hin, dass eine vermehrte Expression von Csk hingegen die Bildung von Metastasen beim Kolonkarzinom zu verringern scheint, sodass Csk möglicherweise eine Tumorsuppressorrolle einnehmen könnte (Nakagawa et al. 2000, Rengifo-Cam et al. 2004). Außerdem kann SRC durch die Bindung von Focal Adhesion Kinase (FAK) und CRK-Associated Substrate (CAS) an die SH2-Domäne des SRC-Moleküls aktiviert werden (Sakai et al. 1994). Bei Bindung dieser Substrate erfolgt eine Aktivierung von SRC durch eine Unterbrechung inhibitorischer intramolekularer Interaktionen. Dabei stellen FAK und CAS generell Regulatoren fokaler Adhäsionskomplexe und dynamischer aktinischer Zytoskelettvorgänge und somit wichtige Prozesse bezüglich Zelladhäsion und Zellmigration dar (Westhoff et al. 2004). Der aktivierte SRC-FAK-Komplex begünstigt weiterhin das Zellüberleben durch Aktivierung des PI3K/Akt-Pathways und dessen Interaktion, wobei der exakte SRC/PI3K-Mechanismus noch nicht vollständig geklärt ist (Siesser und Hanks 2006). Weitere bekannte SRC-Substrate stellen Paxillin und p130Cas dar, also aus der Gruppe der Cas-Substrate. p130Cas und Paxillin als Adapterproteine sind weitere wichtige Mediatoren für Zellmobilität und können an einen SRC-FAKProteinkomplex gebunden werden. Dieser Komplex ermöglicht dadurch eine vermehrte Zellinvasivität durch Aktivierung gewisser Matrixmetalloproteinasen (Hsia et al. 2003). Wie bereits erwähnt, kann die SRC-Aktivität auch durch verschiedene Rezeptortyrosinkinasen wie EGFR, HER2, PDGFR, Fibroblast 
Growth Factor Receptor und VEGFR reguliert werden (Parsons und Parsons 1997). Auf die SRCInteraktion mit EGFR wurde bereits eingegangen. Eine Überexpression von SRC kann demnach eine durch EGFR bedingte DNA-Synthese in Tumorzellen steigern (Belsches et al. 1997). In Brustkrebszelllinien konnte durch die SRC-EGFR-Interaktion ein weiterer Signalweg aktiviert werden, der durch eine vermehrte MAPK-Aktivität (Mitogen-Activated Protein Kinase) charakterisiert und mit einer verstärkten Mitogenese und Zelltransformation verbunden war (Biscardi et al. 2000). Weiterhin führte eine Koexpression von EGFR und SRC in Brustkrebszelllinien zu einer Hyperproliferation der Zellen sowie zu einem steigernden Beweglichkeits- und Invasionsverhalten (Dimri et al. 2007). So kann konstatiert werden, dass die SRC-Kinase-Aktivität durch verschiedene komplexe molekulare Signalkaskaden beeinflusst werden kann, die allesamt einen potenziellen Einfluss auf die SRCExpression in Tumorzellen haben können (Abbildung 9, S.34; Abbildung 10, S.35).

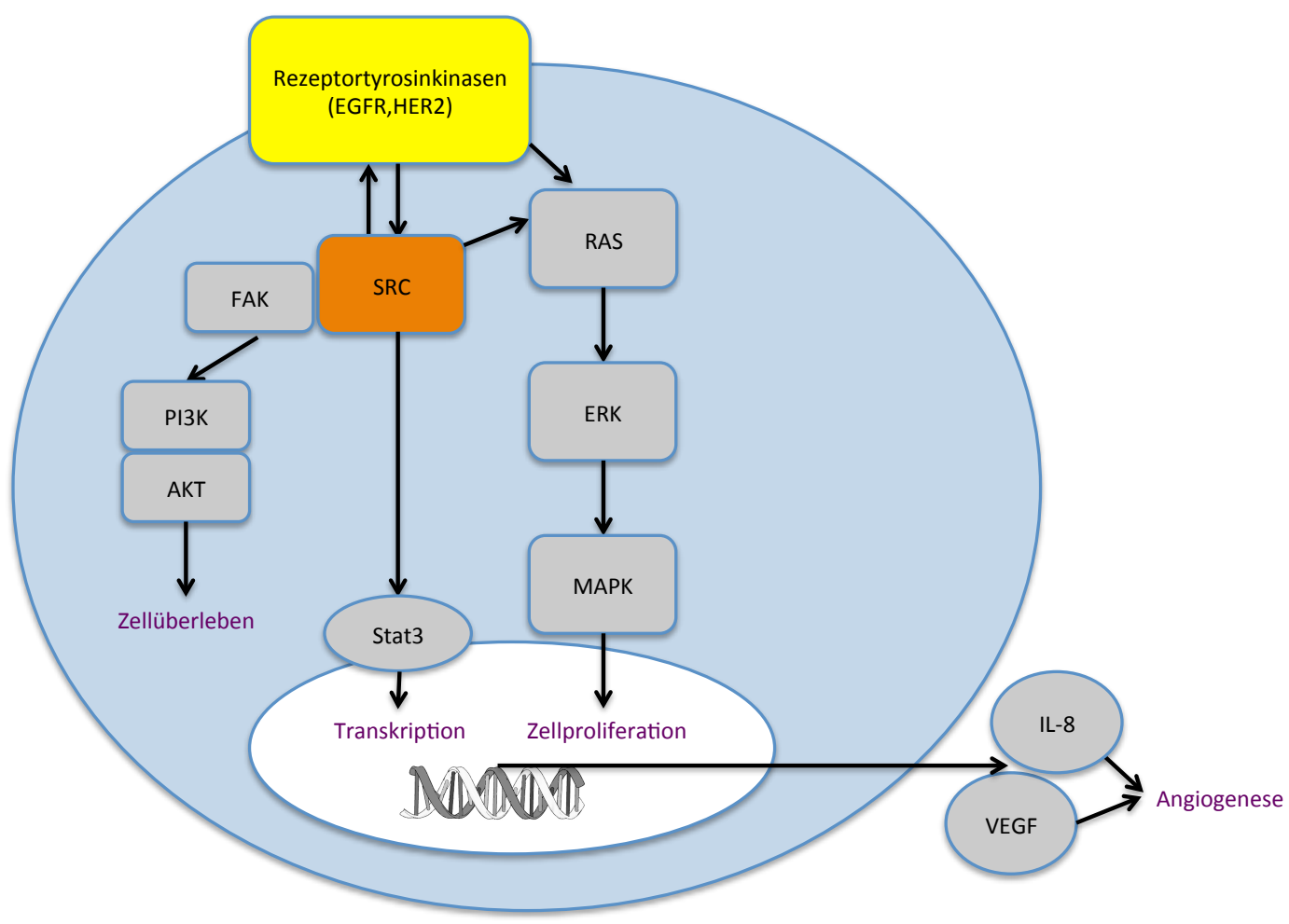

Abbildung 9: Molekulare Interaktionen von SRC; über Aktivierung der verschiedenen pathways werden tumorbegünstigende Prozesse gefördert. So bewirkt eine Coexpression von EGFR und SRC eine Aktivierung des RAS-/ERK-/MAPK-Signalweges, was zu einer vermehrten Zellproliferation führt. Durch die Bildung des SRC-FAK-Komplexes kommt es über eine Induktion des PI3K/AKT-pathways zu einem verlängerten Zellüberleben. SRC aktiviert zudem den STAT3-Signalweg, der über eine verstärkte Genexpression die Angioneogenese über VEGF und Interleukin-8 anregt.

(Abbildung modifiziert nach Kim et al. 2009, S.590) 


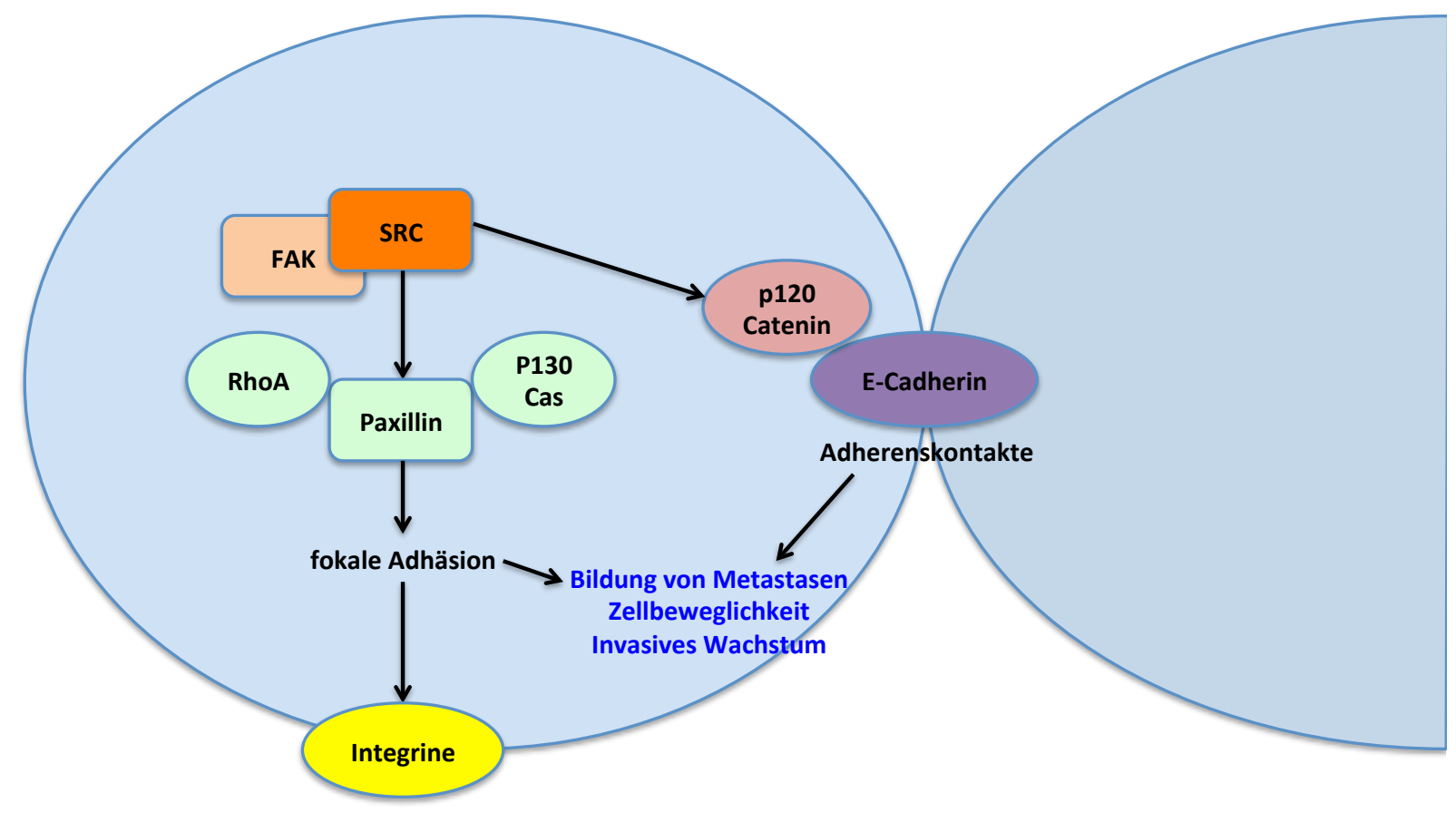

extrazelluläre Matrix

Abbildung 10: Übersicht über weitere Interaktionspartner: SRC spielt eine entscheidende Rolle bei der Regulierung der Zelladhäsion, Zellmigration, des invasiven Wachstums und der Bildung von Metastasen. Das aktivierte SRC ist in der Lage, p120 Catenin zu phosphorylieren und dadurch die Adhäsionskontakte zu unterbrechen, die durch E-Cadherin aufrechterhalten werden. Weiterhin führt SRC zu einem Downstream von FAK, das invasives Zellwachstum begünstigt. p130Cas, Paxillin und RhoA, die durch SRC-FAK-Komplexe herunterreguliert werden können, bilden Verbindungen mit Integrinen aus, die wiederum essenziell für Interaktionen mit der extrazellulären Matrix sind.

(Abbildung modifiziert nach Kim et al. 2009, S. 590)

\subsection{Immunhistochemische Analyse}

\subsubsection{Analyse der immunhistochemischen Färbung}

Aufgrund der Lokalisation von SRC im Zytosol sowie an der Zellmembran wurde bei der immunhistochemischen Auswertung ausschließlich die Zytosol- sowie die Membranfärbung an Malignomgewebe ausgewertet. War der Tumoranteil eines Präparates so gering, dass eine Auswertung nur bedingt oder gar nicht möglich war, so wurde dieses Präparat aus der Auswertung herausgenommen. Als Voraussetzung für eine Auswertung waren mehr als 50 Tumorzellen im Biopsiepräparat und mehr als 100 Tumorzellen im Resektatpräparat notwendig. Eine unterschiedlich starke Färbung wurde berücksichtigt und entsprechend auf die Parameter unter dem Punkt 2.5.4 Auswertung der immunhistochemischen Färbungen aufgeteilt. Die Bewertung der Präparate erfolgte 
ohne Kenntnisse der pathologischen oder klinischen Daten der Patienten und stets verblindet. Die Auswertung wurde unabhängig von zwei unterschiedlichen Untersuchern durchgeführt. Bei Inter- bzw. Intraobservervariationen wurde der Mittelwert gebildet.

\subsubsection{Konventionelle Auswertung der immunhistochemischen Färbung}

Die Analyse eines jeden Präparates erfolgte ohne Kenntnis der klinischen Daten oder der Identität des Patienten. Unter dem Mikroskop wurde das Präparat begutachtet und ausgewertet, wobei die Intensität der Färbung in die Auswertung einbezogen wurde. Zunächst wurde bei 2,5-facher Vergrößerung das Präparat in toto betrachtet, um sich einen Überblick über das Ausmaß des vorhandenen Tumoranteils zu verschaffen und die Qualität der Anfärbung des Präparates zu beurteilen. Danach erfolgte die Einstellung auf eine 10-fache Vergrößerung, um auch kleinere Tumorzellen identifizieren zu können. Bei 40-facher Vergrößerung konnte zudem eine Beurteilung erfolgen, inwieweit die SRC-Anfärbung einer Membranintensität 1 oder Membranintensität 0 entsprach. Eine Bewertung zugunsten der Intensität 1 erfolgte, wenn bei dieser Vergrößerung eine Identifizierung der Zellmembran möglich war. Eine eindeutige Identifizierung konnte bei der Membranintensität 0 nicht erfolgen. Im Anschluss wurden von allen Präparaten digitale Fotografien der entsprechenden Tumorbereiche angefertigt. Alle gewonnenen Daten wurden dabei sorgfältig dokumentiert.

\subsubsection{Statistische Analyse}

Die statistischen Analysen erfolgten in Kooperation mit Dr. phil. nat. Manuel Nietert, Abteilung für medizinische Statistik der Universitätsmedizin Göttingen (Leiter Univ.-Prof. Dr. Tim Friede). Zur Erstellung von Grafiken sowie zur statistischen Berechnung kam die Open-Source Software Knime (Konstanz Information Miner) zur Anwendung (URL http://www.knime.org Version 2.7.0) (Berthold et al. 2007). Dieses Programm basiert auf einem modularen Pipelining-Konzept, bei dem die kompletten Daten des Patientenkollektivs in das Programm geladen werden und durch die Verknüpfung mit sogennanten Nodes eine immer weiter zunehmende Differenzierung in bestimmte Subkollektive möglich ist.

Für die Erstellung von Grafiken sowie für statistische Berechnungen wurde das Statistikprogramm $R$ Project angewandt (URL http://www.r-project.org Version 2.14.2) (Ihaka und Gentleman 1996).

Zum Vergleich von Häufigkeitsunterschieden zwischen den klinikopathologischen Parametern innerhalb der drei Behandlungsgruppen erfolgte die Anwendung des Pearson-Chi-Quadrat-Tests. 
Zur Darstellung des Vergleichs der Überlebenskurven wurde der Logrank-Test eingesetzt. Dieser nicht parametrische Test wird bei zwei oder mehr unverbundenen Stichproben eingesetzt (Hilgers et al. 2007). Die Darstellung der Überlebenskurven erfolgte mittels Kaplan-Meier-Kurven in Abhängigkeit der SRC-Expression. Die Ermittlung einer statistischen Korrelation zwischen der SRC-Expression und dem DFS bzw. CSS erfolgte anhand des Cox-Regressions-Models.

Zur Darstellung einer Varianzanalyse zwischen den immunhistochemischen Daten und den klinikopathologischen Parametern der Patienten wurde der Kruskal-Wallis-Test verwendet. Dieser nichtparametrische Test kann bei unabhängigen Stichproben für den Vergleich von mehr als zwei Gruppen angewendet werden (Trampisch et al. 1997). Bei unabhängigen Stichproben für den Vergleich von zwei Gruppen wurde der parameterfreie Wilcoxon-Mann-Whitney-Test angewandt.

Zur medizinisch-statistischen Untersuchung der Quantifizierung der immunhistochemischen Färbungen wurde für die Auswertung der sogenannte $H$-Score eingesetzt, um die Färbungen sowohl qualitativ als auch quantitativ zu objektivieren. Der $H$-Score nimmt dabei einen beliebigen Wert zwischen 0 und 300 ein und wird aus der Multiplikation der Färbeinstensität X (0-3) und des prozentual gemessenen Anteils der Intensität berechnet (Ishibashi et al. 2003, Vilmar et al. 2012).

\section{Beispiel:}

\begin{tabular}{|l|c|c|c|c|}
\hline Färbeintensität & 0 & 1 & 2 & 3 \\
\hline Anteil in Prozent \% & 15 & 35 & 25 & 25 \\
\hline
\end{tabular}

Rechnung: $0 \times 15+1 \times 35+2 \times 25+3 \times 25=160$

In diesem Beispiel ergibt sich für das Präparat ein H-Score von 160.

Bei allen statistischen Analysen liegt ein 5\%-Signifikanzniveau vor. 


\section{3) Ergebnisse}

\subsection{Durchgeführte Resektionsverfahren im Patientenkollektiv}

Bei allen Patienten wurde eine Operation in kurativer Intention, also eine Ro-Resektion nach onkologischen Resektionskriterien, angestrebt. 159 der 186 Patienten $(85,5 \%)$ erhielten vor der Operation eine neoadjuvante Behandlung in Form einer intensivierten RCT (5-FU + Oxaliplatin) oder einer 5-FU-Monotherapie-basierten RCT. Von 186 Patienten wurden 27 (14,5\%) primär operiert und erst postoperativ einer adjuvanten RCT zugeführt.

Zwei Operationsmethoden stehen dabei insbesondere im Vordergrund: zum einen die abdominoperineale Rektumexstirpation (APE) und zum anderen die tiefe anteriore Rektumresektion (TARR), beide beinhalten eine TME. Die APE ist vor allem bei tief sitzenden, im unteren Rektumdrittel lokalisierten Tumoren indiziert, bei denen eine gleichzeitige Sphinktererhaltung sowie eine Einhaltung eines $2 \mathrm{~cm}$ großen Sicherheitsabstandes zum aboralen Tumorrand nicht möglich ist.

Die TARR stellt ansonsten die Operation der Wahl dar.

In dem untersuchten Patientenkollektiv musste bei 56 von 186 Patienten (30,1\%) eine APE durchgeführt werden, bei 126 von 186 Patienten $(67,7 \%)$ erfolgte dagegen eine TARR. Bei 4 von 186 Patienten $(2,2 \%)$ wurde aufgrund einer schlechten prätherapeutischen Sphinkterfunktion eine alternative, patientenbezogene Operationsmethode wie eine Diskontinuitätsoperation nach Hartmann mit totaler mesorektaler Exzision (TME) durchgeführt. Innerhalb der Behandlungsgruppen wurde bei 12 Patienten $(21,4 \%)$ mit einer intensivierten RCT und bei 38 Patienten $(36,9 \%)$ mit einer 5-FU-RCT eine APE durchgeführt. In der Kohorte der nicht vorbehandelten Gruppe kam es bei 6 Patienten $(22,2 \%)$ zu einer APE-Operation. 


\begin{tabular}{|c|c|c|c|c|c|c|c|}
\hline neoadjuvante Therapie & \multicolumn{2}{|c|}{ Keine } & \multicolumn{2}{|c|}{$\begin{array}{c}\text { intensivierte } \\
\text { RCTx (5-FU } \\
\text { und } \\
\text { Oxaliplatin) }\end{array}$} & \multicolumn{2}{|c|}{$\begin{array}{c}\text { RCT (5-FU- } \\
\text { Mono) }\end{array}$} & \multirow[t]{2}{*}{ p-Wert* } \\
\hline Patientenzahl (n=186) & 27 & $\%$ & 56 & $\%$ & 103 & $\%$ & \\
\hline Operationsverfahren & & & & & & & 0,27 \\
\hline TARR & 21 & 77,8 & 43 & 76,8 & 62 & 60,2 & \\
\hline APE & 6 & 22,2 & 12 & 21,4 & 38 & 36,9 & \\
\hline andere & 0 & - & 1 & 1,8 & 3 & 3,9 & \\
\hline Höhenlokalisation d. Tumors & & & & & & & 0,08 \\
\hline oberes Rektumdrittel & 6 & 22,2 & 2 & 3,6 & 6 & 5,8 & \\
\hline mittleres Rektumdrittel & 12 & 44,4 & 31 & 55,4 & 51 & 49,5 & \\
\hline unteres Rektumdrittel & 9 & 33,3 & 23 & 41,0 & 46 & 44,7 & \\
\hline
\end{tabular}

Tabelle 6: Übersicht über die durchgeführten Operationsverfahren und die Verteilung der Tumorlokalisation auf die drei Rektumdrittel: Die TARR bildet dabei die häufigste Operationsmethode. Bei rund der Hälfte der Patienten ( $n=94 ; 50,2 \%)$ lag der Tumor im mittleren Rektumdrittel. Bei 78 Patienten (41,9\%) war der Tumor im unteren Rektumdrittel lokalisiert.

\subsection{Histopathologisch determinierte Tumorstadien}

Bei 183 Patienten $(98,4 \%)$ konnte eine R0-Resektion durchgeführt werden. Innerhalb des gesamten Patientenkollektivs konnte somit lediglich bei drei Patienten $(1,6 \%)$ keine R0-Resektion erreicht werden, sondern eine R1-Resektion. Dies betraf zwei Patienten der Kohorte, die keine neoadjuvante Vorbehandlung erhielten sowie einen Patienten, der mit einer 5-FU-Monotherapie präoperativ therapiert wurde. Innerhalb der Behandlungsgruppen kam es bei 25 Patienten (92,6\%) ohne Vorbehandlung zu einer RO-Resektion. In der vorbehandelten Kohorte konnten alle 56 Patienten (100\%) der FOLFOX-Gruppe und 102 Patienten (99,0\%) der 5-FU-Mono-Gruppe R0-reseziert werden.

Zum Zeitpunkt der Operation wiesen zwei der insgesamt 27 nicht vorbehandelten Patienten einen (y)pT1-Status auf $(7,4 \%)$. Bei 9 Patienten lag dagegen ein (y)pT2-Tumor vor (33,3\%), während bei 13 Patienten ein (y)pT3-Tumor diagnostiziert wurde (48,1\%). Zwei Patienten wiesen perioperativ einen (y)pT4-Tumor auf, der multiviszeral reseziert werden musste (7,4\%; siehe Tabelle 7, 5.41).

Bei den beiden Gruppen mit neoadjuvanter Therapie wiesen 4 Patienten $(7,1 \%)$ mit FOLFOX-Schema sowie 8 Patienten (7,8\%) mit 5-FU-Mono-Behandlung einen TRG4 mit entsprechendem (y)pT0-Tumor auf. Bei 9 Patienten $(16,1 \%)$ mit FOLFOX-basierter RCT und 5 Patienten $(4,9 \%)$ mit einer 5-FU-MonoBehandlung wurde ein (y)pT1 diagnostiziert. Ein histopathologischer (y)pT2-Tumor konnte bei 12 
Patienten (21,4\%) mit intensivierter RCT und bei 25 Patienten (24,3\%) in der 5-FU-Mono-Kohorte nachgewiesen werden. Einem Großteil der entnommenen Resektate konnte bei beiden Behandlungsgruppen eine Infiltration des Tumors bis in die Muscularis propria (ypT3-Tumor) nachgewiesen werden $(57,2 \%, n=59 ; 50 \%, n=28)$. Bei insgesamt 9 Patienten (3 Patienten $(5,4 \%)$ mit FOLFOX-basierter RCT, 6 Patienten (5,8\%) mit 5-FU-basierter RCT) lag nach kombinierter RCT ein ypT4Tumor vor (siehe Tabelle 7, S.41).

Hinsichtlich des Nodalstatus waren in der primär operierten Kohorte 16 Patienten (59,3\%) nodalnegativ. Einen (y)pN1-Status wiesen 5 Patienten (18,5\%) auf. Ein (y)pN2-Status, der einem Befall von vier oder mehr regionären LK entspricht, konnte in der nicht-vorbehandelten Gruppe bei 6 Patienten (22,2\%) beobachtet werden (siehe Tabelle 7, S.41).

Bei 43 Patienten (76,8\%) der Behandlungsgruppe, die nach dem FOLFOX-Schema vorbehandelt wurde, waren keine LK-Metastasen nachgewiesen. Bei 11 Patienten (19,6\%) lag ein (y)pN1-Status vor. Einen (y)pN2-Status wiesen lediglich zwei Patienten (3,6\%) auf (siehe Tabelle 7, S.41). Ein pN0-Status bei der Gruppe, die mit einer 5-FU-basierten RCT behandelt wurde, konnte bei einem Kollektiv von 64 Patienten (62,1\%) histopathologisch nachgewiesen werden. Ein (y)pN1-Stadium lag bei 23 Patienten (22,3\%) vor. In der 5-FU-Mono-Kohorte wiesen 16 Patienten (15,5\%) einen ypN2-Status auf (siehe Tabelle 7, S.41).

Intraoperativ wurden bei zwei primär operierten Patienten $(7,4 \%)$ im präoperativen Staging okkulte Metastasen detektiert. Bei den neoadjuvant behandelten Gruppen bestehend aus FOLFOX-Schema und 5-FU-Monotherapie gab es ebenfalls 5 bzw. 7 Patienten (8,9\%; 6,8\%), denen ein pM1-Status erstmals diagnostiziert wurde (siehe Tabelle 7, S.41).

Nach histopathologischer Resektatbeurteilung wurden folgende (y)pUICC-Stadien diagnostiziert: Es wurden in der primär operierten Kohorte 9 Patienten (33,3\%) dem (y)pUICC-I-, 7 Patienten (26,0\%) dem (y)pUICC-II-, 9 Patienten (33,3\%) dem (y)pUICC-III- und 2 Patienten (7,4\%) dem (y)pUICC-IVStadium zugeordnet (siehe Tabelle 7, S.41). Bei der Behandlungsgruppe mit einer intensivierten RCT mit zusätzlicher Gabe von Oxaliplatin wiesen 4 Patienten (7,1\%) ein (y)pUICC-0-, 20 Patienten (35,7\%) ein (y)pUICC-I-, 16 Patienten (28,6\%) ein (y)pUICC-II-, 11 Patienten (19,7\%) ein (y)pUICC-III- und 5 Patienten (8,9\%) ein (y)pUICC-IV-Stadium auf. Bei der Kohorte, die mit einer 5-FU-Mono-RCT behandelt wurde, wurde bei 7 Patienten (6,8\%) ein (y)pUICC-0-, bei 21 Patienten (20,4\%) ein (y)pUICCI-, bei 33 Patienten (32,0\%) ein (y)pUICC-II-, bei 35 Patienten (34,0\%) ein (y)pUICC-III- und bei 7 Patienten (6,8\%) ein (y)pUICC-IV-Stadium diagnostiziert (siehe Tabelle 7, S.41).

Eine durch die neoadjuvante RCT induzierte komplette Regression (TRG4) konnte bei insgesamt 12 Patienten (7,5\%) der präoperativ behandelten Gruppen festgestellt werden. Dabei gehörten 4 Patienten (7,1\%) der Gruppe mit intensivierter Vorbehandlung und 8 Patienten (7,8\%) der Gruppe mit einer 5-FU-Monotherapie-basierten RCT an. Ein TRG0 als Ausdruck eines kompletten Nicht- 
Ansprechens auf die neoadjuvante RCT wurde in keiner der Therapiegruppen beobachtet (siehe Tabelle 7, S.41).

\begin{tabular}{|c|c|c|c|c|c|c|c|}
\hline \multirow{2}{*}{$\begin{array}{l}\text { neoadjuvante Therapie } \\
\text { Patientenzahl }(n=186)\end{array}$} & \multicolumn{2}{|c|}{ keine } & \multicolumn{2}{|c|}{$\begin{array}{c}\text { intensivierte } \\
\text { RCT (5-FU } \\
\text { und } \\
\text { Oxaliplatin) }\end{array}$} & \multicolumn{2}{|c|}{$\begin{array}{c}\text { RCT } \\
\text { (5-FU-Mono) }\end{array}$} & \multirow[t]{2}{*}{ p-Wert* } \\
\hline & 27 & $\%$ & 56 & $\%$ & 103 & $\%$ & \\
\hline \multicolumn{7}{|l|}{ R-Status } & \multirow[t]{4}{*}{0,03} \\
\hline Ro & 25 & 92,6 & 56 & 100 & 102 & 99,0 & \\
\hline R1 & 2 & 7,4 & 0 & - & 1 & 1,0 & \\
\hline R2 & 0 & - & 0 & - & 0 & - & \\
\hline \multicolumn{8}{|l|}{ (y)pTNM-Status } \\
\hline (y)pT-Status & & & & & & & \multirow[t]{6}{*}{0,47} \\
\hline 0 & 1 & 3,7 & 4 & 7,1 & 8 & 7,8 & \\
\hline 1 & 2 & 7,4 & 9 & 16,1 & 5 & 4,8 & \\
\hline 2 & 9 & 33,3 & 12 & 21,4 & 25 & 24,3 & \\
\hline 3 & 13 & 48,1 & 28 & 50,0 & 59 & 57,3 & \\
\hline 4 & 2 & 7,4 & 3 & 5,4 & 6 & 5,8 & \\
\hline \multicolumn{7}{|l|}{ (y)pN-Status } & \multirow[t]{4}{*}{0,1} \\
\hline 0 & 16 & 59,3 & 43 & 76,8 & 64 & 62,1 & \\
\hline 1 & 5 & 18,5 & 11 & 19,6 & 23 & 22,3 & \\
\hline 2 & 6 & 22,2 & 2 & 3,6 & 16 & 15,6 & \\
\hline \multicolumn{7}{|l|}{ (y)pM-Status } & \multirow[t]{3}{*}{0,8} \\
\hline 0 & 25 & 92,6 & 51 & 91,1 & 96 & 93,2 & \\
\hline 1 & 2 & 7,4 & 5 & 8,9 & 7 & 6,8 & \\
\hline \multicolumn{7}{|l|}{ (y)pUICC-Stadium } & \multirow[t]{2}{*}{0,48} \\
\hline 0 & 0 & - & 4 & 7,1 & 7 & 6,8 & \\
\hline
\end{tabular}




\begin{tabular}{|c|c|c|c|c|c|c|c|}
\hline 1 & 9 & 33,3 & 20 & 35,7 & 21 & 20,4 & \\
\hline II & 7 & 26,0 & 16 & 28,6 & 33 & 32,0 & \\
\hline III & 9 & 33,3 & 11 & 19,7 & 35 & 34,0 & \\
\hline IV & 2 & 7,4 & 5 & 8,9 & 7 & 6,8 & \\
\hline $\begin{array}{l}\text { Tumorregressionsgrad } \\
\text { (n. Dworak) }\end{array}$ & & & & & & & \multirow[t]{6}{*}{0,68} \\
\hline 0 (keine Regression) & & & 0 & - & 0 & - & \\
\hline 1 (<25\% Regression) & & & 5 & 8,9 & 14 & 13,6 & \\
\hline 2 (<50\% Regression) & & & 14 & 25,0 & 30 & 29,1 & \\
\hline 3 (>50\% Regression) & & & 33 & 58,9 & 51 & 49,5 & \\
\hline 4 (komplette Regr.) & & & 4 & 7,2 & 8 & 7,8 & \\
\hline
\end{tabular}

Tabelle 7: Übersicht über die klinikopathologischen Parameter der Patienten nach den entsprechenden unterschiedlichen Vorbehandlungsschemata;

pTNM-Status sowie R-Status und TRG wurden histopathologisch erfasst.

\subsection{Rezidive, Auftreten von Fernmetastasen und tumorbedingte Todesfälle}

Das mediane Follow-Up liegt bei 59 Monaten (2-164 Monate). Dabei beträgt der längste Nachbeobachtungszeitraum sowohl bei Patienten mit primärer Operation als auch bei Patienten mit einer 5-FU-Monotherapie in der Vorbehandlung rund 164 Monate. Die Patientenkohorte mit einer um Oxaliplatin erweiterten Vorbehandlung stellt die Gruppe mit dem kürzesten Follow-Up-Zeitraum dar (siehe Tabelle 8, S.43). Dies ist damit zu erklären, dass erst im Rahmen der CAO/ARO/AIO-04-Studie überprüft wird, ob und inwieweit Oxaliplatin das Outcome des Patienten verbessert.

Innerhalb des Nachbeobachtungszeitraumes kam es bei 10 Patienten (37,0\%) der nicht vorbehandelten Kohorte zu einem Lokalrezidiv. Insgesamt 17 Patienten (30,4\%) mit einer intensivierten neoadjuvanten Therapie erlitten en erneutes Tumorwachstum. Bei 34 Patienten (33,0\%) mit einer 5-FU-Monobehandlung kam es zu einem Wiederauftreten des Tumors (siehe Tabelle 8, S.43). Bezüglich der Fernmetastasierung stellt das primär operierte Kollektiv mit 7 Patienten (25,9\%) die Gruppe mit der niedrigsten Fernmetastasierungsrate dar. In der Kohorte mit einer intensivierten RCT entwickelten 16 Patienten (28,6\%) Fernmetastasen. Bei der mit 5-FU-Mono-vorbehandelten Gruppe kam es bei 33 Patienten (32,0\%) zur Ausbildung von Metastasen (siehe Tabelle 8, S.43). So lässt sich zusammenfassen, dass in allen drei Behandlungsgruppen etwa $26 \%$ bis $32 \%$ Fernmetastasen auftraten. 
Bei 10 Patienten $(17,9 \%)$ der Kohorte mit einer intensivierten RCT kam es zu einem tumorbedingten Versterben. Dies war in der 5-FU-Monotherapie-Kohorte bei 19 Patienten (18,4\%) der Fall (siehe Tabelle 8, S.43).

\begin{tabular}{|c|c|c|c|c|c|c|c|}
\hline neoadjuvante Therapie & \multicolumn{2}{|c|}{ keine } & \multicolumn{2}{|c|}{$\begin{array}{l}\text { intensivierte } \\
\qquad \text { RCT } \\
\text { (5-FU und } \\
\text { Oxaliplatin) }\end{array}$} & \multicolumn{2}{|c|}{$\begin{array}{c}\text { RCT } \\
\text { (5-FU-Mono) }\end{array}$} & \multirow[t]{2}{*}{ p-Wert* } \\
\hline Patientenzahl ( $n=186)$ & 27 & $\%$ & 56 & $\%$ & 103 & $\%$ & \\
\hline \multicolumn{7}{|l|}{ Lokalrezidive } & \multirow[t]{3}{*}{0.83} \\
\hline $\mathrm{Ja}$ & 10 & 37,0 & 17 & 30,4 & 34 & 33,0 & \\
\hline Nein & 17 & 63,0 & 39 & 69,6 & 69 & 67,0 & \\
\hline \multicolumn{7}{|l|}{ Fernmetastasen } & \multirow[t]{6}{*}{0.25} \\
\hline Hepar & 1 & 3,7 & 6 & 10,7 & 9 & 8,7 & \\
\hline Lunge & 4 & 14,8 & 2 & 3,6 & 12 & 11,7 & \\
\hline Peritoneum & 1 & 3,7 & 0 & - & 2 & 1,9 & \\
\hline Andere & 1 & 3,7 & 8 & 14,3 & 10 & 9,7 & \\
\hline Nein & 20 & 74,1 & 40 & 71,4 & 70 & 68,0 & \\
\hline \multicolumn{7}{|l|}{ tumorbedingte Todesfälle } & \\
\hline & 7 & 25,9 & 10 & 17,9 & 19 & 18,4 & \\
\hline \multicolumn{8}{|l|}{ Follow-Up-Zeit } \\
\hline $\begin{array}{l}\text { Median in Monaten } \\
\text { Minimum } \\
\text { Maximum } \\
\text { Mittelwert } \\
\text { Standardabweichung }\end{array}$ & \multicolumn{2}{|c|}{$\begin{array}{c}109,8 \\
21,4 \\
163,6 \\
96,3 \\
40,7\end{array}$} & \multicolumn{2}{|c|}{$\begin{array}{c}48,5 \\
3,2 \\
110,9 \\
49,0 \\
24,1\end{array}$} & \multicolumn{2}{|c|}{$\begin{array}{c}60,0 \\
1,7 \\
163,9 \\
66,4 \\
37,1\end{array}$} & \\
\hline
\end{tabular}

Tabelle 8: Übersicht über das Auftreten von Lokalrezidiven, der Detektion von Fernmetastasen und tumorbedingten Todesfällen im Follow-Up-Zeitraum

Die höchste Rate an Lokalrezidiven und tumorbedingten Todesfälle findet sich innerhalb der Kontrollgruppe (adjuvante Therapie; oberes Rektumdrittel: postoperative CTx, mittleres und unteres Rektumdrittel: postoperative RCT). Die niedrigste Rate an LR und tumorbedingten Todesfällen zeigt sich nach Verabreichung einer neoadjuvanten intensivierten RCT. Die höchste Rate an Fernmetastasen liegt bei der Kohorte mit einer 5-FU-Mono-RCT. 


\subsection{Expressionsstärke von SRC aus prätherapeutischer Biopsie und residuellem Tumorresektat}

Die SRC-Expressionsstärke wurde sowohl im Rahmen der Probeexzision (PE), als auch im residuellen Tumorresektat bestimmt.

In der zytosolischen Färbung zeigte sich für die 152 Biopsien und die 163 Resektate, dass die Expression in beiden Geweben in etwa gleich war (Median des H-Scores etwa bei 170; siehe Abbildung 11, S.45). Bezogen auf die korrespondierenden 129 Präparate (129 Biopsien mit den dazugehörigen 129 Resektaten) zeigte sich in der Zytosolfärbung, dass die Expression in Biopsie und Resektat unterschiedlich war ( $p<0,05$; Abbildung 11, S.45).

Bei der Membranfärbung kam es sowohl bei den nicht korrespondierenden Präparaten $(p<0,05)$ als auch bei den korrespondierenden Präparaten (129 Biopsien mit den entsprechenden 129 Resektaten; $p<0,05)$ zu einer Expressionsänderung von SRC unter der Radiochemotherapie (Abbildung 12, S.46). Zusammenfassend lässt sich festhalten, dass die SRC-Expression unter der neoadjuvanten RCT zunahm, was sich in beiden getrennt voneinander ausgewerteten Zellkompartimenten zeigte. Auch bei den nicht korrespondierenden Präparaten zeigte sich in der Membranfärbung eine signifikante Zunahme der Expression. Lediglich in der zytosolischen Färbung war für Biopsie und Resektat eine in etwa konstante SRC-Expression zu beobachten (Median des H-Scores sowohl in PE als auch im Resektat bei etwa 170).

In der folgenden Abbildung (Abbildung 11, S.45) wird die Darstellung der Expression in der prätherapeutischen Biopsie und dem residuellen Tumor nach neoadjuvanter RCT in der Zytosolfärbung aufgezeigt. Bei den nicht korrespondierenden Präparaten zeigte sich eine in etwa konstante Expression der Biopsie sowie im Resektat ( $p$-Wert=0,14). Bei Betrachtung der 129 korrespondierenden Präparate (PE mit dem entsprechenden Tumorresektat der Patienten) konnte hingegen eine signifikante höhere Expression im Resektat gemessen werden ( $p$-Wert $=0,01$ ). Die Zunahme der Expression wird in unter Punkt B der Abbildung anhand einer Ratio zwischen Biopsie und Resektat dargestellt. 


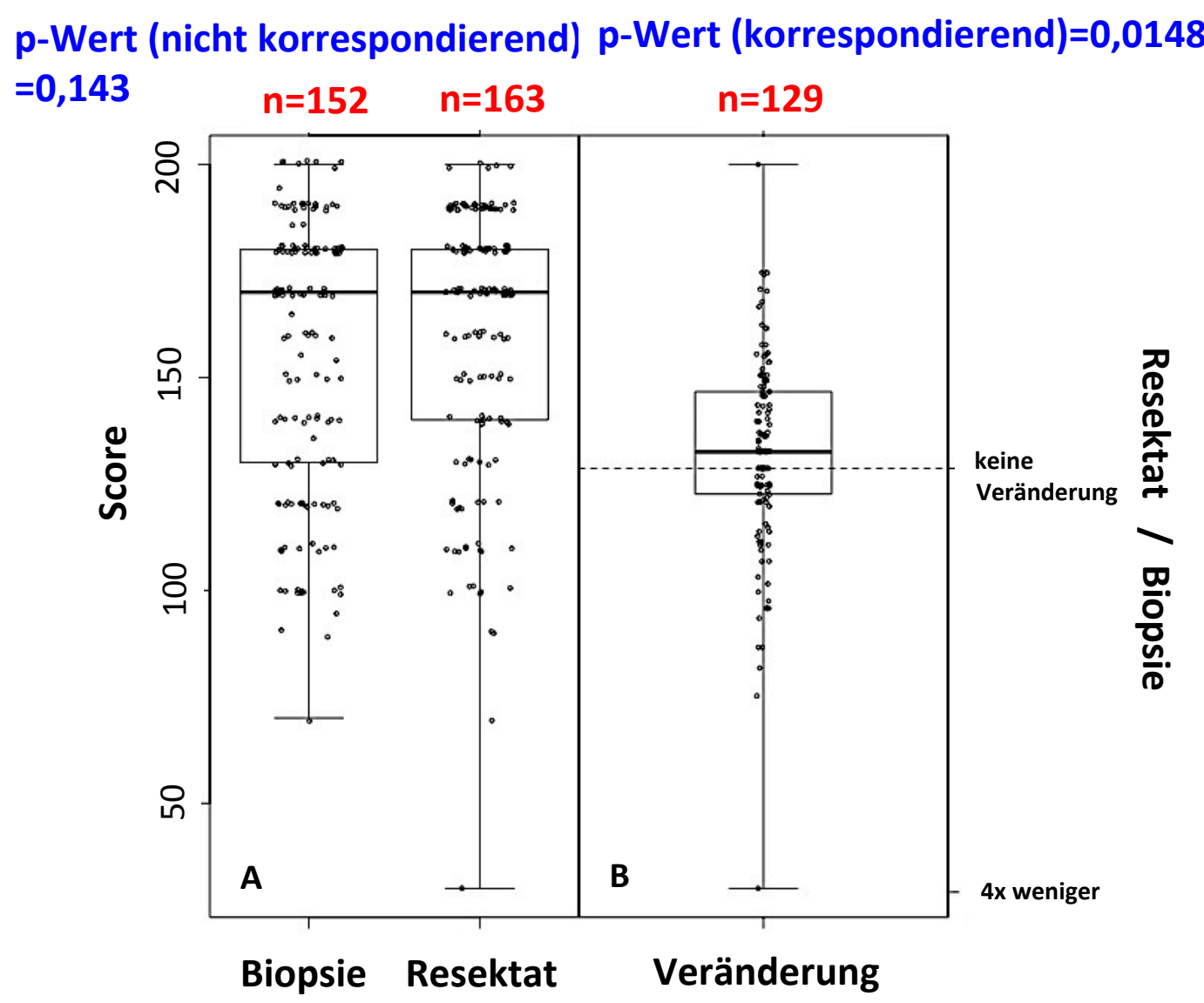

Abbildung 11: Übersicht über die SRC-Expression in Biopsie und Resektat in zytosolischer Färbung: A) bei Betrachtung der nicht korrespondierenden Präparate aus PE und residuellem Tumor gibt es keine signifikante Änderung des SRC-Expressionslevels $(p>0,05)$; bei den korrespondieren Präparaten gibt es eine signifikante Expressionsänderung der SRC-Expression von der PE zum residuellen Tumor $(p<0,05)$ unter der neoadjuvanten RCT. B) Dargestellt ist eine Ratio zwischen der Biopsie- und der Resektat-Expression.

Wie schon erwähnt, zeigte sich die Expressionsintensität der SRC-Expression unter der neoadjuvanten Radiochemotherapie auch in der Membranfärbung sowohl bei den korrespondierenden $(p<0,05)$, als auch bei den nicht korrespondierenden Präparaten ( $p<0,05$; siehe Abbildung 12, S.46).

Somit lässt sich festhalten, dass die SRC-Expression in der Zytosol- und der Membranfärbung ein unterschiedliches Expressionslevel in Biopsie und Resektat aufzeigt. Ob die Zunahme der Expression durch die neoadjuvante RCT bedingt ist, lässt sich allerdings nicht verifizieren. 


\title{
p-Wert (nicht korrespondierend) $p$-Wert (korrespondierend) $=5,13 e-07$
} $=1,05 \mathrm{e}-07$

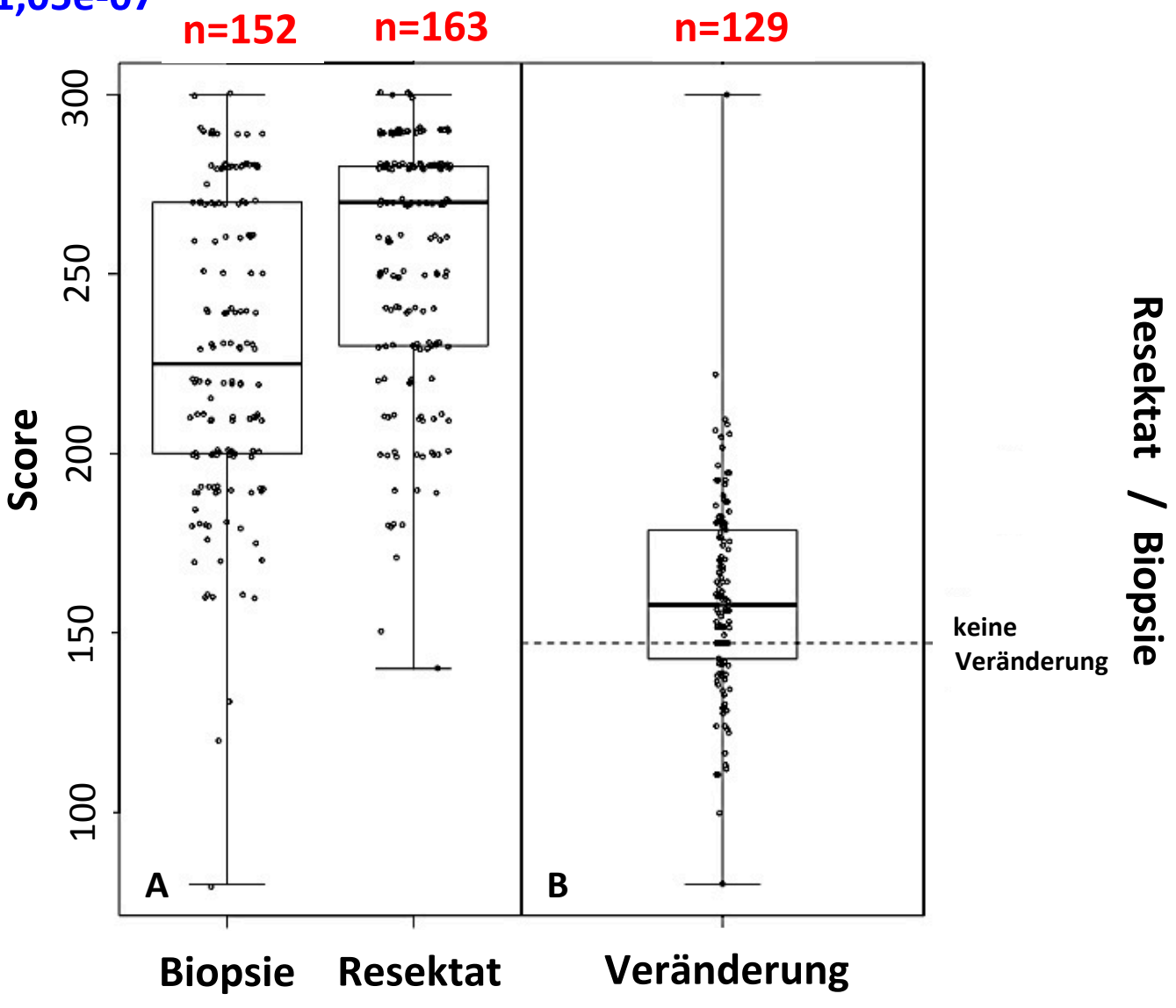

\begin{abstract}
Abbildung 12: Übersicht über die SRC-Expression in Biopsie und residuellem Tumor in der Membranfärbung: A) Hierbei zeigt sich sowohl bei den nicht korrespondierenden $(p<0,05)$, als auch bei den korrespondierenden Präparaten $(p<0,05)$ eine Zunahme der SRC-Expression unter der neoadjuvanten RCT. B) hier ist wiederum eine Ratio zwischen Resektat und Biopsie aufgezeigt.
\end{abstract}

Für die korrespondierenden Präparate von 129 Patienten wurde die Expressionsänderung anhand eines Wasserfalldiagramms für die Zytosolfärbung wie auch für die Membranfärbung angefertigt. Hierfür wurde die Differenz aus Tumorresektat und PE gebildet und als Skalierung die Zu- oder Abnahme der Expression anhand des H-Scores verwendet. Bei denjenigen Balken, die nach oben zeigen, war die Expression im Resektat höher als in der Biopsie. Bei den Balken, die nach unten zeigen, war die Expression in der Biopsie stärker ausgeprägt. Der in der Mitte gelegene graue Balken zeigt an, dass es in der Zytosolfärbung bei zwölf Patienten zu keinerlei Änderung der Expression gekommen ist. Das folgende Wasserfalldiagramm (Abbildung 13, S.47) zeigt in der Zytosolfärbung demnach auf, dass es bei insgesamt 46 von 129 Patienten $(35,7 \%)$ zu einer Abnahme der Expression von der PE zum Resektat kam. Bei 12 von 129 Patienten (9,3\%) gab es keine Expressionsänderung. Bei 71 von 129 Patienten (55,0\%) ließ sich eine Zunahme der Expression feststellen. Bei denjenigen Patienten, bei denen es zu einer Abnahme der Expression kam, lag der $\mathrm{H}$-Score bei einem Großteil der Patienten 
zwischen 0 und -50. Für die Patienten, bei denen es zu einer Zunahme der Färbeintensitätsänderung kam, lag der $\mathrm{H}$-Score beim überwiegenden Teil der Patienten zwischen 0 und +50 . Somit konnte sowohl eine qualitative als auch eine quantitative Darstellung der Expressionsänderung anhand des $\mathrm{H}$ Scores dargestellt werden.

\section{Wasserfalldiagramm der Färbeintensitätsänderung (Tumorresektat-Biopsie)}

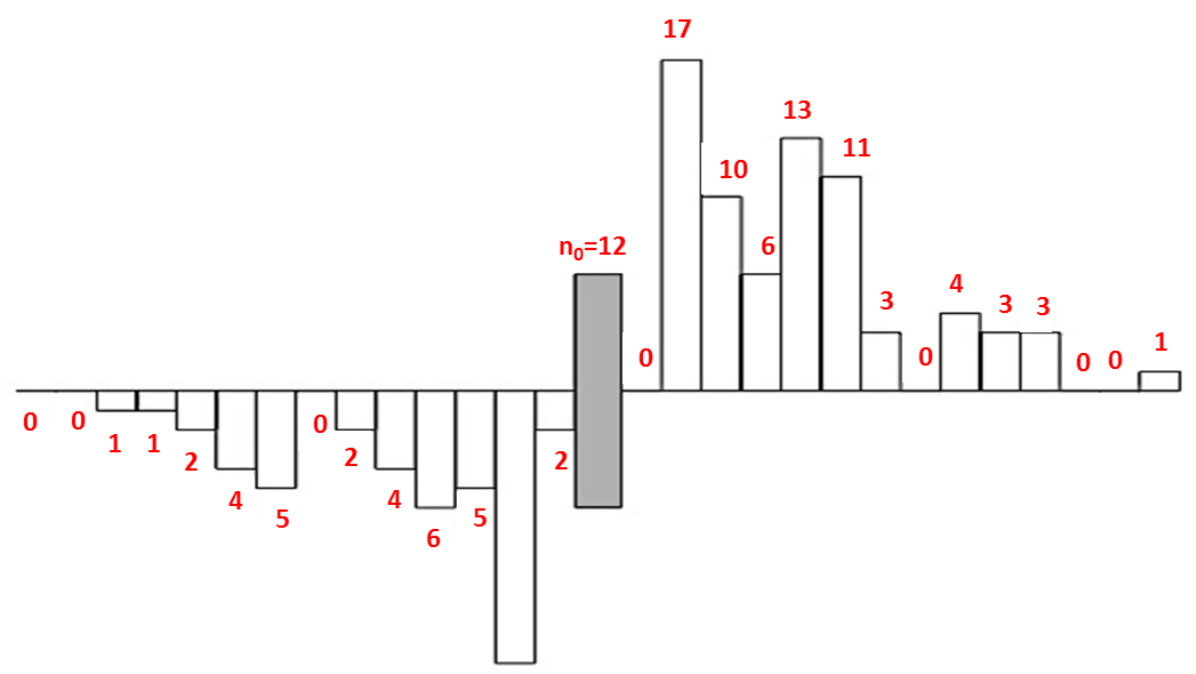

14

\begin{tabular}{r|cccc}
-100 & -50 & 0 & 50 & 100 \\
\hline Abnahme & & Zunahme
\end{tabular}

Abbildung 13: Wasserfalldiagramm der Expressionsänderung bei korrespondierenden Präparaten in der zytosolischen Färbung: hierbei zeigt sich unter der neoadjuvanten RCT für 71 Patienten eine Zunahme der Expression bei den nach oben zeigenden Balken. Bei 12 Patienten war die Expression in etwa konstant. Bei 46 Patienten kam es zu einer Abnahme der Expression.

Analog zeigt sich im Wasserfalldiagramm für die 129 korrespondierenden Präparate auch in der Membranfärbung tendenziell eine Zunahme der Expression von der Biopsie zum Resektat (Abbildung 14, S.48). Bei 34 von 129 Patienten (26,4\%) kam es zu einer Abnahme der SRC-Expression unter der neoadjuvanten RCT. Bei 12 von 129 Patienten (9,3\%) war das Expressionslevel in etwa konstant. Bei 83 von 129 Patienten (64,3\%) kam es zu einer Zunahme der Expression von der PE zum Tumorresektat. Neben der qualitativen Aussage konnte wiederum auch eine quantitative Auswertung mittels $\mathrm{H}$-Score ermittelt werden. So lag der $\mathrm{H}$-Score beim überwiegenden Teil der Patienten, bei denen es zu einer Abnahme der Expression von der Biopsie zum Resektat kam, zwischen 0 und -100. Diejenigen Patienten, die eine Zunahme der Färbeintensität von der PE zum Tumorresektat erfuhren, wiesen zum großen Teil einen H-Score zwischen 0 und +100 auf.

So lässt sich zusammenfassen, dass die Zunahme des SRC-Expressionslevels unter der neoadjuvanten RCT in der Membranfärbung stärker ausgeprägt war als in der Zytosolfärbung. 


\section{Wasserfalldiagramm der Färbeintensitätsänderung (Tumorresektat-Biopsie)}

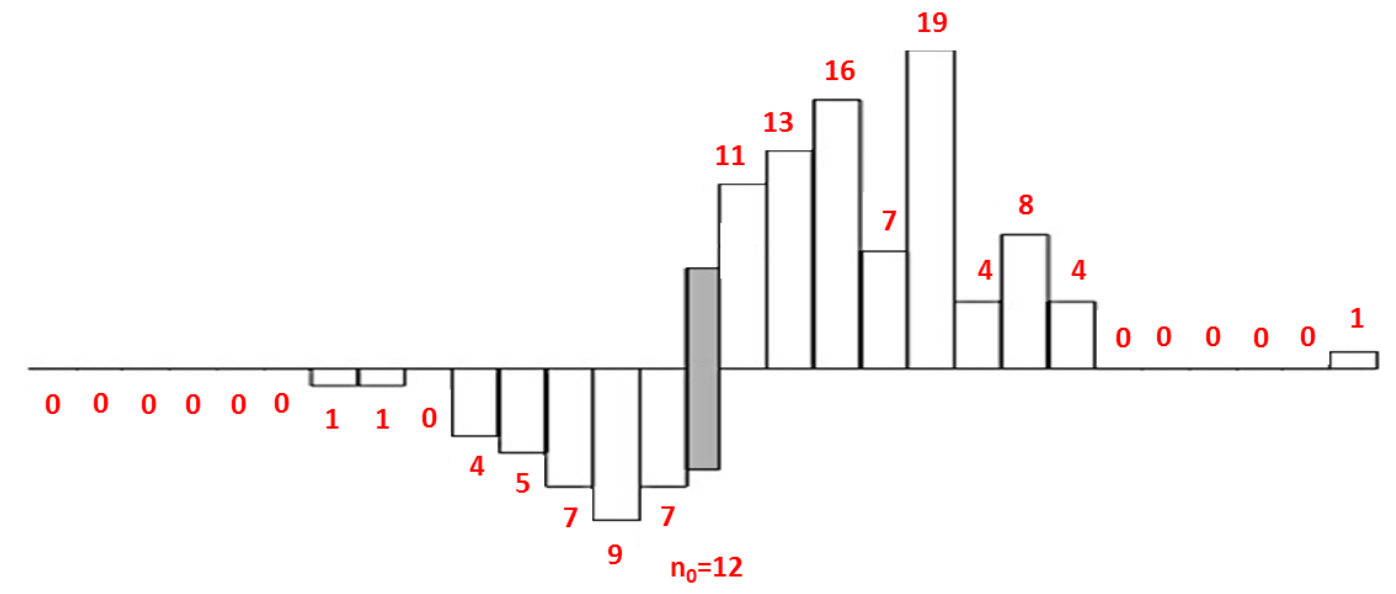

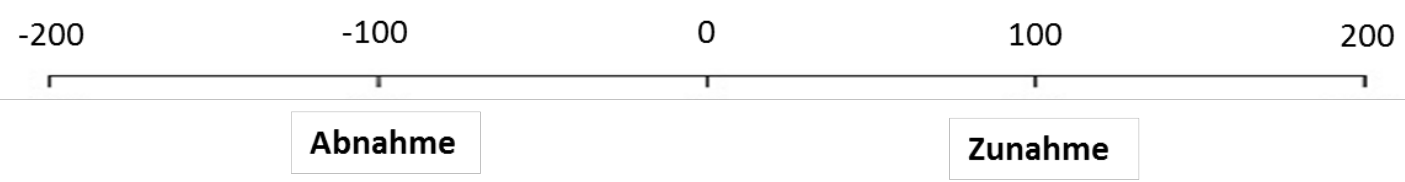

Abbildung 14: Wasserfalldiagramm der Expressionsänderung bei korrespondierenden Präparaten in der Membranfärbung: auch in der Membranfärbung zeigt sich durch den Einfluss der neoadjuvanten RCT eine Zunahme der SRC-Expression bei 83 von 129 Patienten. Bei 12 von 129 Patienten war das Expressionslevel in etwa konstant, während es bei 34 von 129 Patienten zu einer Abnahme der Expression kam.

\subsection{Korrelation der prätherapeutischen SRC-Expressionsstärke mit dem Tumorregressionsgrad}

Es zeigte sich sowohl für die Zytosolfärbung (Abbildung 15, S.49) als auch für die Membranfärbung (Abbildung 16, S.49) keine signifikante Korrelation zwischen dem SRC-Expressionslevel aus der Biopsie und dem Ansprechen des Tumors auf eine neoadjuvante Vorbehandlung. Bei einer hohen zytosolischen SRC-Expression nimmt zwar tendenziell der Grad der Tumorregression zu, allerdings waren hierbei keine signifikanten Unterschiede erkennbar ( $p=0,39$; Abbildung 15, S.49). Auch in der Membranfärbung konnte eine in etwa gleichmäßige SRC-Expression verteilt auf die verschiedenen Tumorregressionsgrade beobachtet werden ( $p=0,95$; Abbildung 16, S.49). 

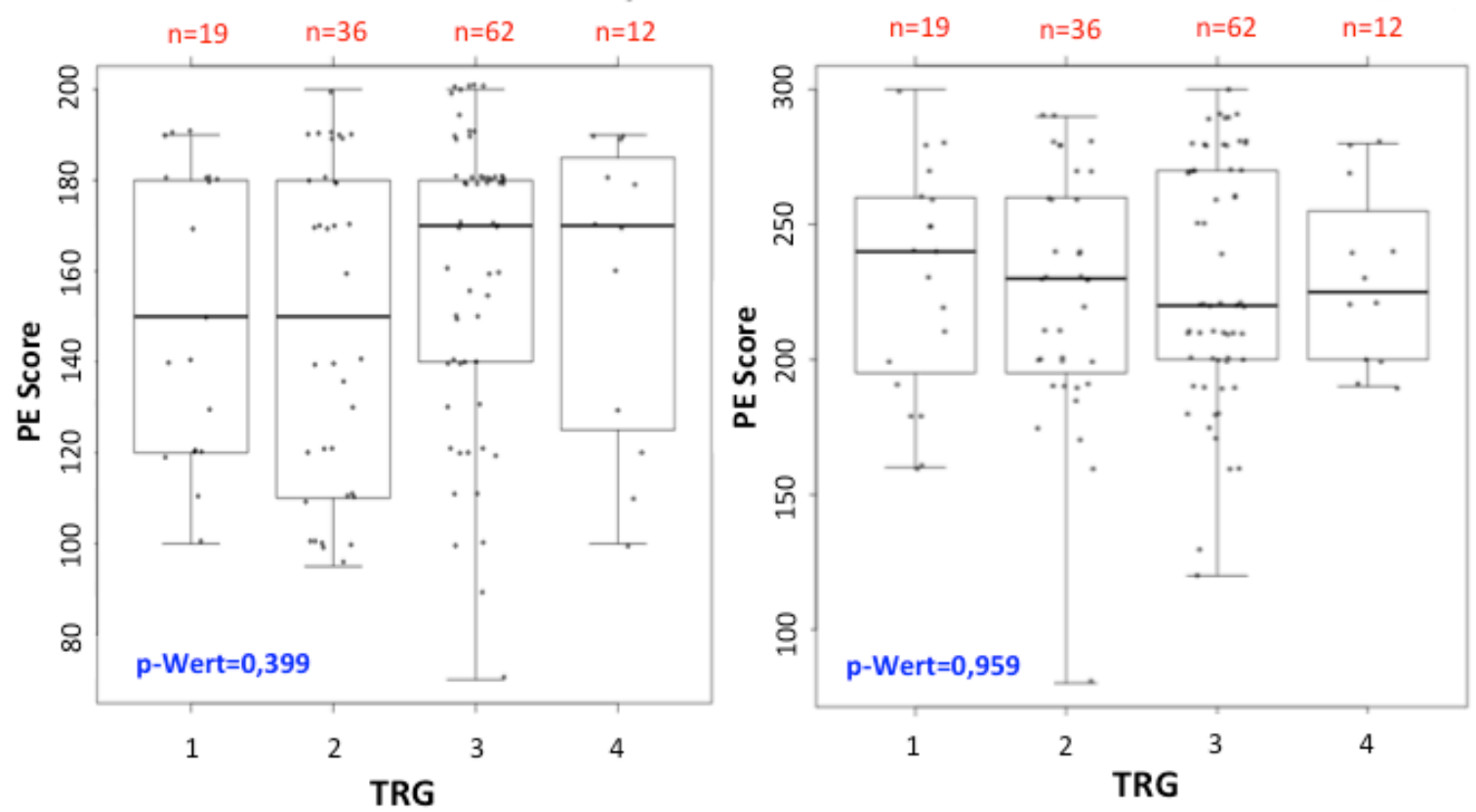

Abbildung 15: Korrelation zwischen der prätherapeutischen SRC-Expression mit dem TRG (Zytosolfärbung): hierbei zeigt sich keine Korrelation $(p=0,39)$

Abbildung 16: Korrelation zwischen der prätherapeutischen SRC-Expression mit dem TRG (Membranfärbung): hierbei zeigt sich keine Korrelation $(p=0,95)$

\subsection{Korrelation der SRC-Expressionsstärke mit dem Nodalstatus und dem Auftreten von Fernmetastasen}

Weiterhin erfolgte eine Korrelation zwischen dem SRC-Expressionslevel in Biopsie sowie in residuellem Tumor und dem Auftreten von LK- und Fernmetastasen.

Es zeigte sich in der Zytosolfärbung der Biopsie, dass eine vermehrte SRC-Expression statistisch signifikant seltener mit residuellen LK-Metastasen nach erfolgter RCT einherging ( $p=0,005$; Abbildung 17, S.50). In der Membranfärbung der Biopsie war das Expressionslevel auf alle drei pN-Gruppen in etwa gleich verteilt (Abbildung 18, S.50). In der Zytosolfärbung im Resektat konnte dieser Trend nicht beobachtet werden. In der Membranfärbung der Biopsien konnte in der Untergruppe der beiden neoadjuvant behandelten Gruppen konstatiert werden, dass eine vermehrte Expression seltener mit einem positiven Nodalstatus assoziiert war ( $p=0,02$; Abbildung 19, S.51). In der Abbildung 20 (S.51) sind alle drei Behandlungsgruppen aufgeführt. In der Membranfärbung der Resektate bestätigte sich die Tendenz bei Betrachtung der beiden neoadjuvant vorbehandelten Gruppen, dass eine vermehrte SRC-Expression seltener mit einem positiven LK-Befall nach RCT vergesellschaftet war $(p=0,06$; Abbildung 21, S.52). 


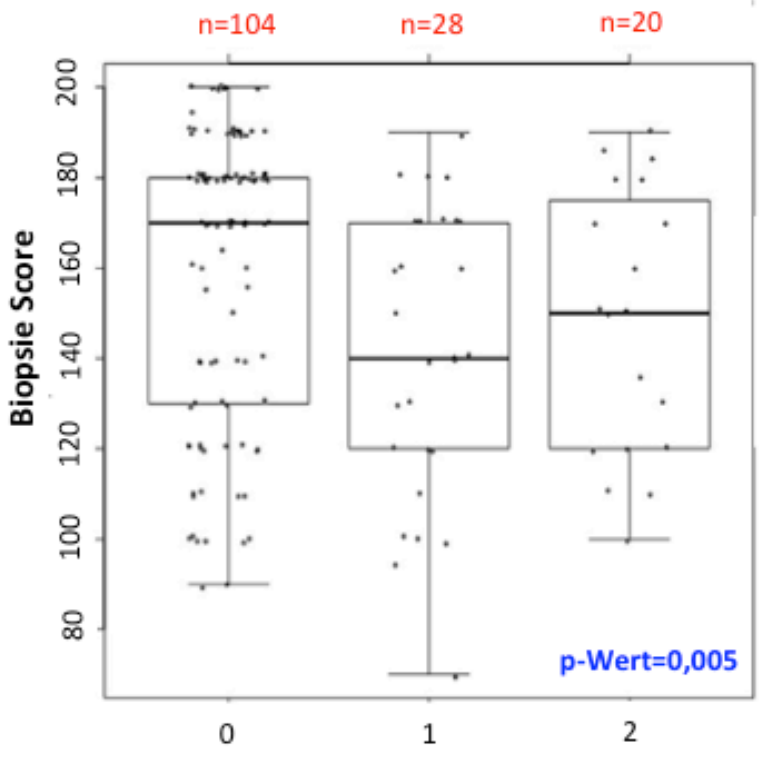

$\mathrm{N}$-Status

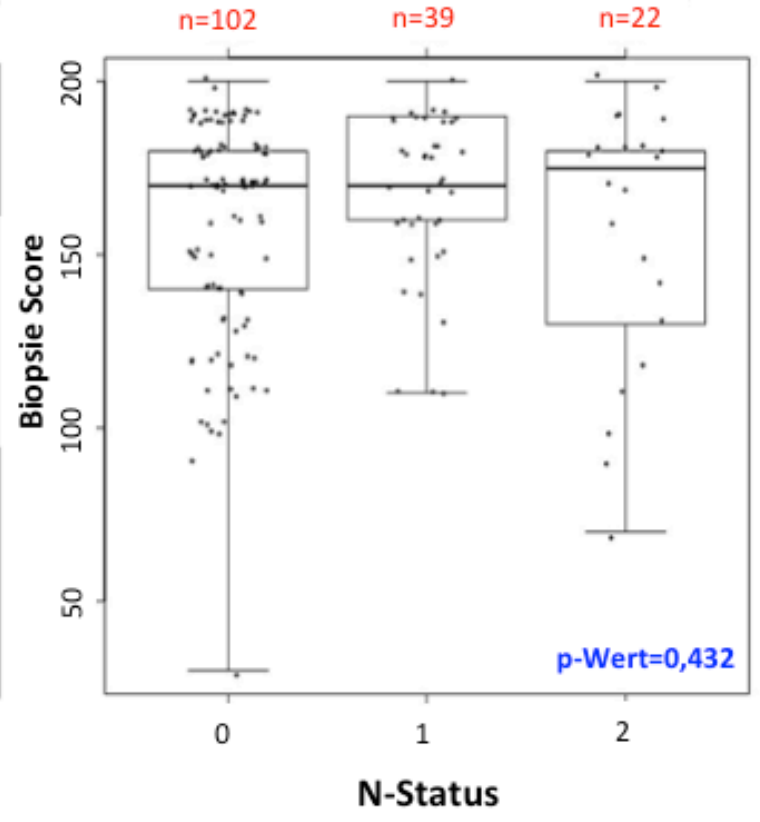

Abbildung 18: Korrelation der SRC-Expression (in der Membranfärbung der Biopsie) mit dem Nodalstatus: das Expressionslevel verteilt sich nahezu gleichmäßig auf die drei pN-Gruppen $(p=0,43)$

Auch bei Betrachtung der drei Behandlungsgruppen zeigt sich, dass eine hohe SRC-Expression seltener mit einem positiven Nodalstatus assoziiert war. So ging eine hohe Expression von SRC in der Membranfärbung der Biopsie bei den beiden neoadjuvant vorbehandelten Gruppen statistisch signifikant seltener mit einem LK-Befall einher ( $p$-Wert=0,021; Abbildung 19, S.51). Die Abbildung 20 beschreibt eine Korrelation zwischen der SRC-Expression in der Membranfärbung der Biopsie und dem Nodalstatus unter Einbezug aller drei Behandlungsgruppen ( $p$-Wert=0,055; Abbildung 20, S.51). 


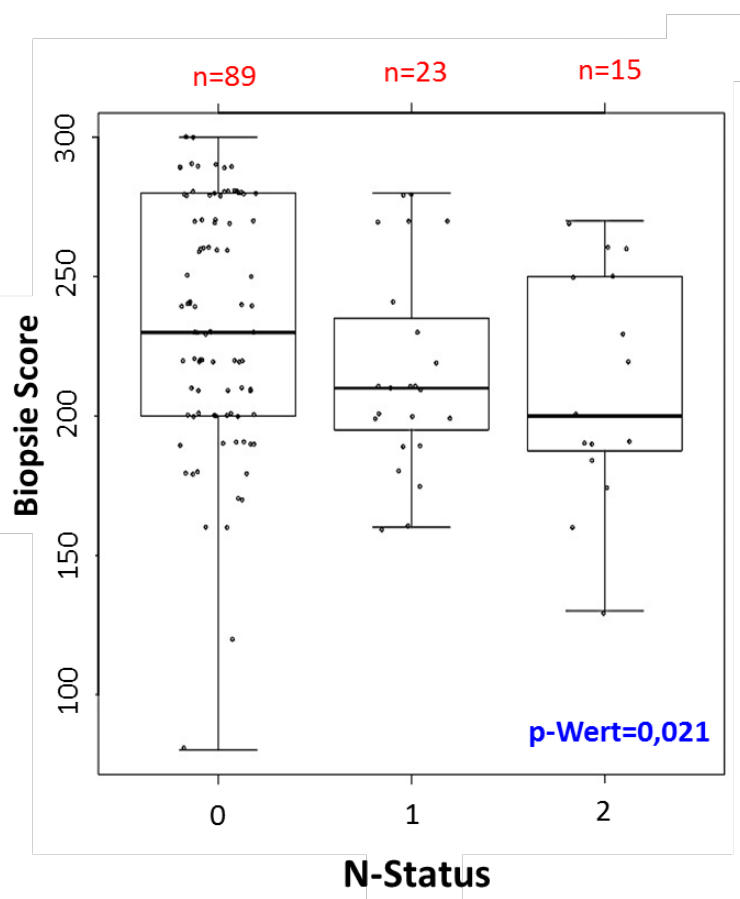

Abbildung 19: Korrelation der Expression mit dem Nodalstatus in der Membranfärbung der Biopsie unter neoadjuvanter Therapie: eine vermehrte Expression geht statistisch signifikant seltener mit einem positiven LK-Befall einher $(p$-Wert $=0,021)$

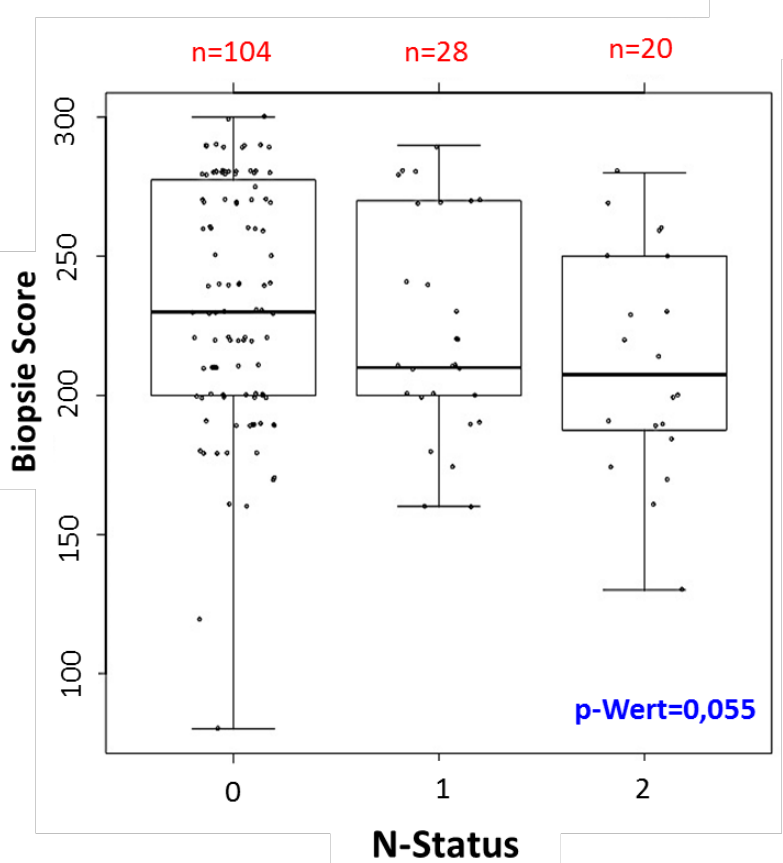

Abbildung 20: Korrelation der Expression mit dem Nodalstatus in der Membranfärbung der Biopsie unter Einbezug aller drei

Behandlungsgruppen: die vermehrte Expression ist tendenziell seltener mit positiven Lymphknotenmetastasen assoziiert $(p=0,055)$

Im Vergleich dazu zeigt sich in der Membranfärbung der Resektate für die beiden vorbehandelten Gruppen, dass eine vermehrte SRC-Expression tendenziell in etwa gleichmäßig mit einem NO- bzw. N1Status einherging ( $p-W e r t=0,067$; Abbildung 21, S.52). Die Abbildung 22 beschreibt wiederum die Expression von SRC in der Membranfärbung der Resektate bei allen drei Behandlungsgruppen bezogen auf den Nodalstatus. Hierbei zeigt sich kein signifikanter Unterschied ( $p$-Wert $=0,159$; Abbildung 22, S.52). 


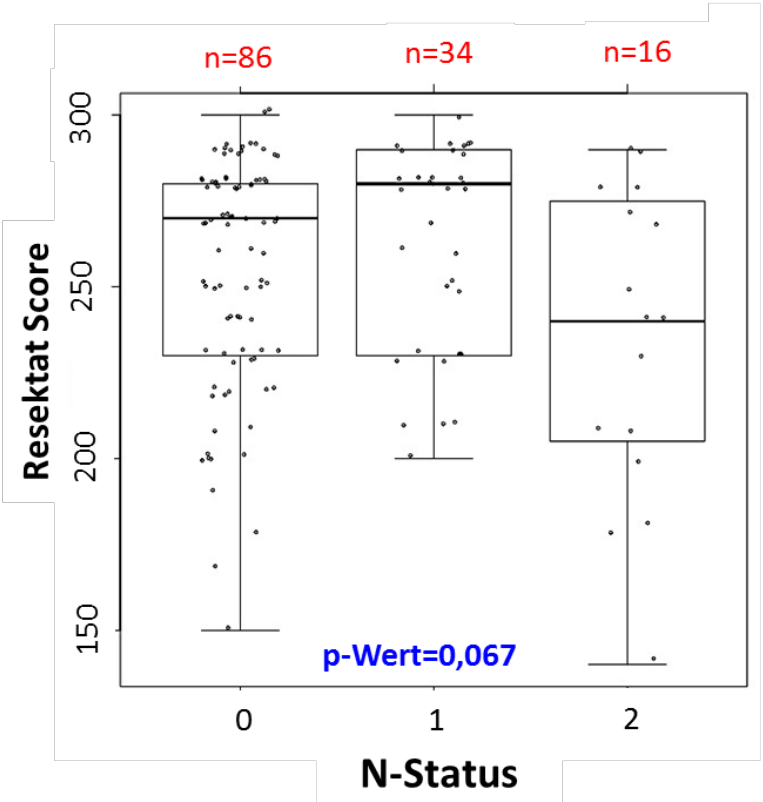

Abbildung 21: Korrelation der Expression mit dem Nodalstatus in der Membranfärbung der Resektate unter neoadjuvanter Vorbehandlung: eine vermehrte Expression geht tendenziell mit einem NO- bzw. N1-Status einher $(p=0,067)$

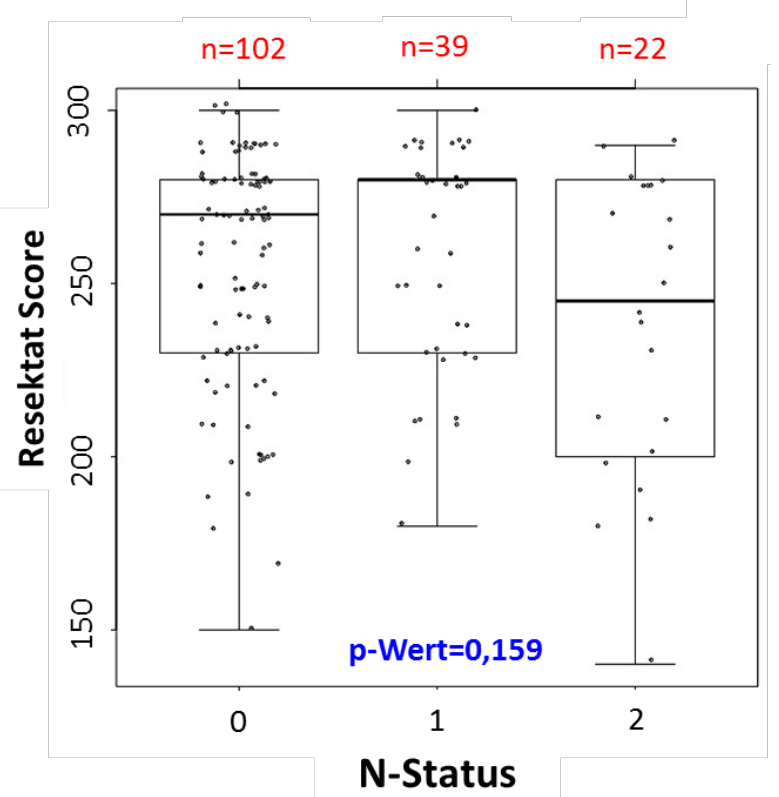

Abbildung 22: Korrelation der Expression mit dem Nodalstatus in der Membranfärbung der Resektate unter Einbezug aller drei Behandlungsgruppen: es zeigt sich kein signifikanter Unterschied $(p=0,159)$

Weiterhin zeigte sich in der Zytosolfärbung der Resektate, dass eine erhöhte SRC-Expression seltener mit der Entwicklung von Fernmetastasen korrelierte ( $p=0,048$; Abbildung 23, S.53). Diese Aussage bestätigt sich auch in einer weiteren Subgruppe. Es handelt sich hierbei um Patienten mit Biopsien in der zytosolischen Färbung, die sich im histopathologischen pUICC-III-Stadium befanden. Auch hier zeigte sich statistisch signifikant, dass eine stärkere SRC-Antigenexpression seltener mit einer Fernmetastasenentwicklung einherging ( $p=0,044$; Abbildung 24, S.54). 


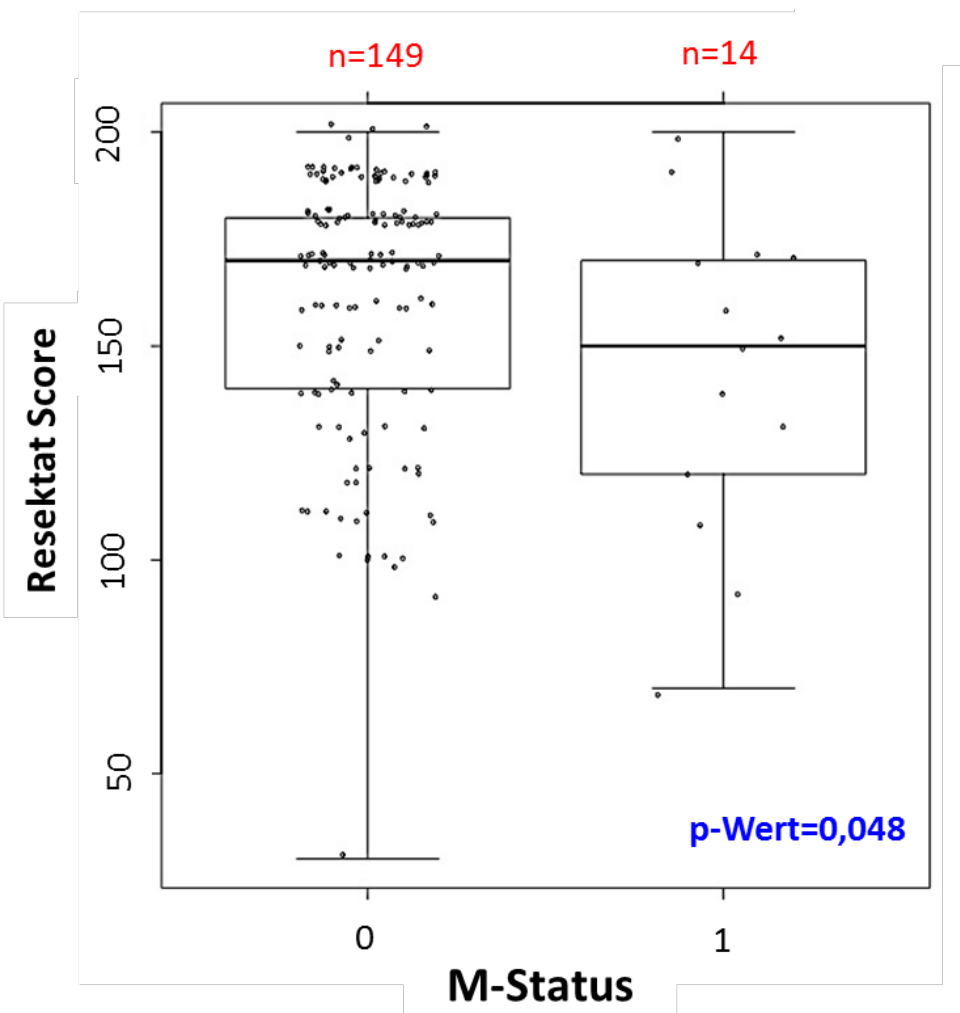

Abbildung 23: Korrelation der SRC-Expression mit dem Auftreten von Fernmetastasen in der Zytosolfärbung von Resektaten: eine vermehrte Expression von SRC ging mit einer selteneren Entwicklung von Fernmetastasen einher $(p=0,048)$

Wie bereits beschrieben, zeigt sich die gleiche Tendenz auch bei Patienten im pUICC-III-Stadium mit Biopsieproben in der Membranfärbung. Eine vermehrte Expression von SRC korrelierte bei dem aus 45 Patienten bestehendem Subkollektiv seltener mit der Entwicklung von Fernmetastasen ( $p$ Wert=0,04; Abbildung 24, S.54). 


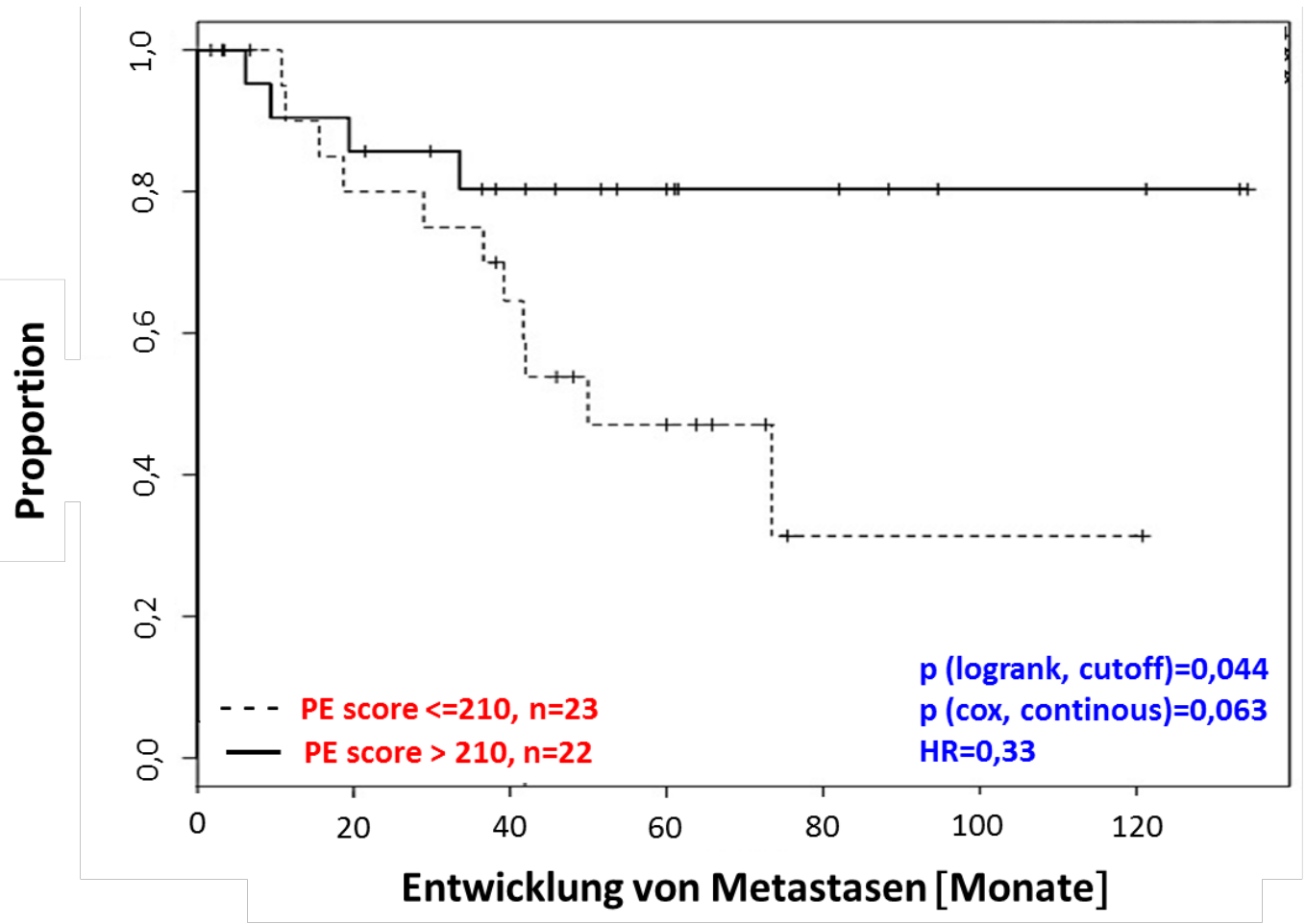

Abbildung 24: Korrelation der SRC-Expression mit dem Auftreten von Fernmetastasen in der Membranfärbung der Biopsie bei Patienten im pUICC-III-Stadium: eine vermehrte Expression war seltener mit dem Auftreten von Fernmetastasen assoziiert $(p=0,044)$.

In der nachfolgenden Abbildung (Abbildung 25, S.55) zeigt sich, dass eine vermehrte SRC-Expression in der Membranfärbung der Biopsie tendenziell seltener mit dem Auftreten von Lokalrezidiven assoziiert war $(p=0,06)$. Hierbei handelt es sich um ein Subkollektiv von 45 Patienten, bei denen positive LK-Metastasen nachgewiesen worden waren (UICC-III-Stadium). 


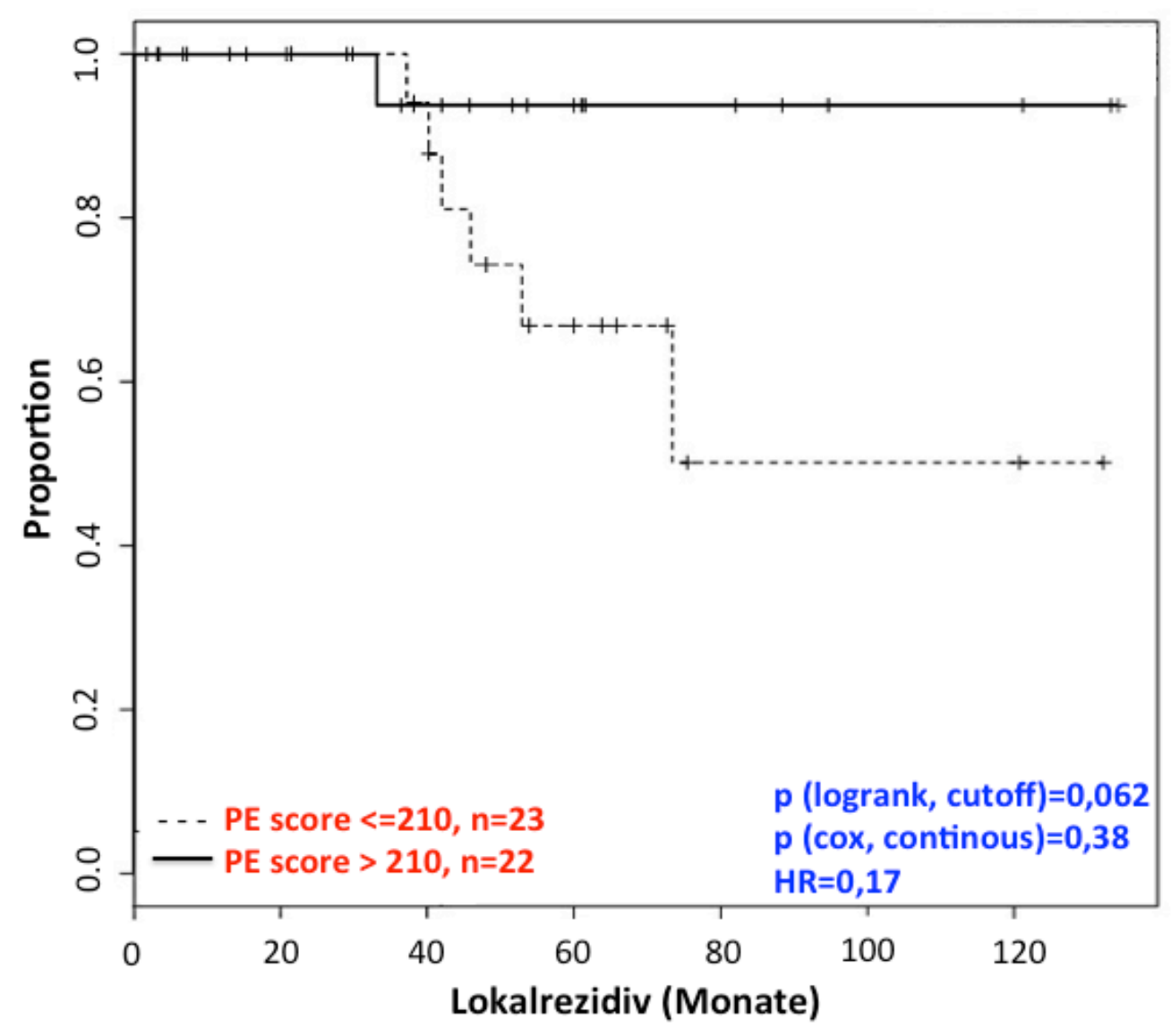

Abbildung 25: Korrelation der SRC-Expression mit dem Auftreten von Lokalrezidiven in der Membranfärbung der Biopsie: hierbei zeigt sich, dass eine vermehrte prätherapeutische SRC-Expression tendenziell mit weniger Lokalrezidiven assoziiert ist $(p=0,062)$

\subsection{Korrelation der SRC-Expression mit dem krankheitsfreien Überleben und dem karzinomspezifischen Überleben}

Es erfolgte weiterhin eine Korrelation des SRC-Expressionslevels mit den prognostischen Parametern wie dem Disease Free Survival (DFS) und dem Cancer Specific Survival (CSS).

Hierbei zeigte sich folgendes: insbesondere bei der Membranfärbung ging eine vermehrte Expression von SRC mit einem längeren DFS und CSS einher. Diese Aussage bestätigte sich größtenteils sowohl im Gesamtkollektiv als auch in verschiedenen Subkollektiven.

In den insgesamt 152 vorliegenden Biopsien war eine vermehrte Expression von SRC in der Membranfärbung tendenziell mit einem verlängerten CSS assoziiert. Der p-Wert liegt dabei knapp oberhalb des Signifikanzniveaus ( $p$-Wert=0,059; Abbildung 26, S.56). 


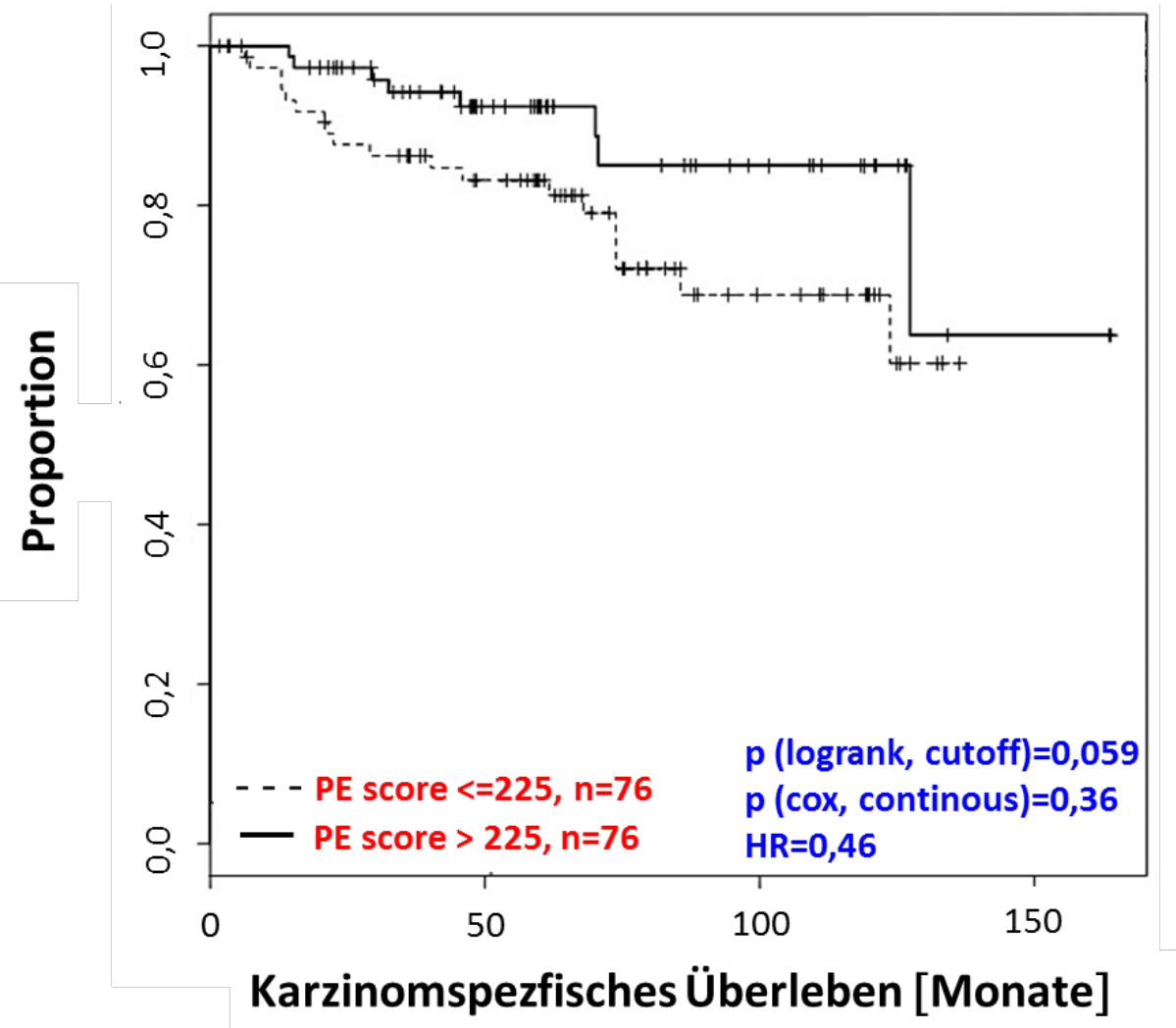

Abbildung 26: Korrelation der SRC-Expression mit dem CSS in der Membranfärbung der Biopsie: eine vermehrte SRC-Expression geht mit einem verlängerten CSS einher. Der pWert $(>0,05)$ zeigt dabei eine statistische Tendenz.

Auch in der Membranfärbung des Tumorresektats zeigte sich bei Patienten mit einer intensivierten Vorbehandlung mit 5-FU und Oxaliplatin, dass eine vermehrte Antigenexpression knapp oberhalb des Signifikanzniveaus mit einem längeren CSS einherging ( $p-W e r t=0,06$; Abbildung 27, S.57). Bei den beiden anderen Behandlungsgruppen ließen sich hingegen keine Tendenzen bezüglich des CSS feststellen. 


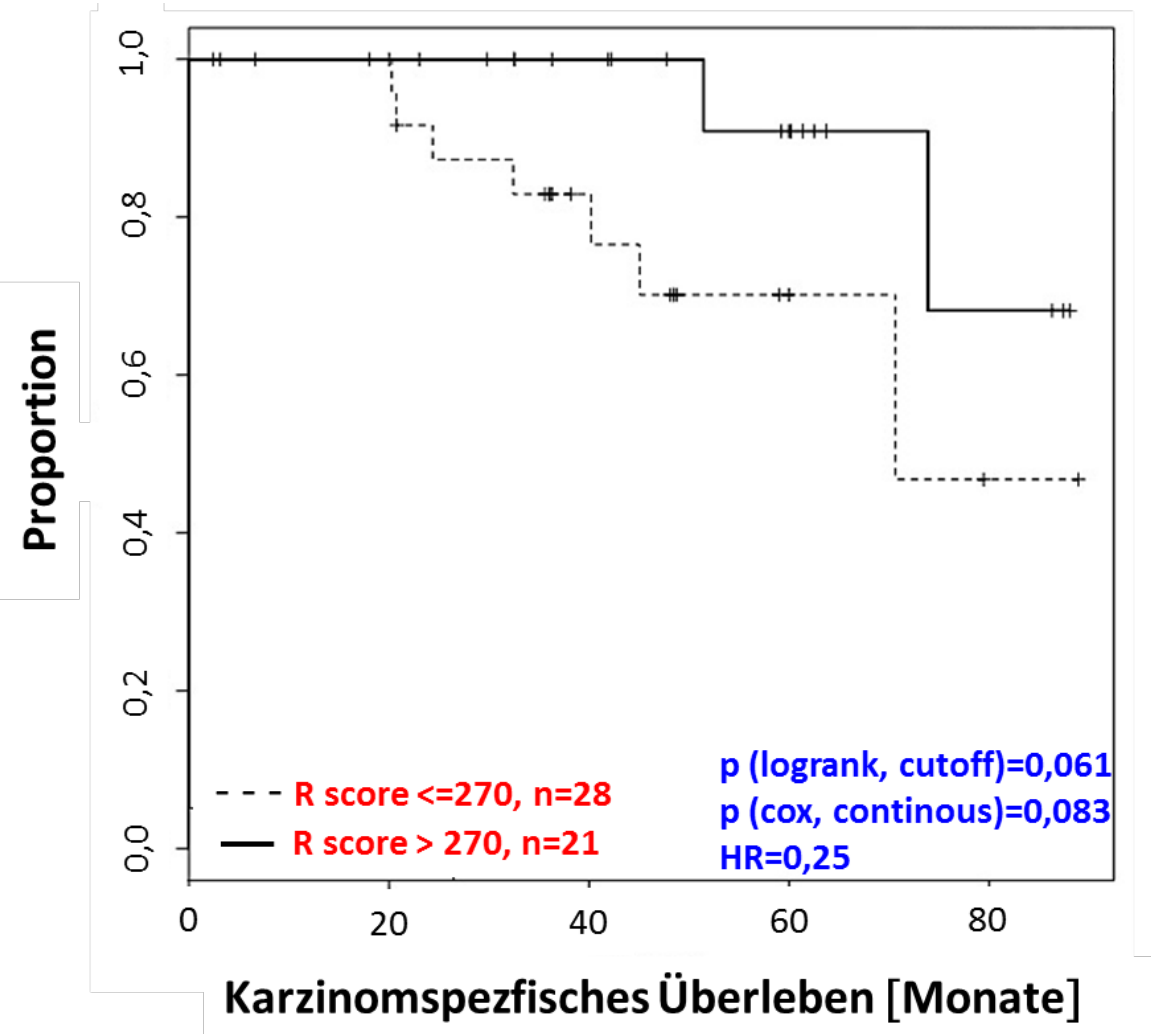

\begin{abstract}
Abbildung 27: Korrelation der SRC-Expression mit dem CSS in der Membranfärbung des Tumorresektats mit 5-FU-Oxaliplatin in der Vorbehandlung: eine vermehrte SRC-Expression geht mit einem verlängerten CSS einher ( $p$-Wert $>0,05)$
\end{abstract}

Bezüglich des DFS scheint eine vermehrte SRC-Expression mit einer günstigeren Prognose vergesellschaftet zu sein.

So zeigte sich in der Membranfärbung der Biopsie des entsprechenden Kollektivs, bei dem ein positiver LK-Befall vorlag, dass eine vermehrte Expression von SRC statistisch signifikant mit einem verlängerten DFS ( $p$-Wert=0,026; Abbildung 28, S.58) vergesellschaftet war. Dieses Kollektiv umfasst dabei insgesamt 48 Patienten bei einem Cut-Off von 210.

Aus dem aus 186 Patienten bestehenden Kollektiv lässt sich also zudem konstatieren, dass eine vermehrte Expression von SRC tendenziell mit einem längeren CSS assoziiert war. Dies zeigte sich bei Patienten mit einer intensivierten Vorbehandlung im Tumorresektat in der Membranfärbung (Abbildung 29, S.59). 


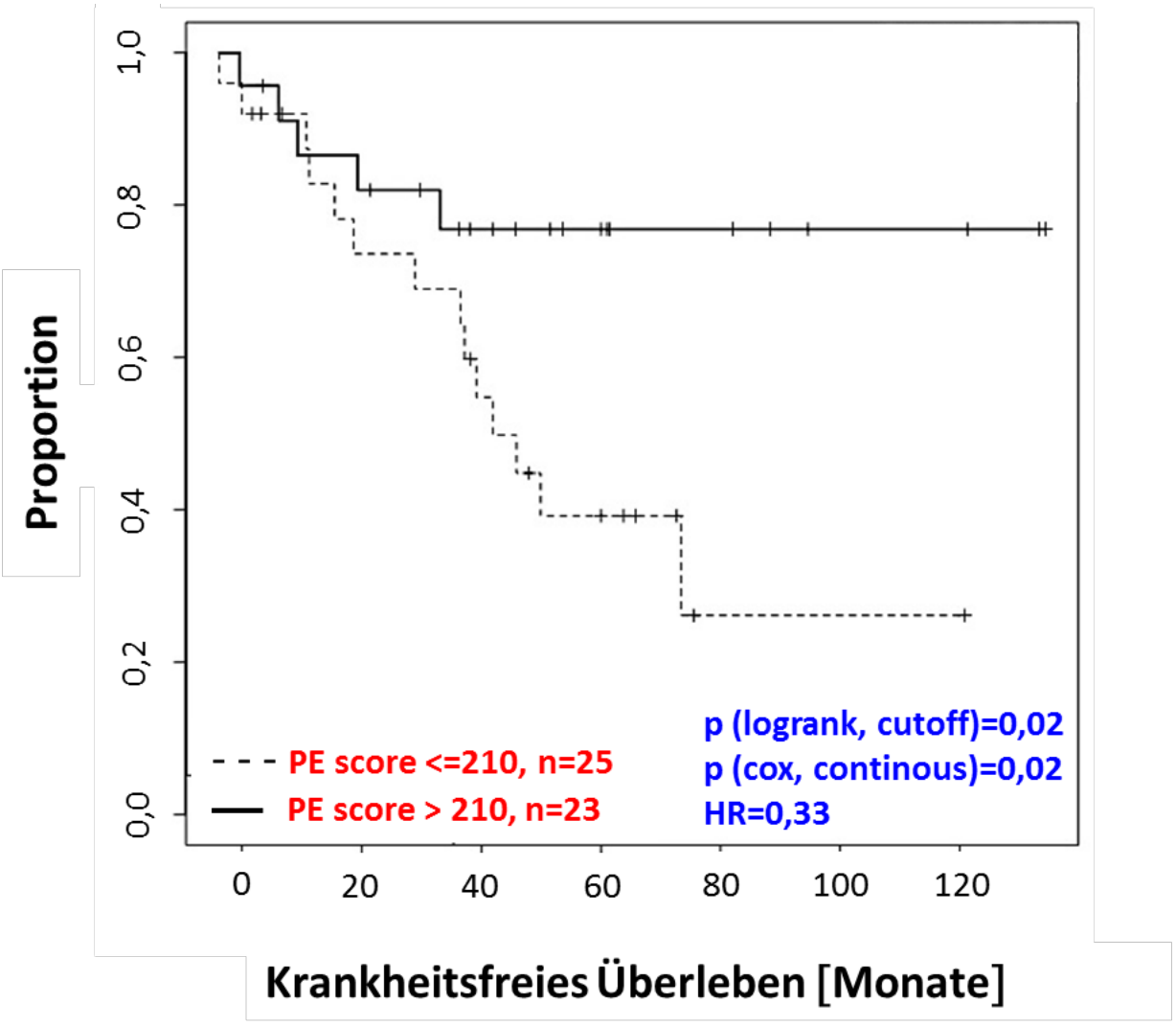

Abbildung 28: Korrelation der SRC-Expression mit dem DFS in der Membranfärbung der Biopsie bei positivem LK-Befall: eine vermehrte SRC-Expression geht mit einem verlängerten DFS einher. Der $p$-Wert $(p=0,026)$ ist dabei statistisch signifikant.

Die gleiche Tendenz bezüglich des DFS zeigt sich auch in der Membranfärbung der Biopsie bei Patienten im pUICC-III-Stadium. Auch hier geht eine vermehrte Expression von SRC bei einem 45 Patienten-umfassenden Kollektiv statistisch signifikant mit einem längeren Disease Free Survival einher ( $p$-Wert=0,027; siehe Abbildung 29, S.59). 


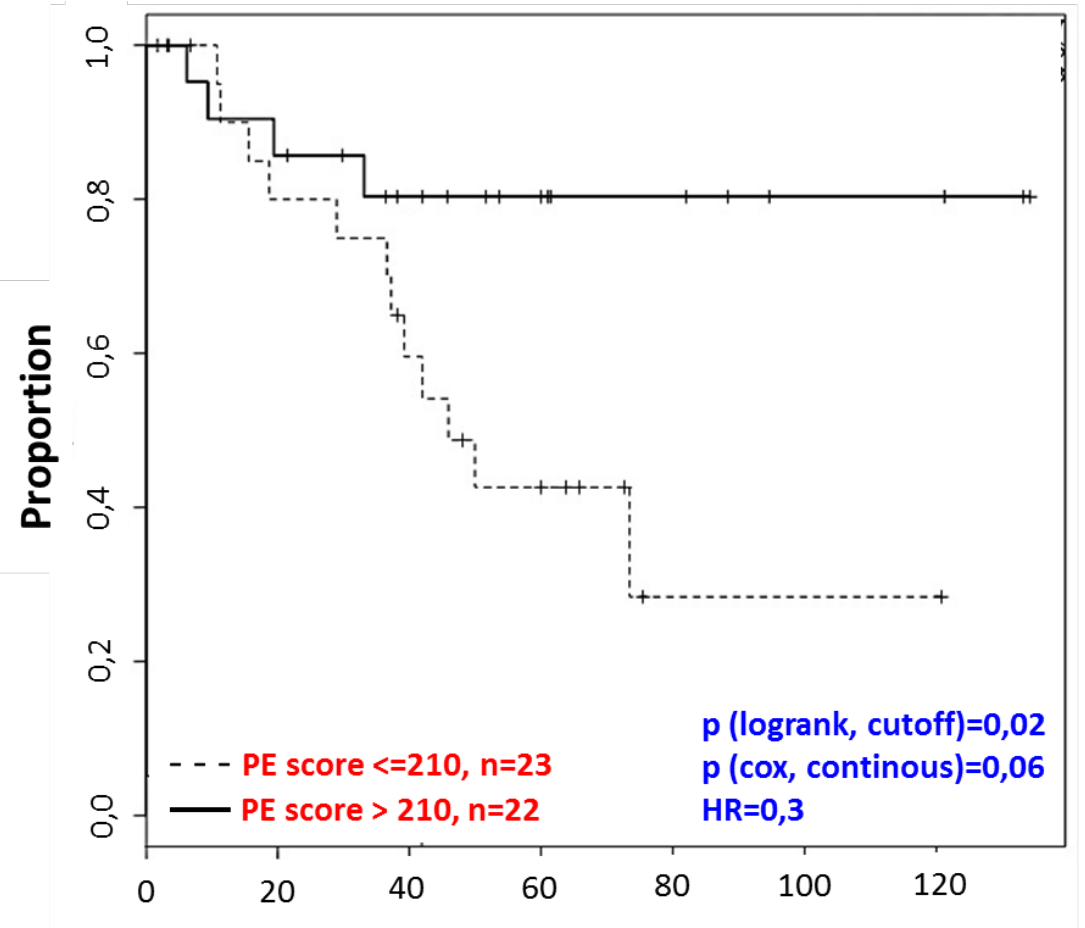

\title{
Krankheitsfreies Überleben [Monate]
}

\begin{abstract}
Abbildung 29: Korrelation der SRC-Expression mit dem DFS in der Membranfärbung der Biopsie bei Patienten mit positivem LK-Befall: eine vermehrte SRC-Expression geht statistisch signifikant mit einem verlängerten DFS einher.
\end{abstract}

Hinsichtlich des Outcomes der drei Behandlungsgruppen (primär operiert, FOLFOX, 5-FU-Mono) konnte folgende Beobachtung gemacht werden: Patienten, die eine intensivierte neoadjuvante RCT erhielten (FOLFOX $+\mathrm{RT}$ ), profitierten von einer vermerten SRC-Expression in der Biopsie hinsichtlich des Nodalstatus. Dies zeigt sich anhand der ROC-Kurve (Receiver Operating Characteristic-Kurve) der folgenden Abbildung (Abbildung 30, S.60). Die ROC-Kurve berechnet sich aus der Ermittlung der relativen Häufigkeitsverteilungen in Form von Sensitivität und Spezifität anhand des entsprechenden Parameters. Je größer der Kurvenabstand von der Diagonalen entfernt ist, desto besser ist die Trennschärfe des Tests. Die AUC (Area Under Curve) als Fläche unterhalb der ROC-Kurve beträgt 81,2\% und dient als Maß für die Güte eines Tests (je höher der Wert, desto besser die Güte). Bei den beiden anderen Behandlungsgruppen zeigte sich dieser Trend hingegen nicht. 


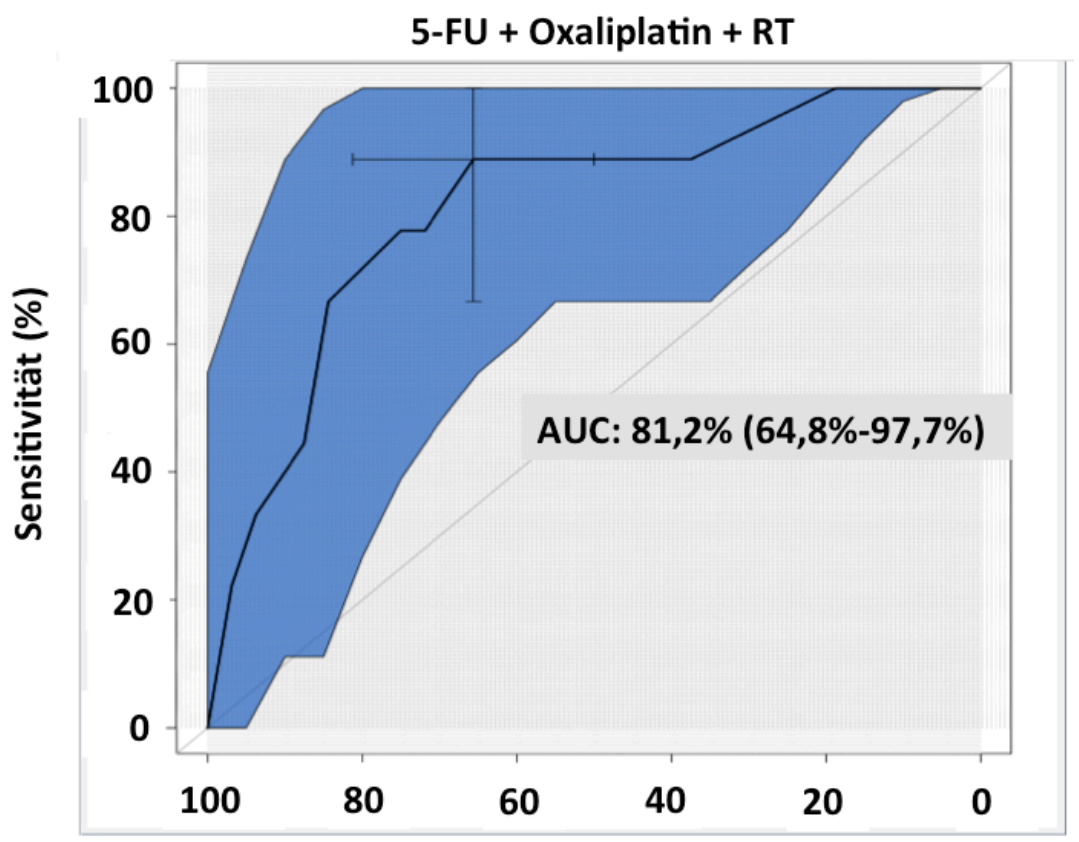

Spezifität (\%)

Abbildung 30: Korrelation der prätherapeutischen SRC-Expression mit dem Nodalstatus unter intensivierter neoadjuvanter RCT (FOLFOX + RT): anhand der ROCKurve zeigt sich eine vergleichweise hohe Sensitivität und Spezifität hinsichtlich einer Korrelation zwischen dem Nodalstatus und der prätherapeutischen SRC-Expression bei Patienten, die zusätzlich Oxaliplatin erhielten. Die AUC (Area Under Curve) beträgt dabei $81,2 \%$. 


\section{4) Diskussion}

\subsection{Potenzial von SRC als Biomarker beim lokal fortgeschrittenen Rektumkarzinom}

Ziel dieser Untersuchung war es, das prädiktive und prognostische Potenzial von SRC als Biomarker beim lokal fortgeschrittenen Rektumkarzinom zu untersuchen. Dabei zeigte sich für das 186 Patienten umfassende monozentrisch untersuchte Patientenkollektiv aufgrund der oben aufgeführten Ergebnisse sowohl ein prädiktives als auch ein prognostisches Potenzial. Es wurde festgestellt, dass eine vergleichsweise hohe SRC-Expression in Biopsie und Resektat seltener mit LK- $(p=0,005)$ bzw. Fernmetastasen $(p=0,048)$ assoziiert war. Weiterhin ging eine vermehrte SRC-Expression im Trend seltener mit dem Auftreten von Lokalrezidiven einher $(p=0,062)$. Außerdem korrelierte eine verstärkte SRC-Expression mit einem verlängerten DFS $(p=0,02)$ und CSS $(p=0,059)$. Weiterhin konnte beobachtet werden, dass Patienten mit einer intensivierten neoadjuvanten RCT (FOLFOX) von einer vermehrten SRC-Expression in der prätherapeutischen Biopsie hinsichtlich des Nodalstatus nach erfolgter RCT profitierten.

Um weitere Aussagen über den prädiktiven bzw. prognostischen Wert von SRC sowohl beim Rektumkarzinom als auch bei weiteren Tumorentitäten treffen zu können, bedarf es selbstverständlich weiterer multizentrischer Untersuchungen. Hierbei wäre insbesondere auch das Mammakarzinom zu erwähnen, das aufgrund der molekularen Interaktionen von SRC mit den Mitgliedern der HER-Familie eine besonders interessante Tumorentität darstellt. Dies ist insofern relevant, als HER2 beim HER2Rezeptor-positivem Mammakarzinom bereits als therapeutisches Target genutzt wird.

Das klinisch-therapeutische Ziel bleibt darin bestehen, zukünftig nur die Therapieformen anzuwenden, bei denen ein Ansprechen für den Patienten zu beobachten ist.

Auch eine Evaluation weiterer Biomarker sollte ein innovativer Bestandteil künftiger Forschungsprojekte sein.

Wie bereits im Kapitel 1.11 SRC-Inhibitoren als zukünftige Therapieoption erwähnt, scheint ein Einsatz von SRC-Inhibitoren bei den verschiedenen Tumorentitäten (beispielsweise Ovarialkarzinom, Bronchialkarzinom oder Prostatakarzinom) als Monotherapie keine ernsthafte Option zu sein, dementsprechend wird auch eine alleinige medikamentöse SRC-Inhibition wohl keine Tumorentstehung bzw.- progression verhindern können. Aber gerade aus der Kombination mit anderen Chemotherapeutika, die derzeit in Phase-I-und -II-Studien getestet werden, scheinen sich mittlerweile vielversprechende und effektive Therapieansätze zu ergeben. Im weiteren Verlauf wird im Kapitel 4.4 Einsatz von SRC-Inhibitoren im klinischen Alltag auf die Rolle von SRC-Antagonisten eingegangen. 


\subsection{Rolle von SRC bei anderen Tumorentitäten und mögliche experimentelle und klinische Ansätze zur Therapieoptimierung beim Rektumkarzinom}

Neben einer Überexpression von SRC beim Rektumkarzinom war eine verstärkte SRC-Expression auch bei weiteren Tumorentitäten in vitro wie in vivo nachzuweisen. Insbesondere beim Mammakarzinom zeigte sich eine vermehrte SRC-Kinaseaktivität gegenüber gesundem Brustgewebe (Biscardi et al. 1998, Verbeek et al. 1996). Frauen mit einem HER2 (Human Epidermal Growth Factor Receptor 2)-positiven Mammakarzinom besitzen einen aggressiveren Phänotyp, dafür sind die Patientinnen Kandidatinnen für Trastuzumab, einen monoklonalen Antikörper, der sich gegen den HER2-Rezeptor richtet und die Progression dieses Brustkrebstyps hemmt (Slamon et al. 1987). Es zeigte sich, dass SRC direkt mit dem aktivierten HER2-Rezeptor interagiert und diese Verbindung zu einer erhöhten SRC-Kinaseaktivität führte (Muthuswamy et al. 1994, Marcotte et al. 2009). Mehrere neuere Studien ergaben außerdem, dass SRC eine führende Rolle bei der Resistenz gegenüber Trastuzumab bei HER2-positiven Mammakarzinomen spielt (Zhuang et al. 2010, Wang et al. 2009, Zhang et al. 2011). Hierbei werden zwei verschiedene Resistenzmechanismen diskutiert: zum einen sprechen viele Patientinnen nicht auf die initiale Trastuzumab-Behandlung an (de-novo-Resistenz), andere Patientinnnen wiederum entwickeln die Resistenz nach fortdauernder Therapie (erworbene Resistenz) (Lan et al. 2005, Piccart 2008). Der häufigste de-novo-Resistenzmechanismus besteht in einer konstitutiven Aktivierung des Phosphoinosotid-3-Kinase (PI3K)-pathways, bedingt durch einen Mangel an PTEN (Phosphatase And Tensin Homolog), einer Phosphatase, die durch das gleichnamige Gen exprimiert wird (Nagata et al. 2004). Es zeigte sich, dass SRC in verschiedenen Trastuzumab-Resistenzmodellen überexprimiert und durch die Aktivität von PTEN dephosphoryliert wurde. Die Aktivierung von SRC führte zu Resistenzen in Brustkrebszellen und korrelierte sowohl mit einer geringeren Ansprechrate als auch mit einem verkürzten Überleben bei Patientinnen, die mit Trastuzumab behandelt werden (Zhang et al. 2011). Die Überexpression von RTK wie EGFR oder IGFR-1 führte zu einer vermehrten Phosphorylierung an SRC-Tyr416 sowie zu einem Trastuzumab-resistenten Phänotyp. Diese Daten zeigen, dass eine SRCAktivierung über die Förderung alternativer RTK zu einer erworbenen Resistenz von Trastuzumab führte (Zhang et al. 2011).

Somit könnte zukünftig untersucht werden, ob und inwieweit Patientinnen mit einem HER2-positiven Mammakarzinom zusätzlich von einer SRC-Inhibition zur Überwindung von Trastuzumab-Resistenzen profitieren könnten.

Bei der de-novo-Resistenz wurde insbesondere die Rolle der Phosphatase PTEN untersucht. Ein Knockdown von PTEN führte zu einer erheblichen Resistenz von Trastuzumab gegenüber Kontrollzellen. Ein PTEN-Knockdown hatte keinen Einfluss auf EGFR, jedoch führte es zu einer erhöhten Phosphorylierung von Src-Tyr416, was darauf hindeutet, dass ein Verlust von PTEN auch zu einer Aktiverung von SRC führte. Da es sich bei PTEN sowohl um eine Lipid- als auch um eine 
Proteinphosphatase handelt, wurde in einem weiteren Schritt untersucht, ob SRC ein direktes Substrat für PTEN darstellt und ob eine erhöhte SRC-Tyr416-Phosphorylierung ein direktes Resultat eines PTENVerlustes ist (Zhang und Yu 2010). In der Coimmunopräzipitation zeigte sich eine direkte Interaktion zwischen PTEN und SRC-Proteinen. Die Daten zeigten, dass PTEN durch seine Phosphataseaktivität direkt und spezifisch SRC-Tyr416 dephosphoryliert. Bemerkenswert war vor allem, dass ein SRCKnockdown in PTEN-defizienten Zelllinien die Sensibilität dieser Zellen auf eine TrastuzumabBehandlung signifikant wiederherstellten $(p=0,013$ und $p=0,008$ verglichen mit sh-PTEN (PTENKnockdown durch sh-RNA)) (Zhang et al. 2011). Somit zeigte sich, dass ein Verlust der PTENPhosphataseaktivität zu einer SRC-Aktivierung führt und in einer de-novo-Trastuzumab-Resistenz in PTEN-defizienten Zellen resultiert.

Die Ergebnisse der vorliegenden Arbeit zeigen, dass eine vergleichsweise vermehrte SRC-Expression mit einem besseren Outcome assoziiert war. Somit könnte die Frage aufgeworfen werden, ob und inwieweit eine Behandlung mit Trastuzumab bei Patienten mit einem HER2-positiven Rektumkarzinom, die eine geringe SRC-Expression zeigten, einen Einfluss auf die Prognose haben könnte. In einer Arbeit von Conradi et al. (2013) konnte beispielsweise demonstriert werden, dass HER2 ein unabhängiger Prädiktor für das $\operatorname{CSS}(p=0,02)$ sowie für den $(y) p N$-Status $(p<0,00001)$ in Rektumkarzinomgewebe war. Anti-HER2-Substanzen, die bereits beim Mamma- sowie beim Magenkarzinom angewandt werden, zeigen ihre Effizienz mit vergleichsweise geringer behandlungsassoziierter Toxizität (Shiroiwa et al. 2011).

Um die Rolle von SRC bei der klinischen Trastuzumab-Resistenz zu beurteilen, wurde die Aktivierung von SRC in Brustkrebszellen von 57 Patientinnen untersucht, die zuvor mit Trastuzumab behandelt wurden. Dafür wurde auf die immunhistochemische Methode zurückgegriffen, bei der ein (AK) gegen phosphoryliertes SRC-Tyr 416 (pSRC-Y416) eingesetzt wurde. Patientinnen mit einem hohen Anteil an phosphoryliertem SRC ( $p S R C$ ) im Tumor zeigten eine geringere klinische Ansprechrate und eine zunehmende fortschreitende Erkrankungsrate als Patientinnen mit geringerem pSRC im Tumorgewebe (Fisher-Test; $p=0,011$ ). Das Overall Survival (OS) war bei Patientinnen mit erhöhtem pSRC bei einem Median von 34 Monaten signifikant geringer als bei Patientinnen mit geringen pSRC-Expressionen mit einem Median von 58 Monaten (log-rank Test; $p=0,044$ ) (Zhang et al. 2011).

Es wäre somit sehr interessant zu beobachten, ob und inwieweit die Expression von pSRC gegenüber nicht-phosphoryliertem SRC aufgrund des unterschiedlichen Aktivitätszustandes des Enzyms einen Einfluss auf das Outcome bei Patienten mit einem Rektumkarzinom hätte. Somit könnte mittels Western-Blots untersucht werden, inwiefern phosphoryliertes und nicht-phosphoryliertes SRC exprimiert werden und diese Expressionsanalysen mit klinischen Daten korrelieren. 
Die Behandlung mit dem SRC-Inhibitor Saracatinib sensibilisierte in vitro sämtliche Trastuzumabresistenten Zellen in allen Zelllinien, darunter auch Zellen mit erworbener Resistenz, PTEN-Defizienz, EGFR-Überexpression, IGF-1R-Überexpression sowie Zellen mit konstitutiver SRC-Aktivierung.

Um zu überprüfen, ob ein SRC-Targeting auch eine effiziente Strategie bei der Überwindung der Trastuzumab-Resistenz in vivo in Tierversuchen darstellt, folgte ein SRC-Knockdown in Trastuzumabresistentem und PTEN-defizientem Brusttumorgewebe durch intratumorale Injektion von Viruspartikeln, die SRC-sh-RNA enthielten. Die Behandlung mit Trastuzumab führte statistisch signifikant zu einer Schrumpfung des Tumorgewebes, welches mit SRC-sh-RNA behandelt wurde $(p=0,0003)$, nicht jedoch bei der Kontrollgruppe, bei der lediglich sh-RNA verwendet wurde (Zhang et al. 2011).

Somit könnte SRC eine Rolle als Target einnehmen, wenn es darum geht, einen Tumor auf Trastuzumab zu sensibilisieren, was wiederum eventuell mit einem verbesserten Outcome assoziiert wäre. Diesen Mechanismus könnte möglicherweise in einem Mausmodell für das Rektumkarzinom überprüft werden. Bislang ist die Datenlage diesbezüglich limitiert.

Bei der erworbenen Resistenz führte eine Behandlung mit Trastuzumab und Saracatinib zu einer erheblichen Inhibition von Trastuzumab-resistenten Tumorzellen, während eine alleinige Behandlung mit Saracatinib bei einer Tagesdosis von $25 \mathrm{mg}$ pro Kilogramm Körpergewicht keinen Effekt zeigte (Tabernero et al. 2007). Bemerkenswert war außerdem, dass eine Kombinationsbehandlung im PTENdefizienten Modell den Tumor eliminierte und dieser nach einer Behandlung von 21 Tagen kaum noch nachzuweisen war. Weiterhin ließ sich durch die Behandlung mit Trastuzumab und Saracatinib ein statistisch signifikanter Anstieg der sogenannten TUNEL-positiven Färbung nachweisen $(p=0,039)$, die vermuten lässt, dass durch die Kombinationsbehandlung die Apoptose von Tumorzellen induziert wurde. Die TUNEL-Methode dient dabei der Darstellung von Zellkernen apoptotischer Zellen. Diese Daten zeigen wiederum auf, dass die SRC-Inhibition in Form von Saracatinib zu einer Sensibilisierung Trastuzumab-resistenter Tumorzellen auf den HER2-Inhibitor führte (Zhang et al. 2011).

Neuere Studien zeigten, dass sich Tumorzellen aufgrund der anhaltenden Behandlung durch eine hoch spezifische zielgerichtete Therapie wie Trastuzumab neu programmieren, um die Zellproliferation aufrechtzuerhalten, was in einer Resistenz auf ein bestimmtes Medikament resultiert (Narayan et al. 2009). Aufgrund der heterogenen Natur von Tumorzellen können mehrere Resistenzmechanismen in einem Patienten gleichzeitig bestehen. Daher ist die Behandlung gegen ein bestimmtes Molekül oder einen bestimmten Resistenzmechanismus üblicherweise wirkungslos (Stommel et al. 2007). Günstiger wäre eine Behandlung gegen multiple veränderte Pathways, die zu einer Resistenz führen. Allerdings wäre eine einfache Kombination von Medikamenten gegen jeden einzelnen Signaltransduktionsweg nicht praktikabel und würde womöglich erhebliche Nebenwirkungen bei einigen Patienten hervorrufen (Tol et al. 2009). 
Die Aktivierung von SRC nimmt somit eine Schlüsselrolle bei den zahlreichen Resistenzmechanismen von Trastuzumab ein. Eine Kombinationsbehandlung bestehend aus SRC-Inhibitor und Trastuzumab zeigte sich bei der Überwindung der de novo- als auch der erworbenen Resistenz beim Mammakarzinom als erfolgsversprechend. Diese Untersuchungen haben somit einen direkten Einfluss auf das klinische Vorgehen bei Patientinnen mit HER2-überexprimierendem Mammakarzinom (Zhang et al. 2011).

Um einen Bezug zum Rektumkarzinom herzustellen, könnte zukünftig das Verhalten des Tumors unter Einfluss von Trastuzumab und einem SRC-Inhibitor sowie in der Kontrollgruppe unter der alleinigen Gabe von Trastuzumab bei HER2-positiven Rektumkarzinomzelllinien in vitro analysiert werden. Weiterhin könnte untersucht werden, ob und inwieweit HER2 ein zukünftiges Target beim Rektumkarzinom in vivo darstellt. In der Arbeit von Conradi et al. (2013) wiesen 12,4\% der Patienten im prätherapeutischen Gewebe sowie $26,7 \%$ der Patienten im Tumorresektat einen positiven HER2Status auf. Für dieses Subkollektiv könnte ein HER2-Targeting eine weitere therapeutische Option darstellen. Allerdings sind diesbezüglich weitere prospektive Studien vonnöten.

\subsection{Weitere Biomarker beim kolorektalen Karzinom in der Übersicht}

Obwohl etwa 45\% der Patienten mit lokal fortgeschrittenem Rektumkarzinom mit einem Downstaging des T-Status auf die neoadjuvante RCT reagieren, gibt es derzeit keine effektive Methode, um vorauszusagen, welcher Patient auf diese Therapie ansprechen wird (Kuremsky et al. 2009, Gaedcke et al. 2011). Trotz bekannter Ansprechraten auf gewisse Therapien kann man bis heute nicht vorhersagen, welcher Patient in die Responder- bzw. Non-Responder-Gruppe fallen wird. Die Entdeckung der KRAS-Mutation als Marker eines mutmaßlichen Scheiterns einer anti-EGFR gerichteten Therapie im adjuvanten Setting stellt dabei einen ersten Schritt in Richtung einer angepassten Therapie für den einzelnen Patienten dar (Walther et al. 2009). Im Zuge dieser zunehmenden Individualisierung der Therapie wurden dabei molekulare Biomarker auf ihr Potenzial überprüft, inwieweit diese das Outcome bei Patienten mit lokal fortgeschrittenem Rektumkarzinom sowohl prädiktiv als auch prognostisch vorhersagen können. Viele Biomarker wurden bereits diesbezüglich untersucht, inwiefern sie prognostische Informationen liefern und den Nutzen einer systemischen Behandlung vorhersagen können. Keiner dieser Marker ist im klinischen Alltag im Routineeinsatz, jedoch lässt sich ein Fortschritt bei anderen Tumorentitäten wie beispielsweise dem Mammakarzinom feststellen (Locker et al. 2006).

Eine Metaanalyse von Kuremsky et al. untersuchte verschiedene relevante Biomarker beim lokal fortgeschrittenen Rektumkarzinom, die zuvor in mindestens fünf Studien beschrieben und mit bestimmten Ereignissen wie dem pCR, TRG, OS oder DFS korreliert wurden: Hierzu zählen u.a. p53, 
EGFR, Thymidylatsynthase oder Ki-67. Diese Analyse richtete sich ausschließlich auf Artikel, die die Fähigkeit eines Biomarkers beschreiben, die Ansprechraten auf eine neoadjuvante RCT beim lokal fortgeschrittenen Rektumkarzinom vorherzusagen.

Die Anwesenheit von Wildtyp-p53 in malignen Zellen wurde bereits häufiger mit der Sensitivität auf einen durch RCT-induzierten Zellschaden korreliert, wohingegen das mutierte p53-Protein mit einer RCT-Resistenz assoziiert wird (Kuerbitz et al. 1992, Lowe et al. 1993, Mcllwrath et al. 1994). Aufgrund der Tatsache, dass p53 eine Schlüsselrolle bei der Apoptose, der Tumorgenese und dem Ansprechen von Tumoren auf Chemotherapie spielt, ist dieses Protein auf seine Eignung als Biomarker häufiger als jedes andere Gen oder Protein untersucht worden. Die Expression von p53 wurde mittels Immunhistochemie, PCR (Polymerase Chain Reaction) und SSCP (Single-Strand Conformation Polymorphism) ermittelt. Die Mehrzahl der Studien zeigte keinerlei Korrelation zwischen der p53Expression und dem Ergebnis der Behandlung. Vier von 21 Studien zeigten eine positive Korrelation: eine Studie behauptete, dass eine Anfärbung von mutiertem p53 ein gutes Ansprechen voraussagte (Esposito at al. 2001), während die anderen drei Studien zu dem Resultat kamen, dass die Anfärbung von p53 ein Anzeichen für eine schwache Ansprechrate zeigte. Auch in unserer Arbeitsgruppe wurde die Rolle von p53 im lokal fortgeschrittenen Rektumkarzinom untersucht. Dabei zeigte sich weder ein prädiktives noch ein prognostisches Potenzial aus der p53-Expression für das lokal fortgeschrittene Rektumkarzinom (Posern 2013). Diese Daten zeigen, dass zum gegenwärtigen Zeitpunkt kein prädiktiver oder prognostischer Nutzen aus der p53-Expression abgeleitet werden kann.

Eine Überexpression von EGFR ist in vitro bei Tumorzellen mit einer Radiatio-Resistenz assoziiert worden (Akimoto et al. 1999, Liang et al. 2003). In der Metaanalyse zeigte nur eine Studie eine Assoziation zwischen einer positiven bzw. negativen EGFR-Anfärbung und dem Outcome. Möglicherweise ist es nützlicher, die EGFR-Expression quantitativ zu messen, anstatt zu beurteilen, ob sich die Biopsien positiv oder negativ auf EGFR anfärben lassen. Zwei der vier Studien, die 87 bzw. 183 Patienten beinhalteten und das Verhältnis zwischen der quantitativen EGFR-Expression und dem Outcome auswerteten, wiesen eine Korrelation auf. Die Evaluation eines SNPs (Single Nucleotide Polymorphism) in der EGFR-Promotorregion stellt möglicherweise einen nützlichen Biomarker dar. Der SNP in Form eines Ersatzes einer Guaninbase an Position 216 in der EGFR-Promotorregion durch eine Thyminbase könnte möglicherweise in einer unterschiedlichen EGFR-Expression resultieren. Bei GGhomozygoten Patienten an der Stelle EGFR Sp1-216 waren 33\% der Patienten Responders, verglichen mit 64\% Responders bei heterozygoten (GT oder TT) Patienten ( $p=0,023)$ (Spindler et al. 2007).

Die Thymidylatsynthase (TYMS) dient als primärer Zielort von 5-FU. Eine TYMS-Überexpression ist mit einer 5-FU-Resistenz sowie einer schlechten Prognose beim kolorektalen Karzinom assoziiert (Salonga et al. 2000, Lenz et al. 1998). 
In unserer Arbeitsgruppe wurde ebenfalls das prädiktive sowie das prognostische Potenzial der TYMS im lokal fortgeschrittenen Rektumkarzinom in dem vorliegenden Patientenkollektiv untersucht. So konnte gezeigt werden, dass eine geringe TYMS-Expression in der prätherapeutischen Biopsie mit einem verkürzten OS einherging $(p=0,01)$. Weiterhin konnte beobachtet werden, dass bei Patienten mit einem positiven Nodalstatus eine vergleichsweise geringe TYMS-Expression im residuellen Tumorgewebe häufiger mit dem Auftreten von lokal- oder fernmetastatischen Rezidiven vergesellschaftet war $(p=0,04)$ (Conradi et al. 2011). Es gibt keinerlei ausreichende Beweise, um den Nutzen einer TYMS-Proteinquantifizierung beim Rektumkarzinom zu belegen. Allerdings hat TYMSDNA womöglich einen Wert als prädiktiver Biomarker und ihr klinischer Nutzen sollte als Ergänzung in größeren Studien mit Einbeziehung der neoadjuvanten RCT beim Rektumkarzinom überprüft werden (Kuremsky et al. 2009).

Ki-67 dient als Marker der Zellproliferation und Zellaktivität und kann in allen aktiven Stadien des Zellzyklus nachgewiesen werden (Scholzen und Gerdes 2000). Obwohl Ki-67 als Prognosefaktor beim kolorektalen Karzinom untersucht wurde, sind die Ergebnisse bisher nicht beweiskräftig gewesen (Brown und Gatter 2002). Auch Ki-67 ist hinsichtlich seines prädiktiven und prognostischen Potenzials in unserer Arbeitsgruppe untersucht worden. Es konnte gezeigt werden, dass die lokoregionäre neoadjuvante RCT zu einer Downregulation des Ki-67-Expressionslevels führte und mit einem signifikant höheren TRG korrelierte $(p=0,005)$. Hinsichtlich der Prognose konnte keine Einflussnahme beobachtet werden (Posern 2013). Basierend auf der Grundlage der Literatur aus 13 Studien erscheint es unwahrscheinlich, dass Ki-67 einen Nutzen für die Vorhersage des Outcomes bei der Behandlung des Rektumkarzinoms besitzt.

Insgesamt wurden 33 Artikel ausgewertet und die sechs am häufigsten erforschten Biomarker beim Rektumkarzinom untersucht. Derzeit gibt es keine etablierten Biomarker, die das Outcome beim Rektumkarzinom vorhersagen können (Kuremsky et al. 2009, George und Kopetz 2011).

Ein signifikantes Problem war der Mangel an großen Patientenkollektiven in den entsprechenden Studien. Die Patientenanzahl lag zwischen 17 und 183 Patienten bei einem Median von 49 Patienten. Auch wenn eine signifikante Korrelation zwischen einem Biomarker und dem Outcome vorlagen, bedarf es einer größeren Anzahl an Patienten, um eine Vorhersage über ein Therapieansprechen zu ermöglichen. Die quantitative Auswertung von EGFR und die Anwendung von TYMS-Polymorphismen sind vielversprechend bei der Vorhersage des Outcomes beim lokal fortgeschritten Rektumkarzinom (Kuremsky et al. 2009). Allerdings konnten diese Studien für diese Biomarker keine Vergleichbarkeit bei den Resultaten des Outcomes aufzeigen. Vor dem Einsatz dieser Biomarker im klinischen Alltag bedarf es prospektiver Studien mit reproduzierbaren Ergebnissen bei einer großen Anzahl von Patienten, um den Nutzen eines Biomarkers bei der Vorhersage eines Therapieansprechens aufzuzeigen. Hinzu kommen einige Confounder, also Störvariablen, die die Interpretation dieser 
Ergebnisse beeinflussen: so wurde bei einigen Studien die 5-FU-basierte Chemotherapie um Oxaliplatin oder Irinotecan erweitert. In anderen Untersuchungen wurde eine intraoperative Radiotherapie angewandt, bei wiederum anderen Studien wurde der IRS (Immunreaktiver Score), der die Auswertung von der Prozentzahl der positiv gefärbten Zellen (0-4 entsprechend dem prozentualen Anteil) mit der Intensivität der Färbung (0-3) kombiniert, unterschiedlich festgelegt. So geben manche Studien eine hohe Expression des Biomarkers bei einem IRS von 5 an, während der höchste IRS in weiteren Studien bei einem score von 4 lag. Des weiteren wurden verschiedene sogenannte Cut-offLevels verwendet, bei denen unterschiedliche Prozentangaben der Zellanfärbung eine Positivität des Biomarkers beschreibt. So wurde in einigen Studien bereits bei $1 \%$ der gefärbten Zellen eine Biomarker-Positivität definiert, während diese in anderen Untersuchungen erst ab 50\% gefärbter Zellen galt. Somit lässt sich zusammenfassen, dass die aktuelle Studienlage nicht ausreicht, um anhand eines einzelnen Biomarkers das Ansprechen auf eine neoadjuvante RCT beim Rektumkarzinom vorherzusagen.

In künftigen klinischen Studien, die sich mit der neoadjuvanten RCT beim Rektumkarzinom auseinandersetzen, sollten Biomarker auf größere Patientenkollektive ausgeweitet evaluiert werden, um ihre Rolle auf das Outcome zu ermitteln. Die Antwort auf die Frage, warum nicht alle Patienten auf die RCT ansprechen, liegt möglicherweise grundsätzlich nicht im Genom des Tumors. Vielmehr könnten epigenetische Faktoren eine Rolle spielen, die es noch zu ergründen gilt. Dabei ist es unwahrscheinlich, dass ein einzelner Faktor die Charakteristika des Ansprechens festlegt, weswegen eine multifaktorielle Herangehensweise vonnöten sein wird.

In diesem Zusammenhang ist auch die TransValid-KFO179/GRCSG-Studie-A zu nennen, welche als einarmige Studie sich mit der Standardtherapie des lokal fortgeschrittenen Rektumkarzinoms bis einschließlich $12 \mathrm{~cm}$ ab Anokutanlinie befasst. Im Rahmen dieser Studie wird eine 5-FU-basierte neoadjuvante RCT verabreicht, an die sich die TME und eine adjuvante CTx mit 5-FU und je nach Tumorstadium zusätzlich Oxaliplatin anschließt. Während der laufenden Therapie werden dabei Plasmaproben von Patienten an definierten Zeitpunkten entnommen und auf epigenetische Faktoren hin untersucht. Die Studie dient dabei als Validierungsstudie für die Ergebnisse der KFO 179.

\subsection{Einsatz von SRC-Inhibitoren im klinischen Alltag}

Nach wie vor ist die Übertragung der molekularbiologischen Erkenntnisse auf die klinische Anwendung nicht unproblematisch. Dies ist zum einen durch die Komplexität des SRC-Pathways aufgrund der Fähigkeit zur Interaktion mit anderen Rezeptortyrosinkinasen bedingt. Zum anderen gibt es bisher nur wenig Beweise, dass SRC in einem höheren Maße exprimiert wird als beispielsweise EGFR oder HER2 
(Kopetz et al. 2007). Weiterhin existiert aktuell kein Biomarker, der auf eine SRC-Aktivität oder eine Sensitivität gegenüber SRC-Inhibitoren schließen lässt. In einer Studie mit Saracatinib bei Xenografts mit humanem Pankreaskarzinom wurde ein Genpaar (LRCC19 und IGFBP2) identifiziert, das ein hohes prädiktives Potenzial hinsichtlich des Ansprechens auf Saracatinib aufzeigte. Dabei könnte dieses Genpaar ein mögliches Potenzial als Biomarker für das Therapieansprechen beim Pankreaskarzinom darstellen (Rajeshkumar et al. 2009). Allerdings sind hierfür weitere Studien notwendig, um eine Aussage darüber treffen zu können, ob und inwieweit Patienten von einer SRC-Inhibition überhaupt profitieren. Bild et al. (2006) verwendeten Genexpressionsanalysen, die den Aktivierungsgrad onkogener Pathways inklusive SRC widerspiegelten. Dabei wurden Brustkrebszelllinien verwendet, um das Ansprechen von Zelllinien auf einen SRC-Inhibitor zu überprüfen. Es zeigte sich, dass eine enge Übereinstimmung und Korrelation zwischen der Wahrscheinlichkeit für die SRC-Pathway-Deregulation anhand der Vorhersage der Genexpression und dem Ausmaß der Zellproliferationshemmung durch den SRC-Inhibitor bestand (Bild et al. 2006). Hierin liegt möglicherweise eine Option, die Sensitivität von Zellen auf SRC-gerichtete therapeutische Therapien vorherzusagen. Weiterhin sind die SRCInhibitoren Dasatinib und Bosutinib nicht selektiv, spezifische SRC-Antagonisten allein können wiederum viele andere Kinasen mit potenziellen Signaleffekten an Tumorzellen und gesundem Gewebe hemmen.

Klinisch wird vor allem bedeutend sein, ob eine SRC-Inhibition die Regression eines Tumors induzieren und die Bildung von Rezidiven oder Metastasen verzögern kann. Auch eine Therapie von SRCInhibitoren in Kombination mit einem Angioneogenesehemmer oder weiteren Rezeptortyrosinkinaseninhibitoren könnten womöglich eine wichtige Rolle in der künftigen Therapie spielen. Weiterhin wird es von großer Bedeutung sein, die molekularen Mechanismen der SRCAntagonisten weiter zu entschlüsseln, um potenzielle Biomarker zu identifizieren, die womöglich eine Vorhersage über das Ansprechen von Patienten auf diese Therapieformen ermöglichen.

Hierzu bedarf es weiterer groß angelegter multizentrischer Studien, die möglicherweise signifikante Fortschritte bei der Behandlung von Patienten mit einem kolorektalen Karzinom liefern und möglicherweise translationale Fragen beantworten könnten.

\subsection{Das prädiktive und prognostische Potenzial von SRC im lokal fortgeschrittenen}

\section{Rektumkarzinom}

\subsubsection{Prädiktion des Therapieansprechens anhand des (y)pTNM-Status und des TRG}

Wie bereits in den Kapiteln 3.2 und 3.5 beschrieben, erfolgte die Korrelation der SRC-Expression mit dem (y)pTNM-Status und dem Tumorregressionsgrad (TRG). 
Im Zusammenhang mit dem (y)pTNM-Status wird überprüft, ob und inwieweit es zu einer Downkategorisierung unter dem Einfluss der RCT gekommen ist. Diese umfasst sowohl das Downsizing (Reduktion der Tiefeninfiltration durch die RCT im Vergleich UT gegenüber ypT) als auch das Downstaging (Reduktion um $\geq 1$ UICC-Stufe im Vergleich zwischen cUICC und ypUICC).

Rödel et al. (2005) beschreiben den TRG als Early Surrogat Parameter mit prognostischer Relevanz für das Rektumkarzinom nach einer neoadjuvanten Vorbehandlung durch die RCT. So konnte in entsprechenden Analysen gezeigt werden, dass eine komplette Remission (TRG4) bzw. ein intermediäres pathologisches Ansprechen (TRG2 + TRG3) auf ein verlängertes DFS nach der präoperativen RCT hindeutet. Diese Ergebnisse konnten durch die Arbeit von Fokas et al. (2014) bestätigt werden. In der multivariaten Analyse zeigten sich der TRG sowie histopathologisch nachgewiesene LK-Metastasen ( $\mathrm{ypN}+$ ) als einzige unabhängige prognostische Faktoren bezüglich der Fernmetastasierung und des DFS (Fokas et al. 2014). Bisher stellen jedoch weiterhin der pT- und pNStatus nach erfolgter RCT die wichtigsten unabhängigen prognostischen Faktoren hinsichtlich des DFS (Rödel et al. 2005, Sprenger et al. 2009).

Auch Moreno García et al. (2010) konnten nachweisen, dass der TRG ein unabhängiger Prädiktor für das DFS $(p=0,05)$ und das OS ( $p=0,001)$ ist. Vironen et al. (2005) kamen zu dem Ergebnis, dass der TRG detailierte Informationen über den Effekt der RCT liefert und zudem als Ergebnis hatte, dass die Tumorregression stärker nach einer längerfristigen RCT als nach einer Kurzzeitradiatio ausgeprägt ist $(p=0,02)$. Es konnte nachgewiesen werden, dass der TRG ein Prädiktor für das OS und das DFS ist und bei Patienten mit positivem Nodalstatus und ohne dem Nachweis von Fernmetastasen in Einzelfällen eine Möglichkeit bietet, nach stattgehabter neoadjuvanter RCT eine konservativere Prozedur wie eine lokale Exzision anstatt einer radikalen Operation zu durchzuführen (Vecchio et al. 2005). Es stellt sich dabei jedoch die Problematik, dass ein TRG lediglich zur Verfügung steht, wenn zuvor eine Operation erfolgte. Weiterhin gelingt es bisher nicht, eine vollständige Tumorregression, die einem TRG4 nach Dworak entspricht, mittels Positronen-Emissions-Tomographie-Computertomographie (PET-CT) oder MRT zu detektieren. In einer Studie von Habr-Gama et al. (2013) wurden die Langzeitergebnisse von 70 Patienten mit einem T2-4NO-2MO-Stadium eines Rektumkarzinoms (nicht höher als $7 \mathrm{~cm}$ ab Anokutanlinie) untersucht, die lediglich eine neoadjuvante RCT bestehend aus einer Radiatio von 54Gy und einer Chemotherapie mit 5-FU und Leukovorin erhielten. Dabei zeigten 47 Patienten (67\%) klinisch ein komplettes Ansprechen. Insgesamt entwickelten jedoch 43\% der Patienten Rezidive. Diese Studie ist zudem durch das vergleichsweise kurze Follow-Up und die geringe Anzahl an Patienten limitiert. Daher muss in weiteren Studien untersucht werden, wie ein konservativeres Prozedere zukünftig eine ernsthafte Therapieoption darstellt.

Eine Arbeit von Perez et al. (2013) zeigte zudem, dass es bei Patienten mit einem Rektumkarzinom im Stadium CT2-4NO-2MO im Rahmen von koservativeren Prozeduren wie der transanalen 
endoskopischen Mikrochirurgie bei 15\% der Patienten zu Lokalrezidiven nach einem medianen FollowUp von 15 Monaten kam. Somit stellt diese Behandlungsform lediglich im Einzelfall unter strengster Indikationsstellung eine Alternative zur operativen Standardtherapie mittels TME dar.

Aufgrund der überschaubaren Datenlage war das Ziel dieser Untersuchung, eine Aussage über ein mögliches prädiktives und prognostisches Potenzial von SRC im lokal fortgeschrittenen Rektumkarzinom zu treffen.

Es konnte dabei kein Zusammenhang zwischen der SRC-Expression und einer Downkategorisierung unter einer neoadjuvanten RCT registriert werden. Zudem konnte keine Korrelation zwischen der Expression von SRC und dem TRG beobachtet werden. So ließ sich zwar in der Zytosolfärbung der Biopsie eine Korrelation zwischen der Höhe der SRC-Expression mit dem Tumorregressionsgrad beobachten, ein statistisch signifikanter Zusammenhang besteht hierbei jedoch nicht $(p=0,39)$. Auch in der Membranfärbung der Biopsie konnte keine Korrelation ermittelt werden $(p=0,95)$. Somit ließ sich in dieser Arbeit kein Zusammenhang zwischen der Expression von SRC und dem TRG oder einer Downkategorisierung unter einer neoadjuvanten Therapie nachweisen.

Wie schon unter Punkt 3.4 im Ergebnis-Teil aufgezeigt (siehe Abbildung 11 und 12 S.45/46), kam es bei den 129 korrespondierenden Präparaten zu einer Zunahme der SRC-Expression unter der präoperativen RCT. Dabei konnte anhand des H-Scores auch eine Quantifizierung der Expressionszunahme ermöglicht werden. Auffallend war dabei, dass die Zunahme der Expression anhand des $\mathrm{H}$-Scores bei vielen Patienten nur marginal war. Ob die Zunahme der Expression daher tatsächlich ein schlechteres Ansprechen beim Patienten bedingt, ist bis zum jetzigen Zeitpunkt völlig unklar. Zudem gibt es aktuell keine vergleichbaren Forschungsarbeiten, die diese Fragestellung bisher untersucht haben, was eine Interpretation sowie eine Einordnung in den wissenschaftlichen Kontext bislang erschwert.

Hinzuzufügen ist, dass die Methode der IHC in dieser Arbeit lediglich die Anfärbung des SRC-Antigens widerspiegelt. Die IHC dient hierbei nicht der Überprüfung der SRC-Tyrosinkinaseaktivität, welche anhand anderweitiger Methoden untersucht werden müsste. Daher ist auch nicht ausreichend belegt, dass eine verstärkte Anfärbbarkeit von SRC eine vermehrte SRC-Kinaseaktivität bedingt und diese wiederum einen Einfluss auf das Outcome der Patienten hat.

In dieser Untersuchung konnte zudem nachgewiesen werden, dass es zu einer Zunahme der Expression unter der neoadjuvanten RCT gekommen ist. Ob dies jedoch durch die Vorbehandlung bedingt ist, lässt sich nicht verfizieren. Es zeigte sich in der Membranfärbung sowohl bei den korrespondierenden, als auch bei den nicht korrespondierenden Präparaten unter der neoadjuvanten RCT eine signifikante Zunahme der Expression.

Weiterhin bleibt allerdings unklar, ob eine vermehrte SRC-Expression eine Auswirkung auf das klinische Outcome hat. 
Aufgrund der bisher spärlichen Datenlage bezüglich des prädiktiven Potenzials von SRC, aber auch weiteren Biomarkern hinsichtlich ihres prädiktiven Nutzens folgt eine kurze Zusammenfassung über künftige potenzielle molekulare Marker:

Folkvord et al. (2010) konnten anhand von Microarray-Profilen mit Kinasesubstraten bei 21 von 86 Substraten signifikant höhere Phosphorylierungsspiegel aus präoperativen Rektumkarzinombiopsien bei schlecht ansprechenden Patienten (TRG 4-5; in dieser Arbeit fand die Bouzourene-Klassifikation Verwendung, die sich am TRG nach Mandard orientiert, was eine Vergleichbarkeit zusätzlich erschwert) gegenüber gut ansprechenden Patienten (TRG 1-2), die eine neoadjuvante RCT bestehend aus 5-FU, Oxaliplatin und Folinsäure erhielten, messen. Hierzu gehörten insbesondere Substrate des VEGFR-/ sowie des PI-3K/AKT-Pathways, darunter auch SRC8_Y477/483 ( $p=0,03)$, welches an dieser Stelle vom SRC-Substratprotein p85 phosphoryliert wurde. Diese Profilanalysen von Kinaseaktivitäten stellen möglicherweise neue Strategien dar, um das Ansprechen auf eine Therapie vorherzusagen, müssen allerdings noch in größer angelegten Studien bestätigt werden.

Carlomagno et al. (2010) zeigten anhand der IHC durch Biopsien von Patienten mit einem lokal fortgeschrittenen Rektumkarzinom, dass ein Pathological Complete Response (pCR) nach erfolgter neoadjuvanter RCT siginifikant mit einer erhöhten Expression der Thymidylatsynthase (TS) $(p=0,002)$ und des Ki-67-Proteins $(p=0,05)$ sowie mit einer geringen EGFR-Expression $(p=0,007)$ assoziiert war.

Bertolini et al. (2007) kamen ebenfalls anhand der IHC aus Biopsien vor und nach erfolgter präoperativer RCT zu dem Ergebnis, dass eine geringe p21-Expression, ein Mangel an EGFR-Expression nach RCT und ein hoher TRG nach Dworak signifikant zu einem verbesserten DFS und OS führten. Zudem nahmen die Autoren an, dass eine konstitutive p21-/ sowie EGFR-Expression nach durchgeführter RCT seltener mit einem TRG 3 und 4 assoziiert war und somit womöglich ein schlechteres Ansprechen im lokal fortgeschrittenen Rektumkarzinom vorhergesagt werden kann.

Smith et al. (2006) postulierten anhand von prätherapeutisch entnommenen Biopsien mittels IHC und TUNEL-Färbung, dass Patienten mit einer COX-2-Überexpression ein moderates oder schlechteres Ansprechen (TRG 3+4 nach Mandard) zeigten als Patienten mit einer normalen COX-2-Expression $(p=0,02)$. Außerdem war ein schlechtes Ansprechen eher wahrscheinlich, wenn Patienten niedrigere Level spontaner Apoptosen in der TUNEL-Färbung zeigten $(p=0,0007)$.

Huh et al. (2014) konnten mittels Reverse Transcriptase-Polymerase Chain Reaction (RT-PCR) an Rektumkarzinombiopsien vor präoperativer RCT nachweisen, dass unter 13 molekularen Markern lediglich eine CD44-Expression als signifikant unabhängiger Marker für ein schlechtes TRG-Ansprechen diente $(p=0,03)$. Zusätzlich konnte unter 118 Patienten, die eine radikale OP erhielten, gezeigt werden, dass das Proliferating Cellular Nuclear Antigen (PCNA) als einziger unabhängiger Faktor eventuell eine prädiktive Aussage hinsichtlich eines negativen Nodalstatus treffen könnte $(p=0,03)$. 
Weiterhin konnte die eigene Arbeitsgruppe zeigen, dass eine fehlende Downregulation des Apoptosehemmerproteins Survivin durch die RCT mit der Entwicklung von Fernmetastasen $(p=0,005)$ einherging (Sprenger et al. 2010).

In der vorliegenden Untersuchung gab es keine Korrelation zwischen der SRC-Expression und dem Tumorregressionsgrad. Weiterhin konnte unter der neoadjuvanten RCT kein Zusammenhang zwischen der Proteinexpression und einer Downkategorisierung beobachtet werden.

In der folgenden Tabelle (Tabelle 9, S.74) wird nochmal eine Übersicht über Biomarker mit einem möglichen prädiktiven Potenzial aufgezeigt: 


\begin{tabular}{|c|c|c|c|c|c|}
\hline \multicolumn{6}{|c|}{ Analysen möglicher prädiktiver molekularer Marker beim Rektumkarzinom } \\
\hline Autor & Fallzahl & Methode & Therapie & $\begin{array}{l}\text { Biomarker/ } \\
\text { untersuchte } \\
\text { Endpunkte }\end{array}$ & Ergebnisse \\
\hline $\begin{array}{l}\text { Folkvord et al. } \\
(2010)\end{array}$ & $n=67$ & $\begin{array}{l}\text { Microarray-Kinaseaktivitätsprofil, } \\
\text { Korrelation von } \\
\text { Substratphosphorylierungsspiegel } \\
\text { korreliert mit TRG 1-4 }\end{array}$ & $\begin{array}{l}\text { neoadj. RCT (5-FU, } \\
\text { ggf. Oxaliplatin) } \\
\text { nach Nordic FLOX- } \\
\text { Regime }\end{array}$ & $\begin{array}{l}\text { Substrate des } \\
\text { VEGFR-/PI3K-Akt- } \\
\text { pothwoys, Andere/ } \\
\text { Bouzourene- } \\
\text { Klassifikation; TRG } \\
\text { nach Mandard }\end{array}$ & $\begin{array}{l}\text { erhöhte } \\
\text { Phosphroylie- } \\
\text { rung bei } 21 \text { von } \\
86 \text { Substraten } \\
\text { bei schlecht } \\
\text { ansprechenden } \\
\text { Patienten }\end{array}$ \\
\hline $\begin{array}{l}\text { Carlomagno et } \\
\text { al. }(2010)\end{array}$ & $n=46$ & $\begin{array}{l}\text { IHC; Proteinexpression anteilig } \\
\text { (0-100\%) von Zellen mit } \\
\text { Zytoplasma-/Membran-/Kernfärbung }\end{array}$ & $\begin{array}{l}\text { neoadj. RCT } \\
\text { (Capecitabin/ } \\
\text { Oxaliplatin) }\end{array}$ & $\begin{array}{l}\text { EGFR,VEGF, TS, } \\
\text { Ki67/ } \\
\text { pCR; } \\
\text { TRG nach Mandard }\end{array}$ & $\begin{array}{l}\text { pCR assoziiert } \\
\text { mit hoher TS-/ } \\
\text { Ki67-Expression } \\
\text { und niedriger } \\
\text { EGFR- } \\
\text { Expression }\end{array}$ \\
\hline $\begin{array}{l}\text { Smith et al. } \\
(2006)\end{array}$ & $n=49$ & $\begin{array}{l}\text { IHC: Einteilung der Färbeintensitāt in } \\
\text { vier Grade: } 0 \%,<10 \%, 10-50 \%,>50 \% \\
\text { TUNEL-Färbung: apoptotischer Index } \\
\text { (AI), Anteil von Apoptosomen pro } \\
1000 \text { Zellen unter Lichtmikroskopie }\end{array}$ & neoadj. RCT (5-FU) & $\begin{array}{l}\text { COX-2, Apoptose/ } \\
\text { TRG nach Mandard }\end{array}$ & $\begin{array}{l}\text { COX-2- } \\
\text { Überexpression } \\
\text { mit } \\
\text { moderatem/ } \\
\text { schlechten } \\
\text { Ansprechen } \\
\text { (TRG 3+4); hohe } \\
\text { Rate an } \\
\text { Spontanapop- } \\
\text { tosen assoziiert } \\
\text { mit gutem } \\
\text { Ansprechen }\end{array}$ \\
\hline $\begin{array}{l}\text { Bertolini et al. } \\
(2007)\end{array}$ & $\mathrm{n}=91$ & $\begin{array}{l}\text { IHC; Expression der prozentualen } \\
\text { Anfärbung von Tumorzellen; negativ/ } \\
\text { positiv bei EGFR ( }<1 \% \text { vs. } \geq 1 \% \text { ), VEGF } \\
\text { und p } 53 \text { ( } \leq 10 \% \text { vs. }>10 \% \text { ), TS ( } \leq 15 \% \\
\text { vs. }>15 \% \text { ), p } 21 \text { ( } \leq 20 \% \text { vs. }>20 \% \text { ) }\end{array}$ & neoadj. RCT (5-FU) & $\begin{array}{l}\text { EGFR, VEGF, p53, } \\
\text { TS, p21/ } \\
\text { DFS, OS, TRG nach } \\
\text { Dworak }\end{array}$ & $\begin{array}{l}\text { niedrige p21- } \\
\text { Expression, } \\
\text { fehlende EGFR- } \\
\text { Expression und } \\
\text { hoher TRG nach } \\
\text { Dworak } \\
\text { assoziiert mit } \\
\text { verlăngertem } \\
\text { DFS/OS }\end{array}$ \\
\hline $\begin{array}{l}\text { Huh et al. } \\
\text { (2014) }\end{array}$ & $n=123$ & $\begin{array}{l}\text { RT-PCR: Nachweis des } \\
\text { Tumorzellanteils }>20 \% \text { des } \\
\text { Gewebevolumens der Biopsie } \\
\text { gegenüber eingefrorenem Anteil vor } \\
\text { RNA-Extraktion }\end{array}$ & $\begin{array}{l}\text { neoadj. RCT (5-FU/ } \\
\text { Leukovorin) }\end{array}$ & $\begin{array}{l}\text { mRNA von TS, bax, } \\
\text { p53, VEGF,MMP-2, } \\
\text { Survivin, CD133, } \\
\text { CD44, COX-2/ } \\
\text { TNM-downstaging, } \\
\text { TRG nach Dworak }\end{array}$ & $\begin{array}{l}\text { CD44-mRNA- } \\
\text { Expression } \\
\text { assoziiert mit } \\
\text { gutem } \\
\text { Ansprechen } \\
\text { (TRG4) }\end{array}$ \\
\hline $\begin{array}{l}\text { Sprenger et al. } \\
(2010)\end{array}$ & $n=116$ & $\begin{array}{l}\text { IHC: Einteilung der Färbeintensităt in } \\
\text { drei Grade: } 1+(\text { schwach), } 2+ \\
\text { (moderat), } 3+\text { (Intensiv); Einteilung } \\
\text { des Anteils Survivin-positiver Zellen } \\
\text { in vier Grade: } 1(0-25 \%), 2(25-50 \%) \text {, } \\
3(50-75 \%), 4(<75 \%)\end{array}$ & $\begin{array}{l}\text { neoadj. RCT (5-FU } \\
\text { bzw. } 5 \text {-FU/ } \\
\text { Oxaliplatin) }\end{array}$ & $\begin{array}{l}\text { Survivin/ } \\
\text { pTNM, TRG nach } \\
\text { Dworak, DFS, CSS }\end{array}$ & $\begin{array}{l}\text { mangelnde } \\
\text { Runterregula- } \\
\text { tion assoziiert } \\
\text { mit Entwicklung } \\
\text { von } \\
\text { Fernmetastasen } \\
\text { sowie } \\
\text { verkürztem DFS } \\
\text { und CSS }\end{array}$ \\
\hline $\begin{array}{l}\text { eigene } \\
\text { Untersuchung } \\
\text { (2014) }\end{array}$ & $\mathrm{n}=186$ & $\begin{array}{l}\text { IHC: Einteilung der Färbeintensităt in } \\
\text { vier Grade: } \\
\text { Zytosol: } 0 \text { (keine), } 1 \text { (schwach), } 2 \\
\text { (stark), } 3 \text { (intensiv): Färbeintensität } \\
\text { und -anteil } \\
\text { Membran: } 0 \text { (keine Differenzierung } \\
\text { der Zellmembran), } 1 \text { (Abgrenzung bis } \\
\text { 20x Vergrößerung möglich), } 2 \\
\text { (Abgrenzung bis } 40 x \text { Vergrößerung } \\
\text { möglich), } 3 \text { (keine Abgrenzung bei } \\
40 x \text { Vergrößerung) }\end{array}$ & $\begin{array}{l}\text { neoadj. RCT (5-FU } \\
\text { bzw. 5-FU/ } \\
\text { Oxaliplatin) }\end{array}$ & $\begin{array}{l}\text { SRC/ } \\
\text { pTNM, TRG nach } \\
\text { Dworak, DFS, CSS }\end{array}$ & n.s. \\
\hline
\end{tabular}


Tabelle 9: Übersicht über die aktuelle Studienlage hinsichtlich eines prädiktiven Potenzials von verschiedenen Biomarkern im lokal fortgeschrittenen Rektumkarzinom:

Diese Tabelle bezieht sich lediglich auf Untersuchungen, die ausschließlich Patienten mit einer Tumorlokalisation im Rektum einschließen.

(Al - apoptotischer Index, bax - Apoptoseprotein- CD44- Adhäsionsmolekül, CD133 - Glykoprotein, COX-2 Cyclooxygenase-2 , CSS- krankheitsspezifisches Überleben, DFS - krankheitsfreies Überleben, EGFR - epidermaler Wachstumsfaktorrezeptor, 5-FU - 5-Fluorouracil, IHC - Immunhistochemie, neaodj. - neoadjuvant, Ki-67 - Protein zur Darstellung von Mitosen, MMP-2- Matrix-Metalloproteinase-2, mRNA- messenger-Ribonukleinsäure, Nordic FLOX Regime - Chemotherapieregime bestehend aus Oxaliplatin, 5-Fluorouracil und Folinsäure, OS - Gesamtüberleben, p21Tumorsuppressorprotein, p53- Genexpressions-Transkriptionsfaktor, pCR - pathologische Komplettremission, PI3K-Aktmolekularer pathway, RCT - Radiochemotherapie, RNA - Ribonukleinsäure, RT-PCR - reverse Transkriptase- PolymeraseKetten-Reaktion, TRG - Tumorregressionsgrad, TS - Thymidylatsynthase, TUNEL - Methode zum Nachweis von Apoptosen, VEGF - vaskulärer Wachstumsfaktor)

Die Beobachtungen dieser Untersuchung bezüglich eines prädiktiven Potenzials von SRC im lokal fortgeschrittenen Rektumkarzinom werfen die Frage auf, ob und inwieweit SRC in Zukunft tatsächlich eine Rolle bezüglich der Prädiktion spielen könnte. Insofern kann spekuliert werden, ob und inwieweit ein prätherapeutisches und postoperatives SRC-Monitoring künftig eine Aussage über das Outcome des Patienten beim lokal fortgeschrittenen Rektumkarzinom zulassen würde. Bei einer Zunahme der SRC-Expression von der PE zum Resektat könnte perspektivisch möglicherweise ein therapeutischer SRC-Inhibitor künftig angewandt werden, wobei es äußerst fraglich erscheint, ob die Zunahme der SRC-Expression unter laufender neoadjuvanter Therapie allein ein schlechteres Outcome bedingt. Da bislang kaum vergleichbare Ergebnisse in der Literatur vorliegen, ist dieser Ausblick höchst spekulativ, hierzu bedarf es weiterer multizentrischer Untersuchungen mit möglichst groß angelegten Patientenkollektiven.

Die bisherigen wissenschaftlichen Untersuchungen hinsichtlich der Detektion von Biomarkern mit einem prädiktiven Potenzial beim lokal fortgeschrittenen Rektumkarzinom reichen bislang nicht aus, diese in den klinischen Alltag zu integrieren. Diese Tatsache ist dabei auf verschiedene Problematiken zurückzuführen. Zum einen bestehen die bisherigen Studien aus zu kleinen Fallzahlen, um eine allgemeingültige Aussage zu treffen. Zum anderen existieren keine standardisierten Methoden (verschiedene Cut-Off-Levels, unterschiedliche Anwendung der Einteilung des TRG). Weiterhin gibt es bisher lediglich eine überschaubare Anzahl an potenziellen Biomarkern für das lokal fortgeschrittene Rektumkarzinom (George und Kopetz 2011, Kuremsky et al. 2009). Zudem erschwert die molekularbiologische Komplexizität der verschiedenen Signalkaskaden das Verständis über die Pathogenese und mögliche neue Therapieformen des Rektumkarzinoms.

So bleibt festzuhalten, dass eine weitere intensive Auseinandersetzung mit neuen potenziellen Biomarkern auch zukünftig unabdingbar ist, um in einer Zeit der zunehmenden Individualisierung bei der Behandlung von Tumorerkrankungen neue Therapieformen und -zusammensetzungen zu gewährleisten. 


\subsubsection{Das prognostische Potenzial von SRC gemessen an den Follow-Up-Daten}

Zur Beurteilung des prognostischen Potenzials von SRC erfolgten Korrelationsanalysen mit den Follow-Up-Daten hinsichtlich des Langzeitverlaufs der Patienten. Aufgrund der erhobenen Daten konnte anhand von Kaplan-Meier-Kurven ein Zusammenhang zwischen der SRC-Expression und dem Auftreten von Lokalrezidiven und Fernmetastasen sowie dem DFS und CSS festgestellt werden. So zeigen die Ergebnisse dieser Untersuchung, dass eine vergleichsweise vermehrte SRC-Expression in PE und residuellem Tumor seltener mit Lokalrezidiven oder Bildung von Fernmetastasen assoziiert war und mit einem verlängerten DFS und CSS einherging. Hierbei wird die Dynamik der Hoch- oder Herunterregulation von SRC unter der RCT wie bei der Prädiktion außer Acht gelassen.

Auch die Untersuchungen von Theocharis et al. (2012) konnten bei Plattenepithelkarzinomen der Zunge nachweisen, dass eine vergleichsweise hohe SRC-Expression mit einem verlängerten OS $(p=0,01)$ sowie einem verlängerten DFS $(p=0,03)$ assoziiert war.

Im Gegensatz dazu wiesen de Heer et al. (2008) beim kolorektalen Karzinom nach, dass Patienten mit einer hohen Expression von SRC vermehrt zu einem Lokalrezidiv neigten $(p=0,03)$. In der vorliegenden Untersuchung war eine vergleichsweise hohe SRC-Expression mit weniger Lokalrezidiven assoziiert. Eine verstärkte Expression von FAK und SRC zeigten prognostisch zudem ein häufigeres Auftreten von Fernmetastasen $(p=0,004)$, während in der vorliegenden Untersuchung eine vermehrte Expression von SRC seltener mit Fernmetastasen einherging.

Allgayer et al. (2002) kamen zu dem Ergebnis, dass eine vergleichsweise hohe SRC-Expression signifikant mit dem $p T$-Status $(p=0,007)$, einem positiven $p N-S t a t u s(p=0,01)$ und mit einem verkürzten OS $(p=0,0004)$ assoziiert war. Das Patientenkollektiv umfasste 45 Personen, die allesamt primär operiert wurden. Die vorliegende Untersuchung lieferte die Erkenntnis, dass eine vermehrte SRCExpression mit einem negativen pN-Status und einem verlängerten DFS und CSS einherging.

Auch in weiteren Untersuchungen konnte gezeigt werden, dass eine vergleichsweise hohe SRCExpression prognostisch mit einem verkürzten Überleben korreliert. So wiesen Hou et al. (2013) beim Plattenepithelkarzinom der Cervix uteri nach, dass eine vermehrte Expression von phosphoryliertem c-SRC (phospho-c-SRC) einhergehend mit einer verstärkten Kinaseaktivität mit einem verkürzten DFS $(p=0,02)$ und einem verkürzten OS $(p=0,03)$ korrelierte. Auch beim Hepatozellulären Karzinom $(H C C)$ postulierten Chen et al. (2011), dass eine vermehrte phosphorylierte SRC-Expression (p-Tyr416-c-Src) mit einem verkürzten OS assoziiert war $(p=0,004)$.

Elsberger et al. (2011) zeigten beim Östrogenrezeptor-positiven Mammakarzinom, dass die zytoplasmatische SRC-Expression mit einem positiven Nodalstatus einherging $(p<0,001)$. Außerdem hatten Östrogenrezeptor-positive Patientinnen mit einer hohen zytoplasmatischen SRC-Expression ein 
kürzeres CSS gegenüber Patientinnen mit einer geringen zytoplasmatischen SRC-Expression nach der Beendigung der Behandlung mit Tamoxifen bis zum fünften Jahr nach der Operation $(p=0,02)$.

In der folgenden Tabelle (Tabelle 10, S.78) kommt es zur Darstellung der aktuellen Studienlage zum prognostischen Potenzial von SRC in verschiedenen Tumorentitäten: 


\begin{tabular}{|c|c|c|c|c|c|}
\hline \multicolumn{6}{|c|}{ Analysen des prognostischen Potenzials der Src-Expression in verschiedenen Tumorentitäten } \\
\hline Autor & Fallzahl & Methode & Karzinom-Entität & $\begin{array}{l}\text { Untersuchte } \\
\text { Endpunkte }\end{array}$ & Ergebnisse \\
\hline $\begin{array}{l}\text { Allgayer et } \\
\text { al. (2002) }\end{array}$ & $\begin{array}{l}\mathrm{n}=45 \\
\text { davon } \\
\mathrm{n}=28 \text { mit RO- } \\
\text { Resektion }\end{array}$ & $\begin{array}{l}\text { Immunkomplex-Kinase- } \\
\text { Assay, CART-Analyse }\end{array}$ & $\begin{array}{l}\text { Kolonkarzinom/ } \\
\text { Rektumkarzinom }\end{array}$ & $\begin{array}{l}\text { pT,pN,pM, DFS, } \\
\text { OS }\end{array}$ & $\begin{array}{l}\text { vermehrte SRC- } \\
\text { Expression korreliert mit } \\
\text { pT-,pN-pM-Stadium } \\
\text { sowie mit einem } \\
\text { verkürzten OS. } \\
\text { Vermehrte SRC- } \\
\text { Expression bei Patienten } \\
\text { (n=28) mit RO-Resektion } \\
\text { korreliert mit } \\
\text { verkürztem DFS }\end{array}$ \\
\hline $\begin{array}{l}\text { de Heer et } \\
\text { al. }(2008)\end{array}$ & $n=104$ & $\begin{array}{l}\text { IHC; Einteilung der } \\
\text { Intensităt der } \\
\text { Antikörperexpression in } \\
\text { vier Grade; Auswertung } \\
\text { der zellulären } \\
\text { Lokalisation und des } \\
\text { Anteils positiver Zellen }\end{array}$ & $\begin{array}{l}\text { Kolorektales } \\
\text { Karzinom }\end{array}$ & LR, DFS, OS & $\begin{array}{l}\text { erhöhte SRC-Expression } \\
\text { assozilert mit höherer } \\
\text { LR-Rate }\end{array}$ \\
\hline $\begin{array}{l}\text { Theocharis } \\
\text { et al. (2012) }\end{array}$ & $\mathrm{n}=48$ & $\begin{array}{l}\text { IHC; Immunoreaktivităt } \\
\text { anhand des Anteils SRC- } \\
\text { positiver Tumorzellen in } \\
\text { vier Grade; Einteilung } \\
\text { der Färbeintensität in } \\
\text { vier Grade }\end{array}$ & $\begin{array}{l}\text { Plattenpithelkarzi- } \\
\text { nom der Zunge }\end{array}$ & $\begin{array}{l}\text { klinikopathologi- } \\
\text { sche Parameter, } \\
\text { OS, DFS }\end{array}$ & $\begin{array}{l}\text { erhöhte SRC-Expression } \\
\text { korreliert mit längerem } \\
\text { OS und DFS }\end{array}$ \\
\hline $\begin{array}{l}\text { Ben-Izhak et } \\
\text { al. }(2010)\end{array}$ & $\mathrm{n}=39$ & $\begin{array}{l}\text { IHC; Einteilung des } \\
\text { Intensităts-scores in vier } \\
\text { Grade sowie Einteilung } \\
\text { des Anteil-scores in } \\
\text { sechs Grade nach dem } \\
\text { Allred Score }\end{array}$ & Zungenkarzinom & $\begin{array}{l}\text { pT,pN,pM, } \\
\text { OS }\end{array}$ & $\begin{array}{l}\text { erhöhte phospho-SRC- } \\
\text { Expression korreliert mit } \\
\text { Tumorgröße, positivem } \\
\text { Nodalstatus und } \\
\text { Fernmetastasie-rung; OS } \\
\text { bei Patienten mit } \\
\text { positivem phospho-SRC- } \\
\text { Kinaselevel niedriger als } \\
\text { bei Patienten mit } \\
\text { negativem phospho- } \\
\text { SRC-Kinaselevel }\end{array}$ \\
\hline $\begin{array}{l}\text { Cheng et al. } \\
\text { (2011) }\end{array}$ & $n=93$ & $\begin{array}{l}\text { IHC; SRC Protein labeling } \\
\text { index als Ratio zwischen } \\
\text { immunfärbe-positiven } \\
\text { Zellen gegenüber der } \\
\text { Anzahl aller gezählten } \\
\text { Zellen }\end{array}$ & $\begin{array}{l}\text { Mundhöhlenkarzi- } \\
\text { nom }\end{array}$ & $\begin{array}{l}\text { klinikopathologi- } \\
\text { sche Parameter, } \\
\text { CSS }\end{array}$ & $\begin{array}{l}\text { erhöhte SRC-Expression } \\
\text { assoziiert mit pT, } \\
\text { positivem Nodalstatus } \\
\text { und Fernmetastasie- } \\
\text { rung sowie mit } \\
\text { verkürztem CSS }\end{array}$ \\
\hline $\begin{array}{l}\text { Michailidi et } \\
\text { al. }(2010)\end{array}$ & $\mathrm{n}=108$ & $\begin{array}{l}\text { IHC; SRC-Expression } \\
\text { positiv wenn }>5 \% \text { der } \\
\text { Follikelzellen angefärbt }\end{array}$ & $\begin{array}{l}\text { Benigne/maligne } \\
\text { Schilddrüsener- } \\
\text { krankungen }\end{array}$ & pT,pN,pM, & $\begin{array}{l}\text { t-SRC-Positivität } \\
\text { signifikant verringert bei } \\
\text { Patienten mit T2-T4 } \\
\text { Tumor }\end{array}$ \\
\hline $\begin{array}{l}\text { Wilson et al. } \\
(2006)\end{array}$ & $n=129$ & $\begin{array}{l}\text { Western blotting, IHC; } \\
\text { Einteilung der } \\
\text { Färbeintensität in vier } \\
\text { Grade }\end{array}$ & $\begin{array}{l}\text { Duktales } \\
\text { Carcinoma in situ } \\
\text { bei } \\
\text { Mammakarzino- } \\
\text { men }\end{array}$ & $\begin{array}{l}\text { klinikopathologi- } \\
\text { sche Parameter, } \\
\text { DFS }\end{array}$ & $\begin{array}{l}\text { erhöhte SRC-Expression } \\
\text { korreliert mit } \\
\text { verkürztem 5-Jahres-DFS }\end{array}$ \\
\hline $\begin{array}{l}\text { Elsberger et } \\
\text { al. (2009) }\end{array}$ & $\mathrm{n}=314$ & $\begin{array}{l}\text { IHC; Einteilung der } \\
\text { Färbeintensität in vier } \\
\text { Grade }\end{array}$ & Mammakarzinom & $\begin{array}{l}\text { klinikopathologi- } \\
\text { sche Parameter, } \\
\text { CCS }\end{array}$ & $\begin{array}{l}\text { hohe c-SRC-Expression/ } \\
\text { erhöhte Y419-SRC- } \\
\text { Expression korreliert mit } \\
\text { verkürztem CSS; erhöhte } \\
\text { Y215-SRC-Expression } \\
\text { einhergehend mit } \\
\text { verlängertem CSS }\end{array}$ \\
\hline $\begin{array}{l}\text { Elsberger et } \\
\text { al. (2012) }\end{array}$ & $\mathrm{n}=392$ & $\begin{array}{l}\text { IHC; Einteilung der } \\
\text { Färbeintensität in vier } \\
\text { Grade }\end{array}$ & $\begin{array}{l}\text { ER-positives } \\
\text { Mammakarzinom }\end{array}$ & $\begin{array}{l}\text { klinikopathologi- } \\
\text { sche Parameter, } \\
\text { CSS }\end{array}$ & $\begin{array}{l}\text { erhöhte SRC-Expression } \\
\text { korreliert mit positivem } \\
\text { Nodalstatus und } \\
\text { verkürztem CSS }\end{array}$ \\
\hline
\end{tabular}




\begin{tabular}{|c|c|c|c|c|c|}
\hline Autor & Fallzahl & Methode & Karzinom-Entität & $\begin{array}{l}\text { Untersuchte } \\
\text { Endpunkte }\end{array}$ & Ergebnisse \\
\hline $\begin{array}{l}\text { Morgan et } \\
\text { al. (2009) }\end{array}$ & $n=75$ & $\begin{array}{l}\text { Zelllinien, Western } \\
\text { blotting, Zellwachstums- } \\
\text { Assays, } \\
\text { Immunzytochemie, IHC; } \\
\text { Einteilung unbekannt }\end{array}$ & Mammakrzinom & $\begin{array}{l}\text { Klinikopathologi- } \\
\text { sche Parameter, } \\
\text { OS }\end{array}$ & $\begin{array}{l}\text { Erhöhte SRC-Expression } \\
\text { assoziiert mit } \\
\text { verkürztem OS bei ER- } \\
\text { positiven Patientinnen }\end{array}$ \\
\hline $\begin{array}{l}\text { Zhang et al. } \\
\text { (2012) }\end{array}$ & $n=102$ & $\begin{array}{l}\text { IHC; Einteilung der } \\
\text { Färbeintensităt in vier } \\
\text { Grade sowie Einteilung } \\
\text { des Anteils positiver } \\
\text { Tumorzellen in drei } \\
\text { Grade }\end{array}$ & $\begin{array}{l}\text { metastasiertes } \\
\text { Mammakarzinom }\end{array}$ & $\begin{array}{l}\text { Klinikopathologi- } \\
\text { sche Parameter, } \\
\text { DSS }\end{array}$ & $\begin{array}{l}\text { Erhöhte SRC-Expression } \\
\text { verbunden mit } \\
\text { verkürztem DSS bei } \\
\text { Patientinnen mit ossär } \\
\text { metastasiertem } \\
\text { Mammakarzi- } \\
\text { nom }\end{array}$ \\
\hline $\begin{array}{l}\text { Chen et al. } \\
\text { (2011) }\end{array}$ & $n=85$ & $\begin{array}{l}\text { IHC; Einteilung der } \\
\text { Färbeintensităt in drei } \\
\text { Grade }\end{array}$ & $\begin{array}{l}\text { Hepatozelluläres } \\
\text { Karzinom (HCC) }\end{array}$ & $\begin{array}{l}\text { Klinikopathologi- } \\
\text { sche Parameter, } \\
\text { OS }\end{array}$ & $\begin{array}{l}\text { erhöhte aktivierte SRC- } \\
\text { Expression korreliert mit } \\
\text { verkürztem OS, }\end{array}$ \\
\hline $\begin{array}{l}\text { Chatzizacha- } \\
\text { rias et al. } \\
(2010)\end{array}$ & $n=65$ & $\begin{array}{l}\text { IHC; SRC-Expression } \\
\text { positiv wenn }>5 \% \text { der } \\
\text { Tumorzellen angefărbt; } \\
\text { Einteilung der } \\
\text { Färbeintensităt in } 3 \\
\text { Grade }\end{array}$ & $\begin{array}{l}\text { Duktales } \\
\text { Pankreasadeno- } \\
\text { karzinom }\end{array}$ & $\begin{array}{l}\text { Klinikopathologi- } \\
\text { sche Parameter, } \\
\text { OS }\end{array}$ & $\begin{array}{l}\text { SRC-Expression } \\
\text { assoziiert mit pT; } \\
\text { erhöhte SRC-Expression } \\
\text { korreliert mit niedrigen } \\
\text { T-Stadium; SRC- } \\
\text { Expression } \\
\text { einhergehend mit } \\
\text { verkürztem OS }\end{array}$ \\
\hline $\begin{array}{l}\text { Hou et al. } \\
(2013)\end{array}$ & $\begin{array}{l}n=127, \text { davon } \\
\text { Plattenepi- } \\
\text { thelkarzi- } \\
\text { nom ( } n=87 \text { ), } \\
\text { Carcinoma in } \\
\text { situ ( } n=20 \text { ), } \\
\text { normales } \\
\text { Zervixgewe- } \\
\text { be ( } n=20)\end{array}$ & $\begin{array}{l}\text { IHC; Einteilung der } \\
\text { Färbeintensităt in vier } \\
\text { Grade; Einteilung des } \\
\text { Anteils der gefärbten } \\
\text { Zellen }\end{array}$ & $\begin{array}{l}\text { Plattenepithelkar- } \\
\text { zinom der Cervix } \\
\text { uteri }\end{array}$ & $\begin{array}{l}\text { LR, OS, DFS, pN- } \\
\text { Status }\end{array}$ & $\begin{array}{l}\text { erhöhte phospho-SRC- } \\
\text { Expression korreliert mit } \\
\text { LR sowie mit verkürztem } \\
\text { OS und DFS }\end{array}$ \\
\hline $\begin{array}{l}\text { Huang et al. } \\
\text { (2013) }\end{array}$ & $n=82$ & $\begin{array}{l}\text { IHC; Einteilung des } \\
\text { Anteils positiver Zellen } \\
\text { in fünf Grade }\end{array}$ & Ovarialkarzinom & $\begin{array}{l}\text { Klinikopathologi- } \\
\text { sche Parameter, } \\
\text { mittlere } \\
\text { Überlebenszeit }\end{array}$ & $\begin{array}{l}\text { Mittlere Überlebenszeit } \\
\text { von Patienten mit } \\
\text { Phospho-SRC-positiven } \\
\text { Tumoren länger als von } \\
\text { Patienten mit phospho- } \\
\text { SRC-negativen Tumoren }\end{array}$ \\
\hline $\begin{array}{l}\text { eigene } \\
\text { Untersu- } \\
\text { chung } \\
(2014)\end{array}$ & $n=186$ & $\begin{array}{l}\text { IHC: Einteilung der } \\
\text { Färbeintensităt in vier } \\
\text { Grade: } \\
\text { Zytosol: } 0 \text { (keine), } 1 \\
\text { (schwach), } 2 \text { (stark), } 3 \\
\text { (intensiv): } \\
\text { Färbeintensitāt und - } \\
\text { anteil } \\
\text { Membran: } 0 \text { (keine } \\
\text { Differenzierung der } \\
\text { Zellmembran), } 1 \\
\text { (Abgrenzung bis 20x } \\
\text { Vergrößerung möglich), } \\
2 \text { (Abgrenzung bis } 40 x \\
\text { Vergrößerung möglich), } \\
3 \text { (keine Abgrenzung bei } \\
40 x \text { Vergrößerung) }\end{array}$ & Rektumkarzinom & $\begin{array}{l}\text { Klinikopathologi- } \\
\text { sche Parameter, } \\
\text { DFS, CSS }\end{array}$ & $\begin{array}{l}\text { vermehrte SRC- } \\
\text { Expression assoziiert mit } \\
\text { weniger LK-/ } \\
\text { Fernmetastasen, } \\
\text { weniger Lokalrezidive, } \\
\text { verlängertes DFS und } \\
\text { CSS, }\end{array}$ \\
\hline
\end{tabular}

Tabelle 10: Übersicht über die aktuelle Studienlage hinsichtlich eines prognostischen Potenzials von SRC in den verschiedenen Tumorentitäten:

Alle in der Tabelle aufgeführten Ergebnisse sind statistisch signifikant $(p \leq 0,05)$.

Diese Tabelle zeigt lediglich zwei Vergleichsstudien über das prognostische Potenzial von SRC beim kolorektalen Karzinom.

(CSS- Karzinomspezfisches Überleben, DFS- Krankheitsfreies Überleben, ER- Estrogenrezeptor-positiv, HCCHepatozelluläres Karzinom, IHC- Immunhistochemie, LR- Lokalrezidiv, OS- Gesamtüberleben, RO- Resektion des Tumors im Gesunden ohne histopathologischen Nachweis von Tumorgewebe im Resektionsrand) 
Die in der Tabelle aufgeführten Ergebnisse zeigen, dass die Rolle von SRC in verschiedenen Tumorentitäten bei unterschiedlichen Therapiestrategien untersucht wurde. Daher kann das Ausmaß der SRC-Expression möglicherweise auch eine unterschiedliche Bedeutung haben. Derzeit ist die Anzahl von Untersuchungen über die Bedutung von SRC im lokal fortgeschrittenen Rektumkarzinom limitiert. Festzuhalten ist, dass die Mehrzahl der bisherigen Ergebnisse vermuten lassen, dass eine vergleichsweise hohe SRC-Expression in den unterschiedlichen Tumorentitäten mit einem schlechteren Outcome beim Patienten assoziiert zu sein scheint. Allerdings ist hinzuzufügen, dass lediglich in zwei weiteren Arbeiten das prognostische Potenzial von SRC im kolorektalen Karzinom untersucht wurde. So war in der Untersuchung von Allgayer et al. (2002) lediglich ein Kollektiv von 45 Patienten eingeschlossen. Hierbei handelte es sich bei 32 Patienten um ein Kolonkarzinom und nur bei 13 Patienten um ein Rektumkarzinom. Alle 45 Patienten wurden primär operiert und erhielten weder eine prä-, noch eine postoperative RCT. Dabei war eine vergleichsweise hohe SRC-Expression mit dem pT- und pN-Status sowie einem verkürzten OS assoziiert. In der Arbeit von de Heer et al. (2008) wurde nicht zwischen einem Kolon- und einem Rektumkarzinom differenziert, sondern lediglich der Begriff „Kolorektales Karzinom“ verwendet. Auch dieses Kollektiv wurde primär operiert und nicht mittles Chemo- oder Strahlentherapie behandelt. Somit ist die Vergleichbarkeit zwischen dieser Untersuchung und den beiden weiteren Artikeln über die Rolle von SRC beim Rektumkarzinom erschwert. Hinzu kommt, dass neben den unterschiedlichen Methoden auch das festgesetzte CutOff-Level variierte.

In der vorliegenden Untersuchung war eine vermehrte SRC-Expression mit einem verlängerten DFS und CSS assoziiert und ging seltener mit Lokalrezidiven, LK- oder Fernmetastasen einher. Dabei ist abermals kritisch zu hinterfragen, ob allein eine erhöhte SRC-Expression ein besseres Outcome beim Patienten bedingt. Auch ist nochmals zu erwähnen, dass die Methode der Immunhistochemie lediglich eine Aussage über die Expression von SRC trifft, nicht jedoch über deren Kinaseaktivität.

Weiterhin wurde die Vergleichbarkeit zwischen den in der Tabelle dargestellten Ergebnissen durch die Tatsache erschwert, dass teilweise unterschiedliche Aktivierungszustände von SRC in den einzelnen Studien verwendet wurden (c-SRC, Y419-SRC, Y215-SRC, Y416-SRC, Y527-SRC)

Außerdem konnte bei einigen Analysen zwsichen verschiedenen Färbungen unterschieden werden. So zeigte sich in der Arbeit von Elsberger et al. (2009), dass eine hohe Membranexpression bei Y419SRC mit einem kürzeren CSS $(p=0,02)$ assoziiert war, während eine ausgeprägte nukleäre und zytoplasmatische Expression von Y215-SRC mit einem verlängerten CSS $(p=0,001)$ korrelierte. Somit muss folglich berücksichtigt werden, dass die unterschiedlichen Färbungen eine Vergleichbarkeit zusätzlich erschweren.

In der vorliegenden Arbeit konnte ein prognostisches Potenzial von SRC gezeigt werden. Derzeit liegen lediglich zwei Arbeiten vor, die die Rolle von SRC im Rektumkarzinom untersuchten. Auch ist 
nicht gesichert, dass eine vergleichsweise hohe SRC-Expression allein ein besseres bzw. schlechteres Outcome bei Patienten mit einem Rektumkarzinom bedingt. Hierfür sind weitere Untersuchungen notwendig, um die Rolle von SRC im Rektumkarzinom aber auch in anderen Tumorentitäten näher beschreiben zu können. Wünschenswert wären dabei insbesondere Arbeiten, die sowohl den Phosphorylierungsstatus als auch die unterschiedlichen Färbungslokalisationen (Membranfärbung, zytoplasmatische Färbung, nukleäre Färbung) von SRC berücksichtigen. Auch muss der Aspekt der SRC-Inhibition weiterhin untersucht werden. Dabei müsste erst geprüft werden, ob und inwieweit eine SRC-Inhibition eine individualisierte Therapieoption zur weiteren Prognoseverbesserung darstellen könnte.

Aufgrund der Tatsache, dass es sich hierbei um rein retrospektive Untersuchungen handelt, ist es essenziell, weitere Untersuchungen in vivo sowie in vitro durchzuführen. So könnte eine prospektive Validierung weitere Aussagen über die Rolle von SRC sowohl beim Rektumkarzinom als auch bei weiteren Tumorentitäten treffen.

\subsection{Bedeutung und Relevanz für den klinischen Alltag}

Die Ergebnisse dieser Arbeit zeigten ein prognostisches Potenzial von SRC im lokal fortgeschrittenen Rektumkarzinom auf. Es konnte statistisch signifikant sowohl in der zytosolischen Färbung als auch in der Membranfärbung eine Hochregulation von SRC unter der neoadjuvanten RCT beobachtet werden. Weiterhin konnte konstatiert werden, dass eine vergleichsweise hohe SRC-Expression in der prätherapeutischen Biopsie sowohl in der zytosolischen Färbung $(p=0,005)$ als auch in der Membranfärbung $(0,021)$ statistisch signifikant seltener mit LK-Metastasen einherging. Auch konnte nachgewiesen werden, dass eine vergleichsweise hohe SRC-Expression im residuellen Tumor in der zytosolischen Färbung seltener mit einem Auftreten von Fernmetastasen $(p=0,048)$ assoziiert war. Außerdem wurde in dieser Analyse festgestellt, dass eine vermehrte SRC-Expression mit einem verlängerten CSS und DFS korrelierte. Weiterhin zeigte sich, dass Patienten, die eine intensivierte neoadjuvante RCT erhielten, von einer vermehrten SRC-Expression in der prätherapeutischen Biopsie hinsichtlich eines negativen Nodalstatus profitierten.

Somit bleibt festzuhalten, dass in dieser Untersuchung eine vermehrte SRC-Expression mit einem verbesserten Outcome assoziiert war. Das Ergebnis könnte dahingehend interpretieren werden, dass Patienten mit einer vermehrten SRC-Expression womöglich einer anti-SRC-gerichteten Therapie zugeführt werden könnten, da die Zellen unter dem Einfluss von SRC vermehrt proliferieren und eventuell auf eine zielgerichtete Therapie besser ansprechen. Bei Patienten mit einer geringeren SRC-Expression wären vermutlich alternative therapeutische Ansätze anzustreben.

Lediglich in zwei Vergleichsstudien wurde das prognostische Potenzial von SRC beim kolorektalen Karzinom untersucht. Bei weiteren Studien konnte bei verschiedenen Tumorentitäten nachgewiesen 
werden, dass eine vergleichsweise hohe SRC-Aktivität prognostisch mit einem schlechteren Outcome beim Patienten assoziiert war.

Bei der Interpretation der Ergebnisse dieser Arbeit ist kritisch zu hinterfragen, ob die Expression von SRC einen Einfluss auf das Outcome hat. Deshalb sind zusätzliche Methoden zur Untersuchung von SRC unabdingbar, um weitere Aussagen über dieses Protein tätigen zu können. So könnte beispielsweise mittels eines SRC-Gen-Knockdowns oder -Knockouts überprüft werden, welchen Einfluss das Ausschalten des Gens auf die Prognose bei Rektumkarzinomzellen in vivo bzw. in vitro hat. Weiterhin könnten in vitro-Studien die Eignung von SRC als Target überprüfen. So könnten Rektumkarzinomzelllinien mit einem SRC-Antagonisten behandelt werden, um anschließend zu beobachten, ob und inwieweit SRC-Antagonisten einen Einfluss auf das Überleben der Zellen hätten. 


\section{5) Zusammenfassung}

Die aktuelle Therapie des lokal fortgeschrittenen Rektumkarzinoms (klinisches Stadium cUICC-II/-III) erfolgt in Deutschland seit 2004 im Rahmen multimodaler Behandlungskonzepte. Diese umfassen eine präoperative, 5-FU-basierte Radiochemotherapie (RCT) gefolgt von einer onkologischen Rektumresektion (mit totaler mesorektaler Exzision) und einer adjuvanten, 5-FU-haltigen Chemotherapie. Ein derartiges therapeutisches Vorgehen wird durch die aktuellen 10-JahresErgebnisse der CAO-/ARO-/AIO-94-Studie der German Rectal Cancer Study Group bestätigt, die weiterhin eine signifikante Reduktion der lokoregionären Rezidivrate auf 7,1\% nach präoperativer RCT gegenüber 10,1\% mit postoperativer RCT $(p=0,048)$ zeigen. Das 10-Jahres-Gesamtüberleben liegt nach neoadjuvanter RCT bei 59,6\% gegenüber 59,9\% ( $p=0,85)$. Kein Unterschied ergibt sich in der Inzidenz von Fernmetastasen (29,8\% versus $29,6 \%, p=0,9)$ und dem tumorfreien Überleben.

Demzufolge besteht das vorrangige Ziel darin, langfristig eine Prognoseverbesserung beim lokal fortgeschrittenen Stadium durch Reduktion der Inzidenz von Fernmetastasen und einem verbesserten Gesamtüberleben zu erreichen. Trotz derzeitig intensivierter Maßnahmen in der multimodalen Therapie (z.B. durch Erweiterung der Chemotherapie durch Oxaliplatin) wird aufgrund der ausgeprägten Heterogenität der individuellen Tumorbiologie bei bis zu $40 \%$ aller Patienten ein schlechtes oder gar fehlendes Therapieansprechen beobachtet. Somit müssen gerade für PoorResponder oder Non-Responder neue Therapiekonzepte entwickelt werden, die auf der Erkennung eines individuellen Risikoprofils basieren. Dabei stehen vor allem die Etablierung von Biomarkern und die Anwendung neuer zielgerichteter Therapien im Vordergrund.

Ein vielversprechendes Target stellt dabei die Tyrosinkinase SRC dar. SRC ist das am längsten bekannte Protoonkogen, welches für die gleichnamige Tyrosinkinase kodiert. SRC ist in einer Vielzahl an Tumoren überexprimiert und interagiert mit zahlreichen inter- und intrazellulären Signalkaskaden, die letztlich - bedingt durch eine erhöhte Zellinvasion und -mobilität - eine gesteigerte Tumorprogression zur Folge haben. Von besonderem Interesse ist die Interaktion von SRC mit dem EGFR-Pathway, die auch klinisch-therapeutisch zukünftig eine Rolle spielen könnte.

Die Expression der SRC-Tyrosinkinase kann mittels immunhistochemischer Färbung untersucht werden. Die Immunhistochemie ist dabei ein ubiquitär verfügbares und ein vergleichsweise kostengünstiges Verfahren, um die Expression von Proteinen in biologischen Materialien nachzuweisen. Die Schwäche dieser Methode besteht darin, dass mangelnde etablierte Analysekriterien sowie eine fehlende Standardisierung der Färbemethoden weltweit zu hohen Interund Intraobservervariabilitäten führen können.

Das Ziel der vorliegenden Arbeit war es, das prädiktive und prognostische Potenzial des Biomarkers SRC beim lokal fortgeschrittenen Rektumkarzinom (cUICC-II/III-Stadium) zu untersuchen. 
Die Ergebnisse dieser Untersuchung demonstrieren einen prognostischen Nutzen aus der SRCExpression beim lokal fortgeschrittenen Rektumkarzinom. Diese Arbeit zeigt, dass eine vergleichsweise hohe SRC-Expression seltener mit Lokalrezidiven $(p=0,062)$, LK- $(p=0,005)$ und Fernmetastasen $(p=0,048)$ korrelierte. Weiterhin war eine vermehrte SRC-Expression mit einem verlängerten CSS $(p=0,059)$ und bei Patienten mit einem positiven Nodalstatus mit einem verlängerten DFS $(p=0,02)$ assoziiert. Zusätzlich profitierten Patienten mit intensivierter neoadjuvanter RCT von einer vermehrten prätherapeutischen SRC-Expression in der Biopsie hinsichtlich eines negativen Nodalstatus.

Diese Ergebnisse könnten zukünftig beispielsweise helfen, Patienten einer Rezidiv-Risiko-adaptierten adjuvanten Therapie zuzuführen und sollten innerhalb klinischer Studien weiter untersucht werden. Aufgrund von Einschränkungen bei der immunhistochemischen Methodik könnten weitere Untersuchungen in Rektumkarzinomgewebe hinsichtlich des Funktionsstatus von SRC klinisch relevant sein. Auch sollte eine Evaluation von SRC-Inhibitoren erfolgen, inwieweit diese therapeutisch in verschiedenen Tumorentitäten eine Rolle spielen könnten. 


\section{6) Anhang}

a) Aktuell gültige TNM-Klassifikation des Rektumkarzinoms nach Wittekind und Meyer,

\section{0, 7.Auflage}

TNM-Klassifikation nach Wittekind und Meyer 2010

Tis Carcinoma in situ; Tumor hat noch nicht die Lamina muscularis mucosae durchbrochen

T1 Tumor infiltriert Submukosa ohne Durchbruch in Muscularis propria

T2 Tumor durchbricht Muscularis propria

T3 Tumor durchbricht Muscularis propria bis in die Subserosa beziehungsweise in peri-

kolisches oder perirektales Gewebe

T4 Tumor infiltriert in andere Organe oder Strukturen mit möglicher Perforation des viszeralen Peritoneums

T4a - Tumor perforiert viszerales Peritoneum

$\mathrm{T} 4 \mathrm{~b}$ - Tumor infiltriert in andere Organe und andere Strukturen

NO Keine regionären LK-Metastasen nachweisbar

N1 Metastasen in 1 bis 3 regionären LK

$\mathrm{N} 1 \mathrm{a}$ - Metastase in 1 regionären LK nachweisbar

N1b - Metastase in $\mathbf{2}$ bis $\mathbf{3}$ regionären LK nachweisbar

N1C - Befall von nicht-peritonealisierten perirektalem bzw. perikolischem

Fettgewebe ohne regionäre LK-Metastasen mit Satellit(en) bzw. Knötchen

N2 Metastasen in $\geq 4$ regionären LK

N2a- Metastasen in 4-6 regionären LK

N2b- Metastasen in $>7$ regionären LK

M0 keine Fernmetastasen vorhanden

M1 Fernmetastasen vorhanden

M1a- Metastasen auf ein Organ beschränkt

M1b- Metastasen in > 1 Organ bzw. im Peritoneum 
b) Aktuell gültige UICC-Stadiengruppierung des Rektumkarzinoms nach Wittekind und Meyer, 2010, 7. Auflage

\begin{tabular}{|c|c|c|c|}
\hline \multicolumn{4}{|c|}{ Stadiengruppierung nach UICC (Wittekind und Meyer 2010) } \\
\hline Stadium 0 & Tis & No & Mo \\
\hline Stadium I & $\mathrm{T} 1, \mathrm{~T} 2$ & No & Mo \\
\hline Stadium IIA & T3 & No & Mo \\
\hline Stadium IIB & T4a & No & Mo \\
\hline Stadium IIC & T4b & NO & Mo \\
\hline Stadium III & jedes $T$ & N1, N2 & Mo \\
\hline \multirow[t]{2}{*}{ Stadium IIIA } & $\mathrm{T} 1, \mathrm{~T} 2$ & N1a & Mo \\
\hline & T1 & N2a & Mo \\
\hline \multirow[t]{3}{*}{ Stadium IIIB } & T3, T4a & N1 & Mo \\
\hline & $\mathrm{T} 2, \mathrm{~T} 3$ & N2a & Mo \\
\hline & $\mathrm{T} 1, \mathrm{~T} 2$ & $\mathbf{N} 2 \mathrm{~b}$ & Mo \\
\hline \multirow[t]{3}{*}{ Stadium IIIC } & T4a & N2a & Mo \\
\hline & T3, T4b & $\mathbf{N} 2 \mathrm{~b}$ & Mo \\
\hline & T4b & N1, N2 & Mo \\
\hline Stadium IVA & jedes $T$ & jedes $\mathrm{N}$ & M1a \\
\hline Stadium IVB & jedes $T$ & jedes $\mathbf{N}$ & M1b \\
\hline
\end{tabular}


c) TNM-Klassifikation des Rektumkarzinoms nach Wittekind und Sobin, 2002, 6.Auflage

\begin{tabular}{|c|c|}
\hline & TNM-Klassifikation nach Wittekind und Sobin (2002) \\
\hline TO & kein Anhalt für Primärtumor \\
\hline Tis & Carcinoma in situ; Infiltrationstiefe geht nicht über die Muscularis mucosae hinaus \\
\hline T1 & Tumor infiltriert Submukosa ohne Durchbruch in Muscularis propria \\
\hline $\mathrm{T} 2$ & Tumor infiltriert Muscularis propria \\
\hline T3 & Tumor durchbricht Muscularis propria und infiltriert Subserosa beziehungsweise das \\
\hline & Pararektale Gewebe \\
\hline T4 & Tumor infiltriert direkt angrenzende Organe und/oder das viszerale Peritoneum \\
\hline No & Keine regionären LK-Metastasen nachweisbar \\
\hline N1 & Metastasen in 1 bis 3 regionären LK nachweisbar \\
\hline N2 & Metastasen in $\geq 4$ regionären LK nachweisbar \\
\hline M0 & keine Fernmetastasen vorhanden \\
\hline M1 & Fernmetastasen vorhanden \\
\hline
\end{tabular}

\section{d) UICC-Stadiengruppierung des Rektumkarzinoms nach Wittekind und}

Sobin, 2002, 6.Auflage

\begin{tabular}{|llll|}
\hline Stadiengruppierung nach UICC (Wittekind und Sobin 2002) \\
Stadium 0 & Tis & N0 & M0 \\
Stadium I & T1, T2 & N0 & M0 \\
Stadium II & T3, T4 & N0 & M0 \\
Stadium IIIA & T1, T2 & N1 & M0 \\
Stadium IIIB & T3, T4 & N1 & M0 \\
& jedes T & N2 & M0 \\
Stadium IV & jedes T & jedes N & M1 \\
& & & \\
\hline & &
\end{tabular}




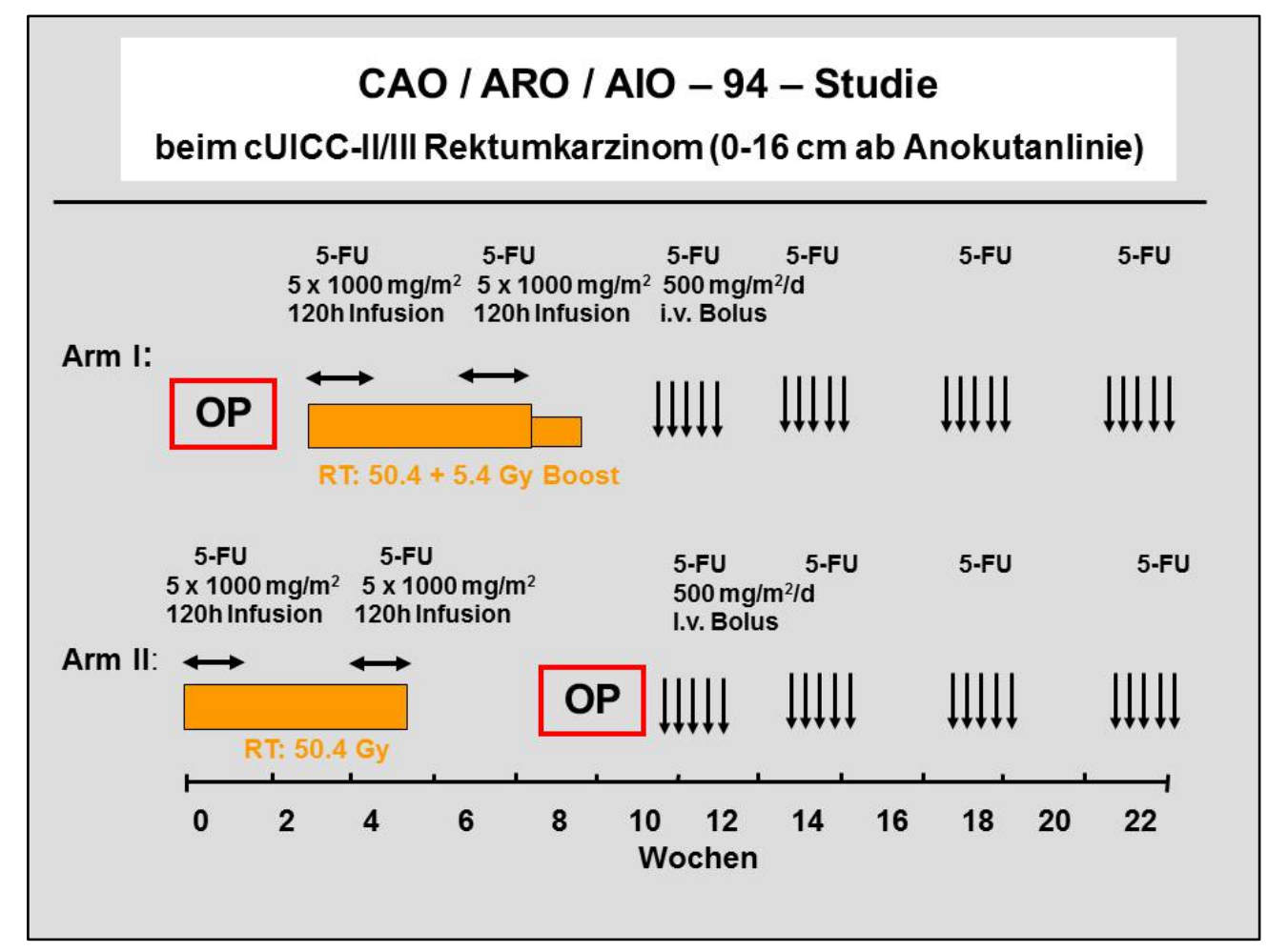

f) Studienprotokoll der CAO-/ARO-/AIO-04-Studie (Studiennummer: NCT00349076)

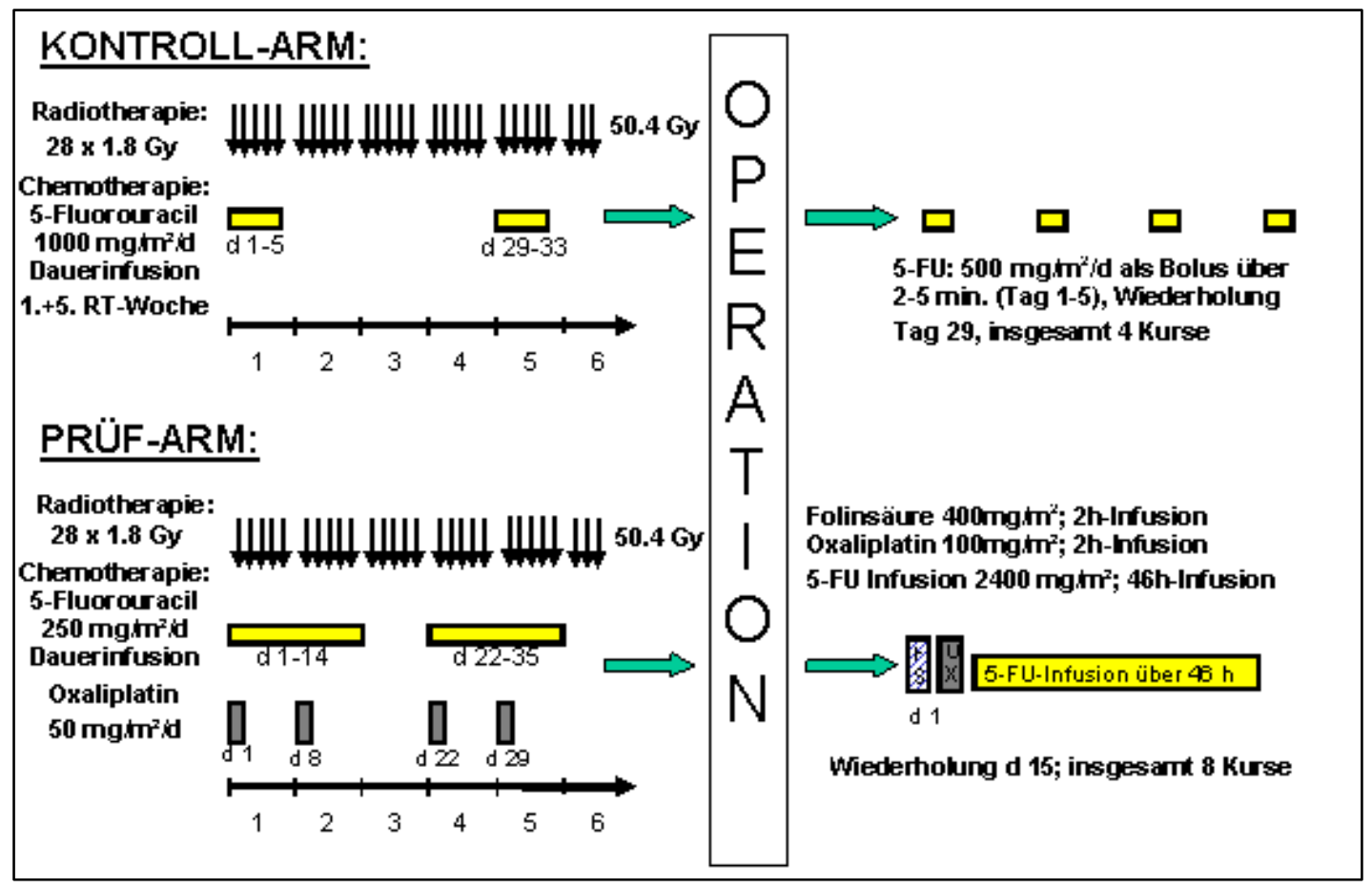




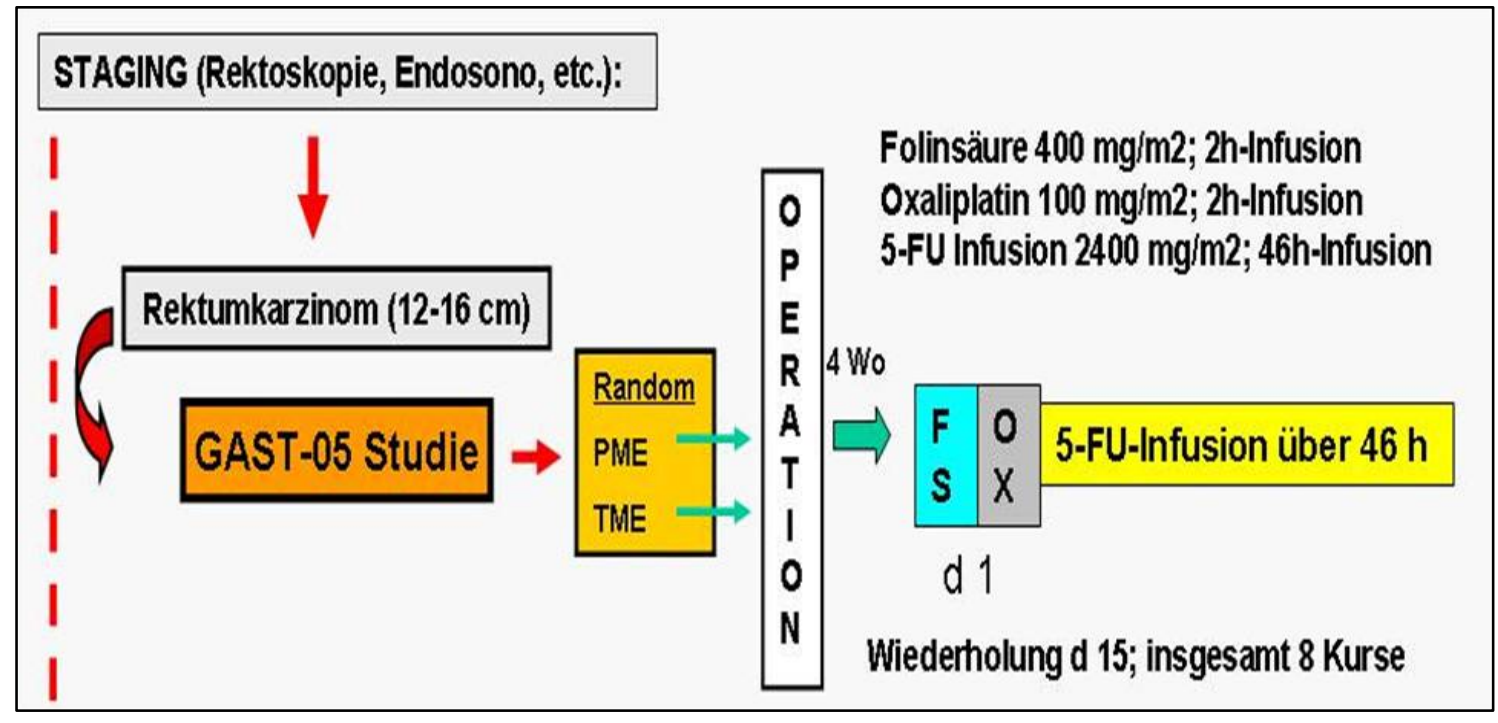




\section{h) Nachsorgeschema beim Rektumkarzinom}

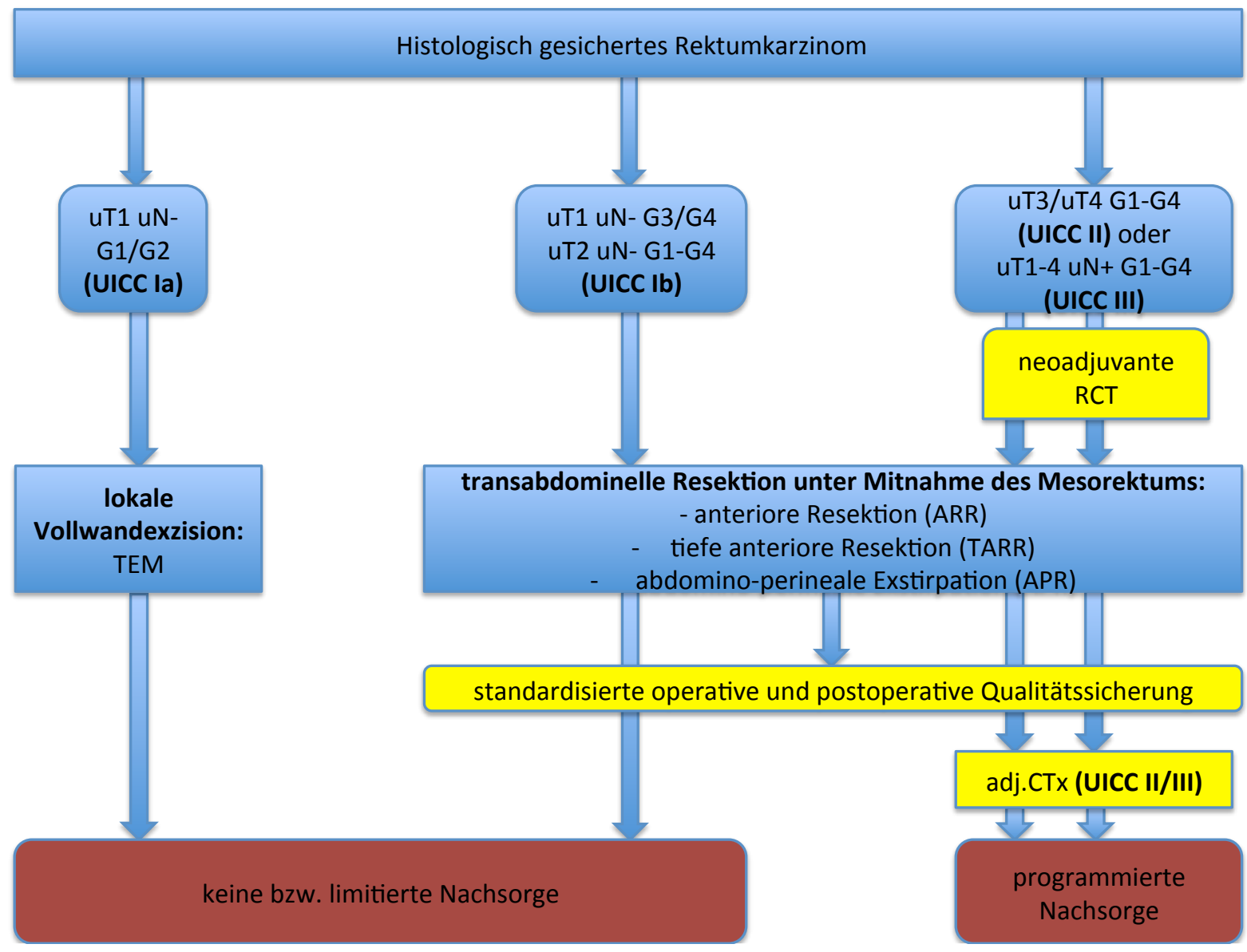

(Abbildung modifiziert nach Liersch et al. 2007, Seite 55) 


\section{7) Literaturverzeichnis}

Akimoto T, Hunter NR, Buchmiller L (1999): Inverse relationship between epidermal growth factor receptor expression and radiocurability of murine carcinomas. Clin Cancer Res 5, 2884-2890.

Aleshin A, Finn RS (2010): SRC: a century of science brought to the clinic. Neoplasia 12, 599-607.

Allgayer H, Boyd DD, Heiss MM, Abdalla EK, Curley SA, Gallick GE (2002): Activation of Src kinase in primary colorectal carcinoma: an indicator of poor clinical prognosis. Cancer $\underline{94}, 344-351$.

Argiris A, Feinstein TM, Wang L, Yang T, Agrawal S, Appleman LJ, Stoller RG, Grandis JR, Egloff AM (2012): Phase I and pharmacokinetic study of dasatinib and cetuximab in patients with advanced solid malignancies. Invest New Drugs 30, 1575-1584.

Becker H, Encke A, Röher HD: Viszeralchirurgie. 2. Auflage; Elsevier, Urban und Fischer, München 2006.

Belsches AP, Haskell MD, Parsons SJ (1997): Role of c-Src tyrosine kinase in EGF-induced mitogenesis. Front Biosci 2, 501-518.

Ben-Izhak O, Cohen-Kaplan V, Nagler RM (2010): The prognostic role of phospho-Src family kinase analysis in tongue cancer. J Cancer Res Clin Oncol 136, 27-34.

Berthold MR, Cebron N, Dill F, Gabriel TR, Kötter T, Meinl T, Ohl P, Sieb C, Thiel K, Wiswedel B (2007): KNIME: The Konstanz Information Miner. In Studies in Classification, Data Analysis, and Knowledge Organization. Springer

Bertolini F, Bengala C, Losi L, Pagano M, lachetta F, Dealis C, Jovic G, Depenni R, Zironi S, Falchi AM (2007): Prognostic and predictive value of baseline and posttreatment molecular marker expression in locally advanced rectal cancer treated with neoadjuvant chemoradiotherapy. Int J Radiat Oncol Biol Phys 68, 1455-1461.

Bild AH, Yao G, Chang JT, Wang Q, Potti A, Chasse D, Joshi MB, Harpole D, Lancaster JM, Berchuck A (2006): Oncogenic pathway signatures in human cancers as a guide to targeted therapies. Nature 439, 353-357.

Biscardi J, Belsches A, Parsons S (1998): Characterization of human epidermal growth factor receptor and c-Src interactions in human breast tumor cells. Mol Carcinog 21, 261-272.

Biscardi JS, Ishizawar RC, Silva CM, Parsons SJ (2000): Tyrosine kinase signalling in breast cancer. epidermal growth factor receptor and c-Src interactions in breast cancer. Breast Cancer Res 2 , 203210.

Bjorge J, Jakymiw A, Fujita D (2000): Selected glimpses into the activation and function of Src kinase. Oncogene 19, 5620-5635.

Brown DC, Gatter KC (2002): Ki-67 protein: The immaculate deception? Histopathology 40, 2-11.

Brown MT, Cooper JA (1996): Regulation, substrates and functions of src. Biochim Biophys Acta 1287, 121-149.

Bruns CJ, Kreis ME, Typmner C, Geinitz H, Adam M, Gross M, Michl GM, Walther J, Wiese-Junginger D, Göring H, et al.: Gastrointestinale Tumore - Empfehlungen zur Diagnostik, Therapie und Nachsorge., 8. Auflage; Zuckschwerdt Verlag, München 2010. 
Carlomagno C, Pepe S, D’Armiento FP, D’Armiento M, Cannella L, de Stefano A, Crispo A, Giordano $M$, de Placido $S$ (2010): Predictive factors of complete response to neoadjuvant chemoradiotherapy. Oncology $\underline{78}, 369-375$.

Chang Q, Jorgensen C, Pawson T, Hedley D (2008): Effects of dasatinib on EphA2 receptor tyrosine kinase activity and downstream signalling in pancreatic cancer. Br J Cancer 99, 1074-1082.

Chatzizacharias NA, Giaginis C, Zizi-Serbetzoglu D, Kouraklis GP, Karatzas G, Theocharis SE (2010): Evaluation of the clinical significance of focal adhesion kinase and SRC expression in human pancreatic ductal adenocarcinoma. Pancreas 39, 930-936.

Chen ML, Chai CY, Yeh KT, Wang SN, Tsai CJ, Yeh YT, Yang SF (2011): Crosstalk between activated and inactivated c-Src in hepatocellular carcinoma. Dis Markers 30, 325-333.

Cheng SJ, Kok SH, Lee JJ, Kuo MY, Cheng SL, Huang YL, Chen HM, Chang HH, Chiang CP (2011): Significant association of SRC protein expression with the progression, recurrence, and prognosis of oral squamous cell carcinoma in Taiwan. Head Neck 34, 1340-1345.

ClinicalTrials.gov (2006): Study of XL999 in Patients With Metastatic Colorectal Cancer. ClinicalTrials.gov Identifier: NCT00277303. Terminated study, First received: January 12, 2006; https://clinicaltrials.gov/ct2/show/NCT00277303?term=src+rectal+cancer\&rank=3

ClinicalTrials.gov (2007): FOLFOX Chemotherapy Regimen (5-FU, Leucovorin, Oxaliplatin) in Metastatic Colorectal Cancer. ClinicalTrials.gov Identifier: NCT00501410. Ongoing study, First received: July 12, 2007;

https://clinicaltrials.gov/ct2/show/NCT00501410?term=src+rectal+cancer\&rank=2

Conradi LC, Bleckmann A, Schirmer M, Sprenger T, Jo P, Homayounfar K, Wolff HA, Rothe H, Middel $P$, Becker H (2011): Thymidylate synthase as a prognostic biomarker for locally advanced rectal cancer after multimodal treatment. Ann Surg Oncol 18, 2442-2452.

Conradi LC, Styczen H, Sprenger T, Wolff HA, Rödel C, Nietert M, Homayounfar K, Gaedcke J, Kitz J, Talaulicar R (2013): Frequency of HER-2 positivity in rectal cancer and prognosis. Am J Surg Pathol 37, 522-531.

Cooper JA, Gould KL, Cartwright CA, Hunter T (1986): Tyr527 is phosphorylated in pp60c-src: implications for regulation. Science 231, 1431-1434.

Datta A, Huber F, Boettiger D (2002): Phosphorylation of beta3 integrin controls ligand binding strength. J Biol Chem 277, 3943-3949.

de Heer P, Koudijs MM, van de Velde CJ, Aalbers RI, Tollenaar RA, Putter H, Morreau H, van de Water B, Kuppen PJ (2008): Combined expression of the non-receptor protein tyrosine kinases FAK and SrC in primary colorectal cancer is associated with tumor recurrence and metastasis formation. Eur J Surg Oncol 34, 1253-1261.

Dehm S, Bonham K (2004): SRC gene expression in human cancer: the role of transcriptional activation. Biochem Cell Biol 82, 263-274.

Dimri M, Naramura M, Duan L, Chen J, Ortega-Cava C, Chen G, Goswami R, Fernandes N, Gao Q, Dimri GP (2007): Modeling breast cancer-associated c-Src and EGFR overexpression in human MECs: c-Src and EGFR cooperatively promote aberrant three-dimensional acinar structure and invasive behaviour. Cancer Res 67, 4164-4172.

Dunston RW, Wharton KA Jr, Quigley C, Lowe A (2012): The use of immunohistochemistry for biomarker assessment- can it compete with other technologies? Toxicol Pathol 39, 988-1002. 
Duxbury MS, Ito H, Zinner MJ, Ashley SW, Whang EE (2004): Inhibition of SRC tyrosine kinase impairs inherent and acquired gemcitabine resistance in human pancreatic adenocarcinoma cells. Clin Cancer Res 10, 2307-2318.

Dworak O, Keilholz L, Hoffmann A (1997): Pathological features of rectal cancer after preoperative radiochemotherapy. Int J Colorectal Dis $\underline{12}, 19-23$.

Elsberger B, Tan BA, Mitchel TJ, Brown SB, Mallon EA, Tovey SM, Cooke TG, Brunton VG, Edwards J (2009): Is expression or activation of Src kinase associated with cancer-specific survival in ER-, PRand HER2-negative breast cancer patients? Am J Pathol 175, 1389-1397.

Elsberger B, Paravasthu DM, Tovey SM, Edwards J (2011): Shorter disease-specific survival of ERpositive breast cancer patients with high cytoplasmic Src kinase expression after tamoxifen treatment. J Cancer Res Clin Oncol 138, 327-332.

Esposito G, Pucciarelli S, Alaggio R, Giacomelli L, Marchiori E, laderosa GA, Friso ML, Toppan P, Chieco-Bianchi L, Lise M (2001): P27kip1 expression is associated with tumor response to preoperative chemoradiotherapy in rectal cancer. Ann Surg Oncol 8, 311-318.

Fearon ER, Vogelstein B (1990): A genetic model for colorectal tumorigenesis. Cell 61, 759-767.

Fokas E, Liersch T, Fietkau R, Hohenberger W, Beissbarth T, Hess C, Becker H, Ghadimi M, Mrak K, Merkel S (2014): Tumor regression grading after preoperative chemoradiotherapy for locally advanced rectal carcinoma revisited: updated results of the CAO/ARO/AIO-94 trial. J Clin Oncol 32 , 1554-1562.

Folkvord S, Flatmark K, Dueland S, de Wijn R, Grøholt KK, Hole KH, Nesland JM, Ruijtenbeek R, Boender PJ, Johansen M (2010): Prediction of response to preoperative chemoradiotherapy in rectal cancer by multiplex kinase activity profiling. Int J Radiat Oncol Biol Phys. 78, 555-562.

Fuchs R, Guggenberger D, Neumann U, Trautwein C,: Diagnostik und Therapie gastrointestinaler Tumore 2014., 13. Auflage; Nora-Verlag, Stolberg 2014.

Gaedcke J, Liersch T, Hess C, Becker H, Rödel C, Ghadimi B (2011): Rektumkarzinom: Aktueller Stand der multimodalen Therapie - wann und wie? Zentralblatt für Chirurgie 136, 334-342.

Gavioli M, Bagni A, Piccagli I, Fundaro S, Natalini G (2000): Usefulness of endorectal ultrasound after preoperative radiotherapy in rectal cancer. Dis Colon Rectum 43, 1075-1083.

George B, Kopetz S (2011): Predictive and prognostic markers in colorectal cancer. Curr Oncol Rep 13, 206-215.

Gonfloni S, Weijland A, Kretzschmar J, Superti-Furga G (2000): Crosstalk between the catalytic and regulatory domains allows bidirectional regulation of Src. Nat Struct Biol $\mathbf{7}$, 281-286.

Habr-Gama A, Sabbaga J, Gama-Rodrigues J, São Julião GP, Proscurshim I, Bailão Aguilar P, Nadalin W, Perez RO (2013): Watch and wait approach following extended neoadjuvant chemoradiation for distal rectal cancer: are we getting closer to anal cancer management? Dis Colon Rectum 56, 11091117.

Han LY, Landen CN, Trevino JG, Halder J, Lin YG, Kamat AA, Kim TJ, Merritt WM, Coleman RL, Gershenson DM (2006): Antiangiogenic and antitumor effects of Src inhibition in ovarian carcinoma. Cancer Res 66, 8633-8639.

Hanahan D, Weinberg RA (2000): The hallmarks of cancer. Cell 100, 57-70. 
Hermanek P (1995): pTNM and residual tumor classifications: Problems of assessment and prognostic significance. World J Surg $\underline{19}, 184-190$

Hermanek P, Hohenberger W, Klimpfinger M, Kockerling F, Papadopoulos T (2003): The pathological assessment of mesorectal excision: implications for further treatment and quality management. Int J Colorectal Dis 18, 335-341.

Herynk MH, Beyer AR, Cui Y, Weiss H, Anderson E, Green TP, Fuqua SA (2006): Cooperative action of tamoxifen and c-Src inhibition in preventing the growth of estrogen receptor-positive human breast cancer cells. Mol Cancer Ther $\underline{5}$, 3023-3031.

Hilgers R, Bauer P, Scheiber V: Einführung in die medizinische Statistik., 2. Auflage; Springer Verlag, Berlin 2007.

Horne WC, Neff L, Chatterjee D, Lomri A, Levy JB, Baron R (1992): Osteoclasts express high levels of pp60c-Src in association with intracellular membranes. J Cell Biol 119, 1003-1013.

Hou T, Xiao J, Zhang H, Gu H, Feng Y, Li J (2013): Phosphorylated c-Src is a novel predictor for recurrence in cervical squamous cell cancer patients. Int J Clin Exp Pathol 6, 1121-1127.

Hsia DA, Mitra SK, Hauck CR, Streblow DN, Nelson JA, llic D, Huang S, Li E, Nemerow GR, Leng J (2003): Differential regulation of cell motility and invasion by FAK. J Cell Biol 160, 753-767.

Huang YW, Chen C, Xu MM, Li JD, Xiao J, Zhu XF (2013): Expression of c-Src and phospho-Src in epithelial ovarian carcinoma. Mol Cell Biochem 376, 73-79.

Huh JW, Lee JH, Kim HR (2014): Pretreatment expression of 13 molecular markers as a predictor of tumor responses after neoadjuvant chemoradiation in rectal cancer. Ann Surg 259, 508-515.

Ihaka R, Gentleman R (1996): R: A Language for Data Analysis and Graphics. Journal of Computational and Graphical Statistics 3, 299-314.

Irby R, Yeatman T (2002): Increased Src activity disrupts cadherin/catenin-mediated homotypic adhesion in human colon cancer and transformed rodent cells. Cancer Res 62, 2669-2674.

Ishibashi H, Suzuki T, Suzuki S, Moriya T, Kaneko C, Takizawa T, Sunamori M, Handa M, Kondo T, Sasano H (2003): Sex steroid hormone recptors in human thymoma. J Clin Endocrinol Metab 88, 2309-2317.

Ishizawar RC, Miyake T, Parsons SJ (2007): c-Src modulates ErbB2 and ErbB3 heterocomplex formation and function. Oncogene 26, 3503-3510.

Jemal A, Siegel R, Ward E, Hao Y, Xu J,Thun MJ (2009): Cancer statistics, 2009. CA Cancer J Clin 59, 225-49.

Jones RJ, Avizienyte E, Wyke AW, Owens DW, Brunton VG, Frame MC (2002): Elevated c-Src is linked to altered cell-matrix adhesion rather than proliferation in $\mathrm{KM} 12 \mathrm{C}$ human colorectal cancer cells. $\mathrm{Br} \mathrm{J}$ Cancer 87, 1128-1135.

Kanda S, Miyata Y, Kanetake H, Smithgall TE (2007): Non-receptor protein-tyrosine kinases as molecular targets for antiangiogenetic therapy. Int J Mol Med 20, 113-121.

Kim LC, Song L, Haura EB (2009): Src kinases as therapeutic targets for cancer. Nat Rev Clin Oncol $\underline{6}$, 587-595. 
Kloth MT, Laughlin KK, Biscardi JS, Boerner JL, Parsons SJ, Silva CM (2003): STAT5b, a mediator of synergism between c-Src and the epidermal growth factor receptor. J Biol Chem 278, 1671-1679.

Kopetz S, Shah AN, Gallick GE (2007): Src continues aging: current and future clinical directions. Clin. Cancer Res 13, 7232-7236.

Kuerbitz SJ, Plunkett BS, Walsh WV, Kastan MB (1992): Wild-type p53 is a cell cycle checkpoint determinant following irradiation. Proc Natl Acad Sci USA 89, 7491-7495.

Kuremsky JG, Tepper JE, McLeod HL (2009): Biomarkers for Response to Neoadjuvant Chemoradiation for Rectal Cancer. Int J Radiat Oncol Biol Phys 74, 673-688.

Lan KH, Lu CH, Yu D (2005): Mechanisms of trastuzumab resistance and their clinical implications. Ann N Y Acad Sci 1059, 70-75.

Lang G: histotechnik. praxislehrbuch für die biomedizinische analytik. 1. Auflage; Springer-Verlag, Wien/ New York 2006.

Lenz HJ, Danenberg KD, Leichman CG, Florentine B, Johnston PG, Groshen S, Zhou L, Xiong YP, Danenberg PV, Leichman LP (1998): p53 and thymidylate synthase expression in untreated stage II colon cancer: Associations with recurrence, survival, and site. Clin Cancer Res 4, 1227-1234.

Li FY, Lai MD (2009): Colorectal cancer, one entity or three. J Zhejiang Univ Sci B 10, 219-229.

Li JN, Zhao L, Wu J, Wu B, Yang H, Zhang HH, Qian JJ (2012): Differences in gene expression profiles and carcinogenesis pathways between colon and rectal cancer. J Dig Dis 13, 24-32.

Liang K, Ang KK, Milas L, Hunter N, Fan Z (2003): The epidermal growth factor receptor mediates radioresistance. Int J Radiat Oncol Biol Phys 57, 246-254.

Liersch T, Langer C, Ghadimi BM, Becker H (2005): Aktuelle Behandlungsstrategien beim Rektumkarzinom, Der Chirurg $\underline{76}$, 309-334.

Liersch T, Meller J, Kulle B, Behr TM, Markus P, Langer C, Ghadimi BM, Wegener WA, Kovacs J, Horak ID (2005): Phase II trial of carcinoembryonic antigen radioimmunotherapy with 131/-labetuzumab after salvage resection of colorectal metastases in the liver: five-year safety and efficacy results. J Clin Oncol 23, 6763-6770.

Liersch T, Becker H, Langer C (2007): Rektumkarzinom. Allgemeine und Viszeralchirurgie up2date 1 , 41-69.

Liersch T, Rothe H, Ghadimi B, Becker H (2009): Therapie beim lokal fortgeschrittenen Rektumkarzinom. Der Chirurg 80, 281-293.

Lieu C, Kopetz S (2010): The SRC family of protein tyrosine kinases: a new and promising target for colorectal cancer therapy. Clin Colorectal Cancer Journal, 89-94.

Locker GY, Hamilton S, Harris J, Jessup JM, Kemeny N, Macdonald JS, Somerfield MR, Hayes DF, Bast RC Jr (2006): ASCO 2006 update of recommendations for the use of tumor markers in gastrointestinal cancer. J Clin Oncol 24, 5313-5327.

Lowe SW, Schmitt EM, Smith SW, Osborne BA, Jacks T (1993): p53 is required for radiation-induced apoptosis in mouse thymocytes. Nature 362, 847-849.

Lu Y, Li X, Liang K, Luwor R, Siddik ZH, Mills GB, Mendelsohn J, Fan Z (2007): Epidermal growth factor receptor (EGFR) ubiquitination as a mechanism of acquired resistance escaping treatment by the anti-EGFR monoclonal antibody cetuximab. Cancer Res 67, 8240-8247. 
Marcotte R, Zhou L, Kim H, Roskelly CD, Muller WJ (2009): c-Src associates with ErbB2 through an interaction between catalytic domains and confers enhanced transforming potential. Mol Cell Biol 29, 5858-5871.

Masaki T, Okada M, Tokuda M, Shiratori Y, Hatase O, Shirai M, Nishioka M, Omata M (1999): Reduced C-terminal Src kinase (Csk) activities in hepatocellular carcinoma. Hepatology 29, 379-384.

Mason AY (1976): President's Address. Rectal Cancer: The Spectrum of Selective Surgery. Proc R Soc Med 69, 237-244.

Mcllwrath AJ, Vasey PA, Ross GM, Brown R (1994): Cell cycle arrests and radiosensitivity of human tumor cell lines: Dependence on wild-type p53 for radiosensitivity. Cancer Res 54, 3718-3722.

McLean GW, Carragher NO, Avizienyte E, Evans J, Brunton VG, Frame MC (2005): The role of focaladhesion kinase in cancer- a new therapeutic opportunity. Nat Rev Cancer 5, 505-515.

M.E.R.C.U.R.Y.: M.E.R.C.U.R.Y. Project (Magnetic Resonance Imaging and Rectal Cancer European Equivalence Study) Study Protocol (Study Coordinator I. Daniels), FRCS, Pelican Centre, North Hampshire Hospital, Basingstoke, Hampshire, UK, 2002.

Michailidi C, Giaginis C, Stolakis V, Alexandrou P, Klijanienko J, Delladetsima I, Chatzizacharias N, Tsourouflis G, Theocharis S (2010): Evaluation of FAK and Src expression in human benign and malignant thyroid lesions. Pathol Oncol Res 16, 497-507.

Miyazaki T, Tanaka S, Sanjay A, Baron R (2006): The role of c-Src kinase in the regulation of osteoclast function. Mod Rheumatol 16, 68-74.

Moreno García V, Batlle JF, Casado E, Burgos E, de Castro J, Belda C, Barriuso J, Sánchez JJ, GarcíaCabezas MÁ, González-Barón M (2010): Immunohistochemical analysis of tumour regression grade for rectal cancer after neoadjuvant chemoradiotherapy. Colorectal Dis $\underline{13}, 989-998$.

Morgan L, Gee J, Pumford S, Farrow L, Finlay P, Robertson J, Ellis I, Kawakatsu H, Nicholson R, Hiscox $S$ (2009): Elevated Src kinase activity attenuates Tamoxifen response in vitro and is asscociated with poor prognosis clinically. Cancer Biol Ther $\underline{8}, 1550-1558$.

Muthuswamy SK, Siegel PM, Dankort DL, Webster MA, Muller WJ (1994): Mammary tumors expressing the neu proto-oncogene possess elevated c-Src tyrosine kinase activity. Mol Cell Biol $\underline{14}$, 735-743.

Myoui A, Nishimura R, Williams P, Hiraga T, Tamura D, Michigami T, Mundy G, Yoneda T (2003): CSRC tyrosine kinase activity is associated with tumor colonization in bone and lung in an animal model of human breast cancer metastasis. Cancer Res 63, 5028-5033.

Nagata Y, Lan KH, Zhou X, Tan M, Esteva FJ, Sahin AA, Klos KS, Li P, Monia BP, Nguyen NT (2004): PTEN activation contributes to tumor inhibition by trastuzumab, and loss of PTEN predicts trastuzumab resistance in patients. Cancer Cell $\underline{6}, 117-127$.

Nakagawa T, Tanaka S, Suzuki H, Takayanagi H, Miyazaki T, Nakamura K, Tsuruo T (2000): Overexpression of the csk gene suppresses tumor metastasis in vivo. Int J Cancer, 88, 384-391.

Nam JS, Ino Y, Sakamoto M, Hirohashi S (2002): Src family kinase inhibitor PP2 restores the Ecadherin/catenin cell adhesion system in human cancer cells and reduces cancer metastasis. Clin Cancer Res $\underline{8}$, 2430-2436.

Narayan M, Wilken JA, Harris LN, Baron AT, Kimbler KD, Maihle NJ (2009): Trastuzumab-induced HER reprogramming in "resistant“ breast carcinoma cells. Cancer Res 69, 2191-2194. 
Nautiyal J, Majumder P, Patel BB, Lee FY, Majumdar AP (2009): Src inhibitor dasatinib inhibits growth of breast cancer cells by modulating EGFR signaling. Cancer Lett 283, 143-151.

Okada M, Nakagawa H (1989): A protein tyrosine kinase involved in regulation of pp60-src function. J Biol Chem 264, 20886-20893.

Parsons JT, Parsons SJ (1997): Src family protein tyrosine kinases: cooperating with growth factor and adhesion signaling pathways. Curr Opin Cell Biol $\underline{9}$, 187-192.

Pengetnze Y, Steed M, Roby KF, Terranova PF, Taylor CC (2003): Src tyrosine kinase promotes survival and resistance to chemotherapeutics in a mouse ovarian cancer cell line. Biochem Biophys Res Commun 309, 377-383.

Perez RO, Habr-Gama A, Lynn PB, São Julião GP, Bianchi R, Proscurshim I, Gama-Rodrigues J (2013): Transanal endoscopic microsurgery for residual rectal cancer (ypT0-2) following neoadjuvant chemoradiation therapy: another word of caution. Dis Colon Rectum 56, 6-13.

Piccart M (2008): Circumventing de novo and acquired resistance to trastuzumab: new hope for the care of ErbB2-positive breast cancer. Clin Breast Cancer 8, 100-113.

Posern S: Prädiktive und prognostische Relevanz von p53 und Ki67 beim lokal fortgeschrittenen Rektumkarzinom cUICC-II/III. Med. Diss. Göttingen 2013.

Rajeshkumar NV, Tan AC, De Olivera E, Womack C, Wombwell H, Morgan S, Warren MV, Walker J, Green TP, Jimeno A (2009): Antitumor effects and biomarkers of activity of AZD0530, a Src inhibitor, in pancreatic cancer. Clin Cancer Res 15, 4138-4146.

Rengifo-Cam W, Konishi A, Morishita N, Matsuoka H, Yamori T, Nada S, Okada M (2004): CSK defines the ability of integrin-mediated cell adhesion and migration in human colon cancer cells: implication for a potential role in cancer metastasis. Oncogene 23, 289-297.

Rizzardi AE, Johnson AT, Vogel RI, Pambuccian SE, Henriksen J, Skubitz AP, Metzger GJ, Schmechel SC (2012): Quantitative comparison of immunohistochemical staining measured by digital image analysis versus pathologist visual scoring. Diagn Pathol $\underline{7}, 42$.

(RKI/GEKID 2010:) Krebs in Deutschland 2005/2006. Häufigkeiten und Trends. 7. Ausgabe. RobertKoch-Institut und die Gesellschaft der epidemiologischen Krebsregister in Deutschland e.V. (Hrsg.). Robert-Koch-Institut, Berlin 2010

(RKI/GEKID 2012:) Krebs in Deutschland 2007/2008. Häufigkeiten und Trends. 8. Ausgabe. RobertKoch-Institut und die Gesellschaft der epidemiologischen Krebsregister in Deutschland e.V. (Hrsg.). Robert-Koch-Institut, Berlin 2012

Rödel C, Martus P, Papadoupolos T, Füzesi L, Klimpfinger M, Fietkau R, Liersch T, Hohenberger W, Raab R, Sauer R (2005): Prognostic significance of tumor regression after preoperative chemoradiotherapy for rectal cancer. J Clin Oncol 23, 8688-8696.

Rödel C, Liersch T, Becker H, Fietkau R, Hohenberger W, Hothorn T, Graeven U, Arnold D, LangWelzenbach M, Raab H et al. (2012): Preoperative chemoradiotherapy and postoperative chemotherapy with fluorouracil and oxaliplatin versus fluorouracil alone in locally advanced rectal cancer: initial results of the German CAO/ARO/AIO-04 randomised phase 3 trial. Lancet Oncol $\underline{13}$, 679-687.

Rodel C, Liersch T, Fietkau R, Hohenberger W, Graeven U, Hothorn T, Arnold D, Raab HR, Wittekind C, Hess C (2014): Preoperative chemoradiotherapy and postoperative chemotherapy with 5 -fluorouracil 
and oxaliplatin versus 5 -fluorouracil alone in locally advanced rectal cancer: Results of the German CAO/ARO/AIO-04 randomized phase III trial. ASCO Annual Meeting 2014.

Roskoski R Jr (2004): Src protein-tyrosine kinase structure and regulation. Biochem Biophys Res Commun 324, 1155-1164.

Rucci N, Recchia I, Angelucci A, Alamanou M, Del F, Fortunati D, Susa M, Fabbro D, Bologna M, Teti A (2006): Inhibition of protein kinase c-Src reduces the incidence of breast cancer metastasis and increases survival in mice: implications for therapy. J Pharmacol Exp Ther 318, 161-172.

Sakai T, Jove R, Fässler R, Mosher DF (2001): Role of cytoplasmic tyrosines of beta $1 \mathrm{~A}$ integrins in transformation bei v-src. Proc Natl Acad Sci USA 98, 3808-3813.

Salonga D, Danenberg KD, Johnson M, Metzger R, Groshen S, Tsao-Wei DD, Lenz HJ, Leichman CG, Diasio RB (2000): Colorectal tumors responding to 5-fluorouracil have low gene expression levels of dihydropyrimidine dehydrogenase, thymidylate synthase, and thymidine phosphorylase. Clin Cancer Res 6 , 1322-1327.

Sauer R, Becker H, Hohenberger W, Rodel C, Wittekind C, Fietkau R, Martus P, Tschmelitsch J, Hager $E$, Hess $C$ et al. (2004): Preoperative versus postoperative chemoradiotherapy for rectal cancer. $N$ Engl J Med 351, 1731-1740.

Schmiegel W, Pox C, Reinacher-Schick A, Adler G, Arnold D, Fleig W, Fölsch U, Frühmorgen P, Graeven U, Heinemann V et al. (2010): S3 guidelines for colorectal carcinoma: results of an evidencebased consensus conference on February 6/7, 2004 and June 8/9, 2007 (for the topics IV, VI and VII). Z Gastroenterol 46, 65-136.

Schmoll HJ, Van Cutsem E, Stein A, Valentini V, Glimelius B, Haustermans K, Nordlinger B, van de Velde CJ, Balmana J, Regula J (2012): ESMO Consensus Guidelines for management of patients with colon and rectal cancer. A personalized approach to clinical decision making. Ann Oncol 23, 24792516.

Scholzen T, Gerdes J (2000): The Ki-67 protein: From the known and the unknown. J Cell Physiol 182, 311-322.

Seidal T, Balaton AJ, Battifora H (2001): Interpretation and Quantification of Immunostains. The Am J Surg Pathol 25, 1204-1207.

Sen B, Johnson FM (2011): Regulation of SRC family kinases in human cancers. J Signal Transduct 4, 114 (doi: 10.1155/2011/865819).

Shah A, Gallick G (2007): Src, chemoresistance and epithelial to mesenchymal transition: are they related? Anticancer Drugs 18, 371-375.

Sharma MR, Wroblewski K, Polite BN, Knost JA, Wallace JA, Modi S, Sleckman BG, Taber D, Vokes EE, Stadler WM (2012): Dasatinib in previously treated metastatic colorectal cancer: a phase II trial of the University of Chicago Phase II Consortium. Invest New Drugs 30, 1211-1215.

Shiroiwa T, Fukuda T, Shimozuma K (2011): Cost-effectiveness analysis of trastuzumab to treat HER2positive advanced gastric cancer based on the randomised ToGA trial. Br J Cancer 105, 1273-1278.

Siesser PM, Hanks SK (2006): The signaling and biological implications of FAK overexpression in cancer. Clin Cancer Res 12, 3233-3237. 
Slamon DJ, Clark GM, Wong SG, Levin WJ, Ullrich A, McGuire WL (1987): Human breast cancer: correlation of relapse and survival with amplification of the HER-2/neu oncogene. Science 235, 177182.

Smith FM, Reynolds JV, Kay EW, Crotty P, Murphy JO, Hollywood D, Gaffney EF, Stephens RB, Kennedy JM (2006): COX-2 overexpression in pretreatment biopsies predicts response of rectal cancers to neoadjuvant radiochemotherapy. Int J Radiat Oncol Biol Phys 64, 466-472.

Soreide O, Norstein J, Fielding LP (1997): International standardization and documentation of the treatment of rectal cancer. Springer, 405-445.

Spindler KL, Nielsen JN, Lindebjerg J, Jakobsen A (2007): Germline polymorphisms may act as predictors of response to preoperative chemoradiation in locally advanced T3 rectal tumors. Dis Colon Rectum 50, 1363-1369.

Sprenger T, Rothe H, Langer C, Becker H, Liersch T (2009): Comment on "Lymph Nodes After Preoperative Chemoradiotherapy for Rectal Carcinoma: Number, Status, and Impact on Survival". Am J Surg Pathol 33, 1107.

Sprenger T, Rödel F, Beissbarth T, Conradi LC, Rothe H, Homayounfar K, Wolff HA, Ghadimi BM, Yildirim M, Becker $H$ (2010): Failure of downregulation of survivin following neoadjuvant radiochemotherapy in rectal cancer is associated with distant metastases and shortened survival. Clin Cancer Res 17, 1623-1631.

Sterk P, Nagel T, Günter S, Schubert F, Klein P (2000): Verfahren zur postoperativen Kontrolle der vollständigen Exzision des Mesorektums. Zentralblatt für Chirurgie 125, 370-374.

Stommel JM, Kimmelman AC, Ying H, Nabioullin R, Ponugoti AH, Wiedemeyer R, Stegh AH, Bradner JE, Ligon KL, Brennan C (2007): Coactivation of receptor tyrosine kinases affects the response of tumor cells to targeted therapies. Science 318, 287-290.

Summy J, Gallick G (2003): Src family kinases in tumor progression and metastasis. Cancer Metastasis Rev 22, 337-358.

Tabernero J, Cervantes A, Hoekman K, Hurwitz HI, Jodrell DI, Hamberg P, Stuart M, Green TP, lacona RB, Baselga J (2007): Phase I study of AZD0530, an oral potent inhibitor of Src kinase: First demonstration of inhibition of Src activity in human cancers. ASCO Meeting 25, 3520.

Talamonti MS, Roh MS, Curley SA, Gallick GE (1993): Increase in activity and level of pp60c-src in progressive stages of human colorectal cancer. J Clin Invest 91, 53-60.

Taylor CR (2006): Standardization in immunohistochemistry: the role of antigen retrieval in molecular morphology. Biotech Histochem 81, 3-12.

Theocharis S, Klijanienko J, Giaginis C, Alexandrou P, Patsouris E, Sastre-Garau X (2012): FAK and SrC expression in mobile tongue squamous cell carcinoma: associations with clinicopathological parameters and patients survival. J Cancer Res Clin Oncol 138, 1369-1377.

Thomas SM, Brugge JS (1997): Cellular functions regulated by Src family kinases. Annu Rev Cell Dev Biol 13, 513-609.

Tol J, Koopman M, Cats A, Rodenburg CJ, Creemers GJ, Schrama JG, Erdkamp FL, Vos AH, van Groeningen CJ, Sinnige HA (2009): Chemotherapy, bevacizumab, and cetuximab in metastatic colorectal cancer. N Engl J Med 360, 563-572. 
Trampisch HJ, Windeler J, Ehle B, Lange S: Medizinische Statistik., 1. Auflage; Springer Verlag, Berlin 1997.

Trevino JG, Summy JM, Gray MJ, Nilsson MB, Lesslie DP, Baker CH, Gallick GE (2005): Expression and activity of SRC regulate interleukin-8-expression in pancreatic adenocarcinoma cells: implications for angiogenesis. Cancer Res 65, 7214-7222.

Vecchio FM, Valentini V, Minsky BD, Padula GD, Venkatraman ES, Balducci M, Micchichè F, Ricci R, Morganti AG, Gambacorta MA (2005): The relationship of pathologic tumor regression grade (TRG) and outcomes after preoperative therapy in rectal cancer. Int J Radiat Oncol Biol Phys 62, 752-760.

Verbeek BS, Vroom TM, Driaansen-Slot SS (1996): c-Src protein expression is increased in human breast cancer: an immunohistochemical and biochemical analysis. J Pathol 180, 383-388.

Vilmar A, Garcia-Foncillas J, Huarriz M, Santoni-Rugiu E, Sorensen JB (2012): RT-PCR versus immunohistochemistry for correlation and quantification of ERCC1, BRCA1, TUBB3 and RRM1 in NSCLC. Lung Cancer 75, 306-312.

Vironen J, Juhola M, Kairalouma M, Jantunen I, Kellokumpu I (2005): Tumour regression grading in the evaluation of tumour response after different preoperative radiotherapy treatments for rectal carcinoma. Int J Colorectal Dis 20, 440-445.

Waksman G, Kuriyan J (2004): Structure and specifity of the SH2 domain. Cell 116, 45-48.

Walker RA (2006): Quantification of immunhistochemistry- issues concerning methods, utility and semiquantitative assessment I. Histopathology 49, 406-410.

Walther A, Johnstone E, Swanton C, Midgley R, Tomlinson I, Kerr D (2009): Genetic prognostic and predictive markers in colorectal cancer. Nat Rev Cancer 9, 489-499.

Wang SE, Xiang B, Zent R, Quaranta V, Pozzi A, Arteaga CL (2009): Transforming growth factor beta induces clustering of HER2 and integrins by activating Src-focal adhesion kinase and receptor association to the cytoskeleton. Cancer Res 69, 475-482.

Westhoff MA, Serrels B, Fincham VJ, Frame MC, Carragher NO (2004): SRC-mediated phosphorylation of focal adhesion kinase couples actin and adhesion dynamics to survival signaling. Mol Cell Biol 24 , 8113-8133.

Wilson GR, Cramer A, Welman A, Knox F, Swindell R, Kawakatsu H, Clarke RB, Dive C, Bundred NJ (2006): Activated c-SRC in ductal carcinoma in situ correlates with high tumour grade, high proliferation and HER2 positivity. Br J Cancer 95, 1410-1414.

Wittekind C, Sobin LH: TNM. Classification of malignant tumours, 6. Auflage; Wiley-Liss-Verlag, New York 2002.

Wittekind C, Tannapfel A (2003): Regressionsgrading des präoperativ-radiochemotherapierten Rektumkarzinoms. Pathologe 24, 61-65.

Wittekind C, Meyer H-J: TNM Klassifikation maligner Tumoren. 7. Auflage; Wiley-VCH, Weinheim 2010.

Yeatman T (2004): A renaissance for SRC. Nat Rev Cancer 4, 470-480.

Zhang L, Teng Y, Zhang Y, Liu J, Xu L, Qu J, Hou K, Yang X, Liu Y, Qu X (2012): c-Src expression is predictive of poor prognosis in breast cancer patients with bone metastasis, but not in patients with visceral metastasis. APMIS 2012 120, 549-557. 
Zhang S, Yu D (2010): PI(3)king apart PTEN's role in cancer. Clin Cancer Res 16, 4325-4330.

Zhang S, Huang WC, Li P, Guo H, Poh SB, Brady SW, Xiong Y, Tseng LM, Li SH, Ding Z (2011): Combating trastuzumab resistance by targeting SRC, a common node downstream of multiple resistance pathways. Nature Medicine 17, 461-470.

Zhuang G, Brantley-Sieders DM, Vaught D, Yu J, Xie L, Wells S, Jackson D, Muraoka-Cook H, Arteaga C, Chen J (2010): Elevation of recptor tyrosine kinase EphA2 mediates resistance to trastuzumab therapy. Cancer Res 70, 299-308.

Zrihan-Licht S, Lim J, Keydar I, Sliwkowski MX, Groopman JE, Avraham H (1997): Association of Cskhomologous kinase (CHK) (formerly MATK) with HER-2/ErbB-2 in breast cancer cells. J Biol Chem 272, 1856-1863. 


\section{8) Veröffentlichung zum Thema}

Teile dieser Dissertation wurden im Rahmen von Kongressbeiträgen veröffentlicht.

1. Vortrag auf der „191. Tagung der Vereinigung Nordwestdeutscher Chirurgen“ in Kiel im Juni 2013:

Felix RühImann*, Lena-Christin Conradi*, Manuel Nietert, Thilo Sprenger, Hendrik A. Wolff, B. Michael Ghadimi, Tim Beissbarth, Torsten Liersch;

*gleichberechtigte Co-Autoren

SRC-Expression des lokal fortgeschritten Rektumkarzinoms - vor und nach neoadjuvanter Radiochemotherapie

Die Ergebnisse dieses Vortrags wurden auf der 191. Tagung der Vereinigung Nordwestdeutscher Chirurgen in Kiel mit dem Günther-Haenisch-Preis ausgezeichnet.

2.Vortrag auf der Jahrestagung der DGHO (Deutsche Gesellschaft für Hämatologie und Medizinische Onkologie) in Hamburg im Oktober 2014:

F. Rühlmann*, M. Nietert, T. Sprenger, H. A. Wolff, K. Homayounfar, T. Beissbarth, B. M. Ghadimi, T.Liersch, L.-C. Conradi*,

*gleichberechtigte Co-Autoren

Die Expression von SRC vor und nach neoadjuvanter Radiochemotherapie im lokal fortgeschrittenen Rektumkarzinom (cUICC II/III)

\section{Manuskript aktuell eingereicht}




\section{9) Danksagung}

Mein besonderer Dank gilt Frau Dr. med. Lena Conradi. Durch ihre hervorragende Betreuung und ihr unermüdliches Engagement hat sie wesentlich zur Fertigstellung dieser Arbeit beigetragen. Sie hat insbesondere durch die Organisation und Umsetzung der beiden Doktorarbeitswochen auf Sylt sowie auf Gut Herbigshagen den Schreibprozess dieser Arbeit in besonderem Maße beeinflusst.

Herrn Prof. Dr. med. Torsten Liersch danke ich herzlichst für die Auswahl des Themas meiner Dissertation. Dabei hat er mich stets konstruktiv während der Erstellung dieser Arbeit begleitet und stand mir auch jederzeit mit Rat und Tat zur Seite.

Ich möchte mich weiterhin bei Herrn Prof. Dr. med. B. Michael Ghadimi bedanken, der es mir als Direktor der Klinik und Leiter der Klinischen Forschergruppe 179 möglich machte, in der Klinik für Allgemein-, Viszeral- und Kinderchirurgie zu promovieren.

Ganz herzlich bedanken möchte ich mich bei Frau Birgit Jünemann für die Erstellung und Färbung der immunhistochemischen Präparate, ohne die diese Arbeit nicht möglich gewesen wäre.

Weiterhin bin ich Herrn Prof. Gisbert Vogt zu großem Dank verpflichtet, der durch seine finanzielle Unterstützung erst die Doktorarbeitswochen auf Sylt und auf Gut Herbigshagen ermöglichte und somit entscheidend zum Verfassen dieser Arbeit beitrug.

Herrn Dr. phil. nat. Manuel Nietert danke ich für seine Unterstützung bei der Erstellung der statistischen Analysen, die somit erheblich zu den Ergebnissen dieser Untersuchung führten.

Ich danke Frau Dr. med. Susanna Posern für die Einführung in die Mikroskopie sowie in die Auswertung immunhistochemischer Färbungen. 


\section{0) Lebenslauf}

Ich, Felix Rühlmann, wurde am 29.06.1986 in München als Sohn von Suzanne Rühlmann (Hotelfachfrau) und Hans-Joachim Rühlmann (Diplomvolkswirt) geboren. Meine schulische Laufbahn beendete ich mit der Erlangung der allgemeinen Hochschulreife am Luitpold Gymnasium München im Sommer 2006. Im Anschluss absolvierte ich den 9-monatigen Zivildienst am Klinikum Rechts der Isar der TU München. Nach Beendigung des Zivildienstes folgten Auslandsaufenthalte in Irland und Frankreich sowie ein Praktikum in der Abteilung Pathologie des städtischen Krankenhauses München-Schwabing. Im April 2008 begann ich das Studium der Humanmedizin an der GeorgAugust-Universität Göttingen.

Im vorklinischen Studienabschnitt war ich als studentische Hilfskraft als Assistent im Makroskopischen Präparierkurs des Zentrums Anatomie der Universitätsmedizin Göttingen beschäftigt. Im Frühjahr 2010 schloss ich den vorklinischen Teil mit dem Ersten Abschnitt der Ärztlichen Prüfung ab. Während des klinischen Studienabschnitts war ich als studentische Hilfskraft in der Abteilung Unfallchirurgie, Plastische- und Wiederherstellungschirurgie der Universitätsmedizin Göttingen als OP-Assistent tätig. Im Februar 2013 trat ich in das Praktische Jahr ein. Mein Studium habe ich im April 2014 mit dem 2. Abschnitt der Ärztlichen Prüfung beendet.

Ich promoviere seit dem Frühjahr 2012 in der Klinik für Allgemein-, Viszeral- und Kinderchirurgie der Universitätsmedizin Göttingen, Klinische Forschergruppe 179/Teilprojekt 5. 
